Georgia State University

ScholarWorks @ Georgia State University

Early Childhood and Elementary Education

Dissertations

Early Childhood and Elementary Education

Department

Fall 10-20-2010

\title{
The Relationship between Language and Reading in Bilingual English-Arabic Children
}

Lama K. Farran

Georgia State University

Follow this and additional works at: https://scholarworks.gsu.edu/ece_diss

\section{Recommended Citation}

Farran, Lama K., "The Relationship between Language and Reading in Bilingual English-Arabic Children." Dissertation, Georgia State University, 2010.

doi: https://doi.org/10.57709/1661865

This Dissertation is brought to you for free and open access by the Early Childhood and Elementary Education Department at ScholarWorks @ Georgia State University. It has been accepted for inclusion in Early Childhood and Elementary Education Dissertations by an authorized administrator of ScholarWorks @ Georgia State University. For more information, please contact scholarworks@gsu.edu. 


\section{ACCEPTANCE}

This Dissertation, THE RELATIONSHIP BETWEEN LANGUAGE AND READING IN BILINGUAL ENGLISH-ARABIC CHILDREN, by LAMA K. FARRAN, was prepared under the direction of the candidate's Dissertation Advisory Committee. It is accepted by the committee members in partial fulfillment of the requirements for the degree Doctor of Philosophy in the College of Education, Georgia State University The Dissertation Advisory Committee and the student's Department Chair, as representatives of the faculty, certify that this dissertation has met all standards of excellence and scholarship as determined by the faculty. The Dean of the College of Education concurs.

Ramona W. Matthews, Ph.D. Committee Chair

Laura May, Ph.D. Committee Member

Date

Barbara Meyers, Ed.D.

Chair, Department of Early Childhood Education
Gary Bingham, Ph.D.

Committee Member

Alice Dyson, Ph.D.

Committee Member

R. W. Kamphaus, Ph.D.

Dean and Distinguished Research Professor

College of Education 


\begin{abstract}
AUTHOR'S STATEMENT
By presenting this dissertation as a partial fulfillment of the requirements for the advanced degree from Georgia State University, I agree that the library of Georgia State University shall make it available for inspection and circulation in accordance with its regulations governing materials of this type. I agree that permission to quote, to copy from, or to publish this dissertation may be granted by the professor under whose direction it was written, by the College of Education's director of graduate studies and research, or by me. Such quoting, copying, or publishing must be solely for scholarly purposes and will not involve potential financial gain. It is understood that any copying from or publication of this dissertation that involves potential financial gain will not be allowed without my written permission.
\end{abstract}

Lama K. Farran 


\section{NOTICE TO BORROWERS}

All dissertations deposited in the Georgia State University library must be used in accordance with the stipulations prescribed by the author in the preceding statement. The author of this dissertation is:

Lama K. Farran

451 Brushstroke Court, S.E

Marietta, GA 30067

The director of this dissertation is:

Dr. Ramona Mathews

Department of Early Childhood Education

College of Education

Georgia State University

Atlanta, GA 30303-3077 


\title{
CURRICULUM VITAE
}

\author{
Lama K. Farran
}

ADDRESS: 451 Brushstroke Court, S.E.

Marietta, GA 30067

EDUCATION:

Ph.D. 2010 Georgia State University

Early Childhood Education

M.S. 1995 University of Mississippi

Communicative Disorders

Speech-Language Pathology

B.A. 1991 American University of Beirut

Public Administration

\section{PUBLICATIONS:}

Dooley, C. M., Dangel, J. R., \& Farran, L. K. (In Press). Current issues in teacher education: 2006-2009. Action in Teacher Education.

Farran, L.K., Lederberg, A.R., \& Jackson, L. A. (2009). Maternal Input and Lexical Development: The Case of Deaf Preschoolers. International Journal of Language and Communication Disorders, 44 (2), 145- 163.

PRESENTATIONS:

Farran, L.K., Bingham, G., \& Matthews, M. (2011, March). The link between phonological processing, morphological awareness, and reading in bilingual English-Arabic children: A crosslinguistic study. Poster accepted for presentation at the Society for Research in Child Development (SRCD) meeting in Montreal, Canada.

Farran, L.K., Bingham, G., \& Matthews, M. (2011, March). The relationship between language and reading in bilingual English-Arabic children. Poster accepted for presentation at the Society for Research in Child Development (SRCD) meeting in Montreal, Canada.

Farran, L.K. \& Bingham, G. (2011, March). Home Language and Literacy experiences of Arabic Speaking Bilingual Children: Associations to Literacy Development. Poster accepted for presentation at the Society for Research in Child Development (SRCD) meeting in Montreal, Canada.

Farran, L.K. (2010, December). Language predictors of reading in bilingual English-Arabic children. Paper accepted for presentation at the National Reading Conference, Fort Worth, TX.

Farran, L.K., Wiggins, L.D., Oliver, K.B., \& Robins, D.L. (2007, May). Does performance on the Early Social Communication Scales differentiate between toddlers with ASD and toddlers without ASD? Poster presented at the International Meeting for Autism Research, Seattle, WA.

Farran, L.K., McManus, S.M., \& Robins, D.L. (2007, February). Screening for 
autism spectrum disorders: A collaboration between neuropsychologists and primary care providers. Poster presented at the annual meeting of the International Neuropsychological Society, Portland, OR.

Farran, L.K., Oliver, K.B., Angeli, N.C., \& Robins, D.L. (2006, June). Early social communication skills and autistic symptomatology in toddlers with and without autism spectrum disorders. Poster presented at the International Meeting for Autism Research, Montreal, Canada.

Farran, L.K. \& Lederberg., A.R. (2005, November). Effects of deaf children's lexical knowledge on maternal labeling. Poster presented at the American Speech-Language and Hearing Association meeting, San Diego, California.

Farran, L.K., Lederberg, A.R., \& Jackson, L. (2005, July). Maternal labeling and deaf children's fastmapping of novel words: Is there a link? Poster presented at the International Association for the Study of Child Language, Berlin, Germany.

RESEARCH AND SCHOLARSHIP:

2004-Present Graduate Research Assistant, Georgia State University, Atlanta, Georgia

2004-2008 Graduate Research Assistant, Center for Research on Atypical Development and Learning, Georgia State University, Atlanta, Georgia

PROFESSIONAL EXPERIENCE:

1995-Present Speech-Language Pathologist Atlanta, Georgia

AWARDS:

Steven A. Stahl Research Award 2010

PROFESSIONAL SOCIETIES AND ORGANIZATIONS:

1995-Present American Speech-Language-Hearing Association (ASHA)

2005-Present Society for Research in Child Development (SRCD)

2005-2008 International Neuropsychological Society (INS)

2010-Present International Reading Association (IRA)

2010-Present National Reading Conference (NRC)

2010-Present Society for the Scientific Study of Reading (SSSR)

\section{LANGUAGES:}

English

Arabic

French 


\section{ABSTRACT \\ THE RELATIONSHIP BETWEEN LANGUAGE AND READING IN BILINGUAL ENGLISH-ARABIC CHILDREN \\ by \\ Lama K. Farran \\ This dissertation examined the relationship between language and reading in}

bilingual English-Arabic children. The dissertation followed a two chapter Review and Research Format. Chapter One presents a review of research that examined the relationship between oral language and reading development in bilingual English-Arabic children. Chapter Two describes the study that examined this same relationship. Participants were 83 third-, fourth-, and fifth-grade children who attended a charter school in a large school district in the Southeastern portion of the US. The school taught Arabic as a second language daily in the primary and elementary grades. This crosssectional quantitative study used norm-referenced assessments and experimental measures. Data were analyzed using simultaneous and hierarchical regression to identify language predictors of reading. Analysis of covariance was used to examine whether the language groups differed in their Arabic reading comprehension scores, while controlling for age. Results indicated that phonological awareness in Arabic was related to phonological awareness in English. However, morphological awareness in Arabic was not related to morphological awareness in English. Results also revealed that phonological skills predicted word reading, pseudoword decoding, and complex word reading fluency within Arabic and English; morphological awareness predicted complex word reading fluency in Arabic but not in English; and vocabulary predicted reading comprehension within Arabic and English. Further analyses indicated that children with high vocabulary differed from children with low vocabulary in their reading comprehension scores and that this difference was driven by children's ability to read 
unvowelized words. Consistent with the extended version of the Triangle Model of Reading (Bishop \& Snowling, 2004), the results suggest a division of labor among various language components (e.g., phonology, morphology, and semantics [vocabulary]) in the process of word reading and reading comprehension. Implications for research, instruction, and early intervention with bilingual English-Arabic children are discussed. 


\title{
THE RELATIONSHIP BETWEEN LANGUAGE AND READING IN BILINGUAL ENGLISH-ARABIC CHILDREN \\ by \\ Lama K. Farran
}

\author{
A Dissertation \\ Presented in Partial Fulfillment of Requirements for the \\ Degree of \\ Doctor of Philosophy \\ in \\ Early Childhood Education \\ in \\ the Department of Early Childhood Education \\ in \\ the College of Education \\ Georgia State University
}

Atlanta, GA

2010 
Copyright by

Lama K. Farran

2010 


\section{ACKNOWLEDGMENTS}

I would like to thank my committee members for their guidance in shaping this dissertation. Each of you brought a unique perspective and a special interest to the study. To Dr. Mona Matthews, my major advisor, thank you for your mentorship and support and for sharing your knowledge about the development of literacy. You were always willing to meet and discuss; always open to new ideas. I feel very fortunate to have had you as my advisor. To Dr. Gary Bingham, thank you for your support and guidance throughout this dissertation. Your input was essential, especially in the data analysis phase of the study. To Dr. Alice Dyson, thank you for sharing your expertise in speech

and language development. To Dr. Laura May, thank you for your attention to detail and for your insightful comments on culturally relevant teaching. Special thanks go to Kim and Jennifer for assisting me with data collection; Lisa for reading drafts of my prospectus; the school's administration and staff for your help throughout data collection; and children and parents for your participation in this study. Lastly, I would like to thank my family. Kamal, Wafaa, Khalil (for your understanding and patience), Rand, Rawad, Ashraf, Hala, and Tala: your unwavering support and love have been instrumental to my persistence and growth. I am forever grateful. 


\section{TABLE OF CONTENTS}

List of Tables

Page

List of Figures

Chapter

1

A REVIEW OF THE RELATIONSHIP BETWEEN ORAL LANGUAGE AND READING DEVELOPMENT IN BILINGUAL ENGLISH AND ARABIC CHILDREN

Introduction............................................. 1

Review ................................................ 8

References .............................................. 36

2

A STUDY OF THE RELATIONSHIP BETWEEN ORAL LANGUAGE AND READING DEVELOPMENT IN BILINGUAL ENGLISH AND ARABIC CHILDREN

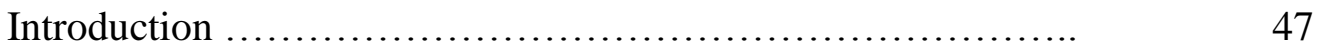

Method ................................................. 61

Results ............................................... 78

Discussion ................................................ 112

Conclusion ............................................... 130

References .......................................... 132

Appendixes $\quad$.................................................. 140 
1 Demographic Characteristics of the Children in the Study

2 Demographic Characteristics: Parent and Partner Education and Home Language Use ................................................... 79

$3 \quad$ Variable Mean and Standard Deviation Scores ......................... 84

$4 \quad$ Correlation Matrix with Age Covaried ............................. 85

5 Summary of Simultaneous Regression Analyses of Language Components on Children's Arabic Reading Skills ...................... 86

6 Summary of Simultaneous Regression Analyses of Language Components on Children's English Reading Skills ................... 87

7 Summary of Hierarchical Regression Analysis for Variables Predicting Arabic Vowelized Word Reading ................................. 88

8 Summary of Hierarchical Regression Analysis for Variables Predicting Arabic Unvowelized Word Reading ....................................

9 Summary of Hierarchical Regression Analysis for Variables Predicting Arabic Pseudoword Decoding ..................................... $\quad 90$

10 Summary of Hierarchical Regression Analysis for Variables Predicting Arabic Complex Word Reading Fluency ........................... 91

11 Summary of Hierarchical Regression Analysis for Variables Predicting Third Grade English Word Reading ............................... 94

12 Summary of Hierarchical Regression Analysis for Variables Predicting Fifth Grade English Word Reading ................................... 95

13 Summary of Hierarchical Regression Analysis for Variables Predicting Third Grade English Pseudoword Decoding .......................... $\quad 96$

14 Summary of Hierarchical Regression Analysis for Variables Predicting Fifth Grade English Pseudoword Decoding .......................... 97

15 Summary of Hierarchical Regression Analysis for Variables Predicting Third Grade English Complex Word Reading Fluency 
16 Summary of Hierarchical Regression Analysis for Variables Predicting Fifth Grade English Complex Word Reading Fluency .................

17 Summary of Hierarchical Regression Analysis of Arabic Language

Measures on Arabic Reading Comprehension .........................

18 Summary of Hierarchical Regression Analysis of English Language Measures on Third Grade English Reading Comprehension

19 Summary of Hierarchical Regression Analysis of English Language

Measures on Fifth Grade English Reading Comprehension

20 Analysis of Covariance of Arabic Reading Comprehension Scores with Chronological Age as the Covariate 


\section{LIST OF FIGURES}

Figure

Page

1 The Triangle Model of Reading as conceptualized by Seidenberg \& McClelland (1989) ........................................... 16

2 An extended version of the Triangle Model of Reading as conceptualized by Bishop \& Snowling (2004) 


\section{CHAPTER 1}

\section{THE RELATIONSHIP BETWEEN ORAL LANGAUGE AND READING DEVELOPMENT IN BILINGUAL ENGLISH-ARABIC CHILDREN}

Oral language plays a potent role in learning to read (Perfetti \& Dunlap 2008).

Across literate societies and cultures studied to date, the development of reading has been linked inextricably to the development of oral language. Perhaps this is due to oral language and reading sharing a common purpose - to communicate among individuals, within societies, and across cultures. As such a bidirectional relationship exists between oral language and reading development (Cain \& Oakhill, 2007; Perfetti, 2003; Snow 2006; Stanovich, 2000); a relationship that begins at birth and continues through the lifespan (Alexander, 2005/2006; Bates, 1978; Berko-Gleason \& Bernstein Ratner, 2009; Snowling, 2007; Wolf, 2007). Hence, at various time points, the development of the former differentially influences, and is influenced by, the development of the latter. Because of their shared purpose and shared trajectories, oral language and reading must be examined in relation to each other (Liberman, 1973). Additional evidence for the importance of oral language in reading comes from research studies that point to a link between language processing deficits and reading disabilities. Research suggests that deficits in language processing skills typically accompany reading disabilities as evident in deficits in speech perception (Metsala, 1997; Walley, 1993), vocabulary (Cunningham \& Stanovich, 1991), and naming skills (Wolf \& Bowers, 1999).

Further support for the significance of oral language in reading is found in crosslinguistic research. According to Perfetti (2003), world languages are subject to the 
Universal Language Constraint, which posits that the written form of a given language must map onto its oral form. Thus, children learning how to read are faced with the mapping problem (Perfetti \& Zhang, 1995), whereby they have to figure out how their writing system encodes their spoken language (Perfetti, 2003). As they learn a second language, children encounter a new mapping problem because they must search for similarities and differences between the spoken and written forms of the second language (Perfetti \& Dunlap, 2008).

The pivotal role of oral language in learning to read is substantiated further in research studies that focus on the role of word reading in reading comprehension processes (August \& Shanahan, 2006; Cain \& Oakhill, 2007; Stanovich 2000). For example, Wilson and Rupley (1997) examined the development of word reading and reading comprehension in children between first and sixth grades. Looking at reading comprehension across four different time points, the researchers found that for children between second and fourth grades, mainly word reading drove reading comprehension. As children grew older, they became reliant increasingly on metalinguistic skills - the ability to reflect deliberately upon and manipulate the structural features (morphology and syntax) of spoken language - to aid their reading comprehension.

Although similarities exist between oral language and reading, evidence also suggests striking differences between them. While language is easy, natural, and a species-typical product of biological evolution; reading is difficult, unnatural, and a social and cultural artifact. According to Liberman, reading is facilitated through and is the product of the human capability for speech (Liberman, 1973). In fact, numerous researchers argue that because reading is unnatural, reading must be taught explicitly in 
school and must be built on a foundation of language (Catts \& Kamhi, 2005).

Recognizing these similarities and differences, scholars interested in understanding reading development in a specific language as well as across languages have examined the relationship between oral language and reading in young children (Dickinson \& McCabe 2001; Joanisse, Manis, Keating, \& Seidenberg, 2000; Perfetti \& Dunlap, 2008; Scarborough, 2001; Solari \& Gerber, 2008). Considerable research across many languages has centered on the phonological aspects of language as strong predictors of reading outcomes and as a core deficit of dyslexia (Stanovich, 2000; Ziegler \& Goswami, 2005). Recent reports of what counts as effective reading, such as those written by the National Reading Panel (2000), the National Literacy Panel on Language-Minority Children and Youth (August \& Shanahan, 2006), and the National Early Literacy Panel (National Institute of Literacy, 2008) underscore the importance of word recognition in reading. Such reviews indicate that the inability to achieve fluent and accurate word reading constitutes a major barrier to establishing meaning and reading comprehension (Perfetti, 2003). As a consequence, the quest for understanding the reading process has witnessed an overemphasis on these limited facets of reading.

Even though empirical support exists for the importance of phonological processing, fluency, and word reading accuracy, current research also suggests they are insufficient for achieving reading comprehension (Paris, Carpenter, Paris, \& Hamilton, 2005). In fact, agreement exists that the primary goal of reading is comprehension and any efforts to understand reading development must include a focus on reading comprehension (Sweet \& Snow, 2003). Because reading comprehension depends on 
linguistic, orthographic, cultural, and experiential factors, understanding all of these factors is paramount for an all-encompassing account of reading development.

A first step in understanding reading development is to examine what current reading research suggests as potent predictors of reading. Recently, mounting evidence underscores the importance of other aspects of oral language, namely morphology and semantics, in predicting reading outcomes (Cain \& Oakhill, 2007; Carlisle \& Stone, 2005; Geva, 2008). This could be attributed to the fact that reading, which is a cognitive process that allows individuals to derive meaning from orthographic representations (Perfetti, 2003), involves mapping written language onto all aspects of oral language, i.e. converting graphic inputs (e.g., letters and words) to linguistic and conceptual units (e.g., morphemes, words, and concepts) (Cain \& Oakhill, 2007; Perfetti \& Zhang, 1995).

Given the well-substantiated importance of oral language in learning to read across languages (Perfetti \& Dunlap 2008), what role does oral language play when learning to read in a language characterized by diglossia? Diglossia describes the phenomenon where two varieties of the same language co-exist and perform different communicative and social functions. This is the case in Arabic, a Semitic language with a spoken vernacular form used at home and everyday conversation, and a more formal form used in educational and professional contexts (Ferguson, 1959). The challenge faced by children who speak a diglossic language is they must learn to read a written language different from their everyday spoken language. Scant research attention has been paid to explore the mechanisms that drive the relationship between oral language and reading in such diglossic languages, particularly in the context of learning a second language. Because in most languages the oral and written forms have a one-to-one 
mapping, the lack of such mapping between the oral and written forms in diglossic Arabic is an anomaly that calls into question the role of oral language in shaping the development of reading. Thus, understanding this relationship in Arabic should deepen understanding of the interplay between oral language and reading in non-diglossic languages.

To examine this relationship, a review was conducted of research that examined the link between language and reading in bilingual English- and Arabic-speaking children. Relevant research was located using a targeted search that focused on studies that address language and reading in monolingual and bilingual Arabic children. Because the research literature on Arabic language and reading is in its infancy, in addition to a search of ERIC and PsycInfo databases, the researcher completed a thorough review of references from studies and book chapters written by prominent scholars who research Arabic and English-Arabic. Specifically, the review examined the link between oral language, with a focus on phonological processing, morphological awareness, and semantics [vocabulary]); and reading, with a focus on word reading, pseudoword reading, and reading comprehension) in English- and Arabic-speaking children.

\section{Theoretical Framework}

The predominant perspective that guided this review supports the notion that oral language plays a paramount role in learning to read. Hence, understanding how reading develops requires a parallel understanding of the mechanisms that undergird the development of language. To reach this understanding, two fundamental questions must be answered: What is reading? And what is language? 
With respect to the former-What is reading? Researchers have conceptualized reading as a language-based activity (Wolf \& Vellutino, 1993) that recruits other cognitive abilities including attention, memory, and motivation (Alexander, 2005/2006). This view emphasizes two aspects of reading, namely reading as decoding and reading for meaning (Berko-Gleason \& Bernstein Ratner, 2009). Reading as decoding focuses on constrained skills (i.e., skills that are mastered and bear influence over a short period of time) (Paris, 2005) such as grapheme-phoneme correspondence rules, letter naming fluency, and phonological awareness. By contrast, reading for meaning stresses unconstrained skills (i.e., skills that continue to develop and bear influence across the lifespan) such as vocabulary and reading comprehension (Paris, 2005).

Concerning the latter-What is language? Efforts to address this question date back to the beginning of the $20^{\text {th }}$ century. In his seminal collection of lectures, Course in General Linguistics, the Swiss linguist Ferdinand de Saussure (1915) provides an account of language as the relationship between units or surface phenomena (e.g., words) and rules or how these units or words are put together (e.g., grammar). He distinguishes between La langue et la parole or what the speaker says (structure) and what the speaker actually means (function). According to Saussure and other proponents of structuralism like Chomsky (1957) and Fodor (1973), language is an ideal object with universal properties, impervious to performance factors and unchanged across languages. With continued use, however, humans render language less ideal as they experience it. This theoretical divide between structure and function or form and meaning has pervaded language research for decades. It continues to be central to current debates of whether to view language as envisioned by Saussure - a formal, ideal object - or whether to 
conceptualize language as a functional system of meanings which essentially emerges from patterns of use (Deacon, 1997; Bates, 1978), highly shaped by experience (Elman et al., 1996).

Although differences exist in views of reading and language, for this review, reading is defined as encompassing both reading as decoding and reading for meaning, in which the development of constrained and unconstrained skills must be examined. For this review, language is conceptualized as an emergent form that consists of separate, yet interacting components (phonology [sound], morphology [word form]; semantics [meaning]; syntax [sentence structure/form]; and pragmatics [social use of language in context]), whose functions change in response to contextual demands. Within this view, the structure of language is important to the extent that structure serves communicative functions and is best viewed as an epiphenomenal, as opposed to a causal, aspect of language, constantly refined through patterns of use. These views are compatible with a developmental-interactionist perspective on learning (Diamond, 2007; Goswami, 2008), wherein individuals are the product of multiple factors, including their biology, cognition, emotion, society, culture, and physical environments; each factor interacting with the other and each playing an equal role in ontogeny (Diamond, 2007, p. 154). Influenced by experience, knowledge acquisition is viewed as a constantly emerging, integrative process that transcends the disciplinary boundaries of language, biology, culture, cognition, emotion, perception, and action (Diamond, 2007).

In sum, the following three fundamental principles guide this review: reading and language are conceptualized as cognitive-developmental phenomena; both reading and 
language develop for the purpose of communication; and the context in which reading and language develop is fundamentally a social context.

\section{Review}

With the foregoing as background, this review examines the link between language and reading in bilingual English- and Arabic-speaking children. Investigations of languages such as Spanish are referenced because most of the studies on language and reading in minority languages spoken in the US have been conducted with bilingual Spanish-speaking children. The review proceeds as follows: an overview of Arabic, the role of experience in language learning, and language predictors of reading.

\section{Overview of the Arabic Language}

An overview of Arabic as a diglossic language is presented with a focus on its two predominant forms: Modern Standard Arabic (MSA) and Spoken Vernacular Arabic (SVA). First, this section describes aspects of the Arabic language and introduces the construct of linguistic distance (Saiegh-Haddad, 2003) between MSA and SVA as a potent factor that aids in predicting reading outcomes. Second, this section describes the literature concerning the differences between MSA and SVA along the dimensions of phonology, morphology, and vocabulary. Third, this section presents the orthographic demands imposed by Arabic that could impact reading outcomes.

Like most languages, Arabic is classified according to its spoken and written forms. Arabic, a Semitic language, belongs to a group of languages spoken in the Middle East and North Africa. It has an alphabetic system known as Abjad (Daniels \& Bright, 1996) — an alphabetic system that does not rely on vowels and uses written scripts adapted from Sumerian Cuneiform (logographic writing that preceded alphabetic 
writing). The Arabic alphabet consists of 28 letters including three long vowels. Diacritics mark short vowels. Most letters can have four shapes depending on their position in the word. For example the letter "ب" appears in four different forms in the following words (صبي ;عنب ;برد ;هرب). There are groups of letter dyads and triads that follow each other in the alphabet and look identical except for the placement of the dot e.g., (ج ج); these letters represent the sounds (/x/, voiceless velar fricative; $/ \check{h} /$, voiceless pharyngeal fricative; and voiced alveo-palatal fricative $/ 3 /$, respectively. Arabic is considered a shallow orthography (one-to-one correspondence between graphemes and phonemes and consistent spelling of words) when vowelized, and a deep orthography (one-to-many relationship between graphemes and phonemes) when unvowelized.

Many children are taught to read and write using the vowelized form of Arabic and then transition to the unvowelized form, as they get older (Abu-Rabia, Share, \& Mansour, 2003). However, other children, because instruction used in schools focuses on sight words, are taught to read the unvowelized Arabic first or in conjunction with vowelized Arabic.

All words in Arabic are based on morphological tri-consonantal patterns built on roots that convey meaning (Abu-Rabia \& Taha, 2004). These can be derivational (vowel pattern may or may not disrupt the order of consonants; order of consonants may be linear or nonlinear), e.g., kataba (wrote) and kutayyeb (small book). Morphological patterns can also be inflectional (vowel patterns are attached as prefixes or suffixes); order of consonants may be linear, e.g., katabat (she wrote). Arabic is characterized also by the presence of the homograph phenomenon whereby certain words that differ in their semantics may look identical, e.g., kataba and kutiba (كتب كتب) (wrote and was written, 
respectively); thus rendering reading unvowelized and partially vowelized words or texts challenging and forcing readers to rely on contextual information to infer the meaning of the text.

One distinguishing characteristic of Arabic is the presence of diglossia. Diglossia is a phenomenon in which two varieties of the same language coexist, each of which occupying a distinct sociolinguistic function and used for a mutually exclusive set of purposes (Ferguson, 1959). In the Arabic language, these two forms are: Spoken vernacular Arabic (SVA), which is used as the primary mode of communication at home and in informal ordinary conversation; and Modern Standard Arabic (MSA), which is acquired via formal education and used in formal speeches, media, and for various written purposes. The result is social-functional complementarity (Ferguson, 1959), meaning SVA and MSA are used in different communicative contexts. Typically when one form is used (e.g., SVA), the other is not used (e.g., MSA), thus leading to linguistic distance (Saiegh-Haddad, 2003) between SVA and MSA across multiple language components.

In Arabic, differences between SVA and MSA are manifest in the phonological component. For example, MSA and SVA share most consonant speech sounds except three: /q/ as in qaraa (read); voiceless fricative /th/ as in thawb (dress); and voiced emphatic fricative /th/ as in thala:m (darkness).

Differences between MSA and SVA also affect the structure of words as determined by phonotactics or rules for combining phonemes. MSA has only three syllable shapes $(C V, C V C$, and $C V C C)$ and consonant clusters are not allowed in the word-initial position of words. Conversely, in SVA consonant clusters exist in the word- 
initial position of words. For example, consonant clusters are permissible in Lebanese Arabic through syllable simplification and vowel deletion seen in the case of $C V C V C$ becoming CCVC as in /Kita:b/ (book) $\rightarrow[k t e: b]$ (Farran, 1995). Another example of permissible consonant clusters is found in Jordanian Arabic, where the CVCC syllable undergoes epenthesis - the insertion of a vowel between two consonants as in /bint/ (girl) $\rightarrow$ [bi.nit] (Amyreh \& Dyson, 2000). As these examples show, changes in phonemes do not always affect the meaning of words. Yet, in some instances they do as in /beyt/ (house) and /be:yit/ (stale). Other changes (e.g., gemination or doubling of consonant speech sounds) that induce change in meaning also exist as seen in the example / kataba/ (he wrote) $\rightarrow$ Ikattabal (he dictated) or /hadaral (he attended) $\rightarrow$ Ihaddaral (he prepared).

At the morphological level, MSA and SVA differ as well. One important morphological factor that influences the structure of words in Arabic is the presence or absence of inflectional morphemes. These morphemes, which mark person, gender, number, tense, and case (Saiegh-Haddad, 2003), characterize MSA but are absent in SVA. For example, the following MSA words /akal-a/ (he ate), /lwalad-u/ (the boy), and Ituffaha-tan/ (an apple) have the inflectional morphemes /a/, /u/, and /tan/, respectively. These same words lose their inflectional morphemes in SVA and become (akal) (he ate), /lwalad/ (the boy), and /tuffahal (an apple) (Saiegh-Haddad, 2003).

In addition to morphology, differences exist between MSA and SVA in the domain of vocabulary. For example, some words that mean the same in MSA and SVA may share the root morpheme but differ in their vowel sound composition (e.g., Ku:b $\rightarrow$ 
kibbe:yi [glass]), although other words may differ substantially along both consonant and vowel sounds (e.g., na:fitha $\rightarrow$ shubba:k [window]).

These similarities and differences between MSA and SVA are similar but not identical across all dialects of Arabic, however. There are several variants of SVA spoken around world countries or in various regions within the same country, but only one MSA. Each SVA differs from MSA in both word structure and meaning, and this difference may be slight or substantial. Thus, SVAs may be conceptualized as lying on a continuum from close to MSA to distant from MSA. All speakers of Arabic, regardless of their SVA, use MSA for formal spoken and written purposes and schooling.

The notion of linguistic distance between SVA and MSA is important particularly because children who learn Arabic are exposed to SVA as their first language from birth. By contrast, they are exposed to MSA as their second language (Ayari, 1996), typically when they enter school. This delayed and limited interaction with MSA leads to delays in reading and writing, thought to be driven by social-cultural and social-political forces (Dakwar, 2005). Such forces directly impact patterns of language use and result in functional illiteracy in Arabic which, in turn, can interfere with the acquisition of various aspects of the reading process (Ayari, 1996; Maamouri, 1998), including word reading accuracy and reading comprehension.

In addition to linguistic distance between SVA and MSA, the orthographic characteristics of Arabic likely place additional cognitive and visual demands on readers. Arabic is written from right to left. And as mentioned previously, Arabic has a transparent orthography with one-to-one correspondence between graphemes and phonemes when vowelized, and an opaque orthography with one-to-many 
correspondence between graphemes and phonemes when unvowelized. Moreover, Arabic is considered a dense orthography because one visual slot is occupied by one consonant and one short vowel or diacritic (e.g., / $/ k a /$ or 5 ). Further, visual similarity exists between letter dyads and triads (e.g., ج ح $ح$ ), and each letter is written in at least three different forms depending on its position in the word (e.g., هبرب ;عنب ;برد ;رب).

Morphological demands of Arabic constitute another challenge to the reading process. Arabic is considered a dense morphology. Arabic words are based on morphological patterns built on roots that convey meaning (Abu-Rabia \& Taha, 2004). Unlike concatenative languages (e.g., English) that use linear morphological processes including prefixes and suffixes, Arabic is a non-concatenative language, that uses both linear and non-linear morphological processes and employs two types of bound morphemes: a consonantal root, which carries the semantic core (meaning) of the word (e.g., KTB); and a word pattern or vowel template, which, together with the consonantal root, make a word (e.g., KaTaBa) (to write). These characteristics add to the challenge of learning to read in Arabic.

The literature on the relationship between reading and language development in Arabic is limited despite the heightened interest in investigating this relationship in English and other European languages. One exception is the work of Saiegh-Haddad and Geva (2008) which investigated the relationship between morphological awareness, phonological awareness, and reading in 43 third, fourth, fifth, and sixth grade bilingual English-Arabic children in Canada. Saiegh-Haddad and Geva found that phonological skills, but not morphological skills, predicted word reading across English and Arabic and that morphological awareness within both languages predicted complex word reading 
fluency. Their study sheds light on the cross-linguistic relationship between phonological and morphological skills and learning to read Arabic. However, other language components, such as semantics (vocabulary), were not assessed in either language and their study only assessed word reading accuracy and derived word reading fluency, not reading comprehension. Although they assessed phonological awareness, Saiegh-Haddad and Geva did not consider other related subskills such as phonological memory and naming speed. Further, within phonological awareness, they only administered the Elision subtest with no consideration of the developmental progression of various aspects of phonological awareness.

As the preceding section demonstrates, even though the research base is limited, the available evidence shows that several factors are implicated in learning to read in Arabic. These include the linguistic distance between the two predominant forms, MSA and SVA, that lead to differences that span all components of language, including phonology, morphology, and semantics.

\section{Role of Experience in Language Learning}

Regardless of the language or components of language being studied, the consensus among researchers holds that experience with language use plays an instrumental role in the development of oral language. By consequence, such experience is implicated in shaping reading developmental outcomes (Saiegh-Haddad, 2007; Seidenberg \& McClelland, 1989). This section presents predominant views of reading that illustrate the role of experience in language learning. Specifically, this section describes prevailing contrasting models (single-route model versus dual-route model) of reading development drawing on interactionist views of reading. First, it provides an 
overview of Connectionism, a modeling tool that highlights the role of experience in learning to read. Next, this section offers a brief description of one connectionist modelthe Triangle Model (Seidenberg \& McClelland, 1989) that accounts for the interplay among the various language components in shaping reading development. Last, this section provides a rationale for selecting the single-route model as a parsimonious account for reading development in Arabic.

For decades, scholarly debates have revolved around the question of how children learn to read. A great deal of research has focused on whether, and the extent to which, children rely on a phonological route or a lexical route to read words (Coltheart, Rastle, Perry, Langdon, \& Ziegler, 2001; Pinker \& Prince, 1988). Two predominant models, dual- route model and single-route model, offer different explanations for how young children read words.

The dual-route model views language as comprised of independent components (phonology and semantics), each responsible for distinctive functions. Therefore, as children learn to read words, either they rely on the phonological route (i.e., apply rules for reading regular words) or the lexical/semantic route (i.e., rely on memory to read words to which rules do not apply), but not both. This model (a) conceptualizes language structure as the most important aspect of language; (b) views language components as developing in a sequential manner; and (c) considers language as impervious to performance factors and contextual influences (Frost, Katz, \& Bentin, 1987). Despite the high impact the dual-route model has had on recent conceptualizations of reading, the model falls short of providing an explicit account of learning language and reading. 
Conversely, the single-route model, as proposed in the Connectionist Triangle Model of reading, offers such explanation as it conceptualizes language as inextricably linked to children's experience with reading (Harm \& Seidenberg, 2004; Plaut, et al., 1996; Seidenberg \& McClelland, 1989). This model is dynamic, allowing for a bidirectional relationship between two interacting subsystems: the phonological pathway that maps orthographic representations to phonological ones, and the semantic pathway that connects phonological and orthographic representations via semantics (see Figure 1). This bidirectional relationship between the two pathways develops within a single system, as opposed to two systems as suggested by the dual-route model. Although, both dual- and single-route models value the importance of phonology and semantics in the

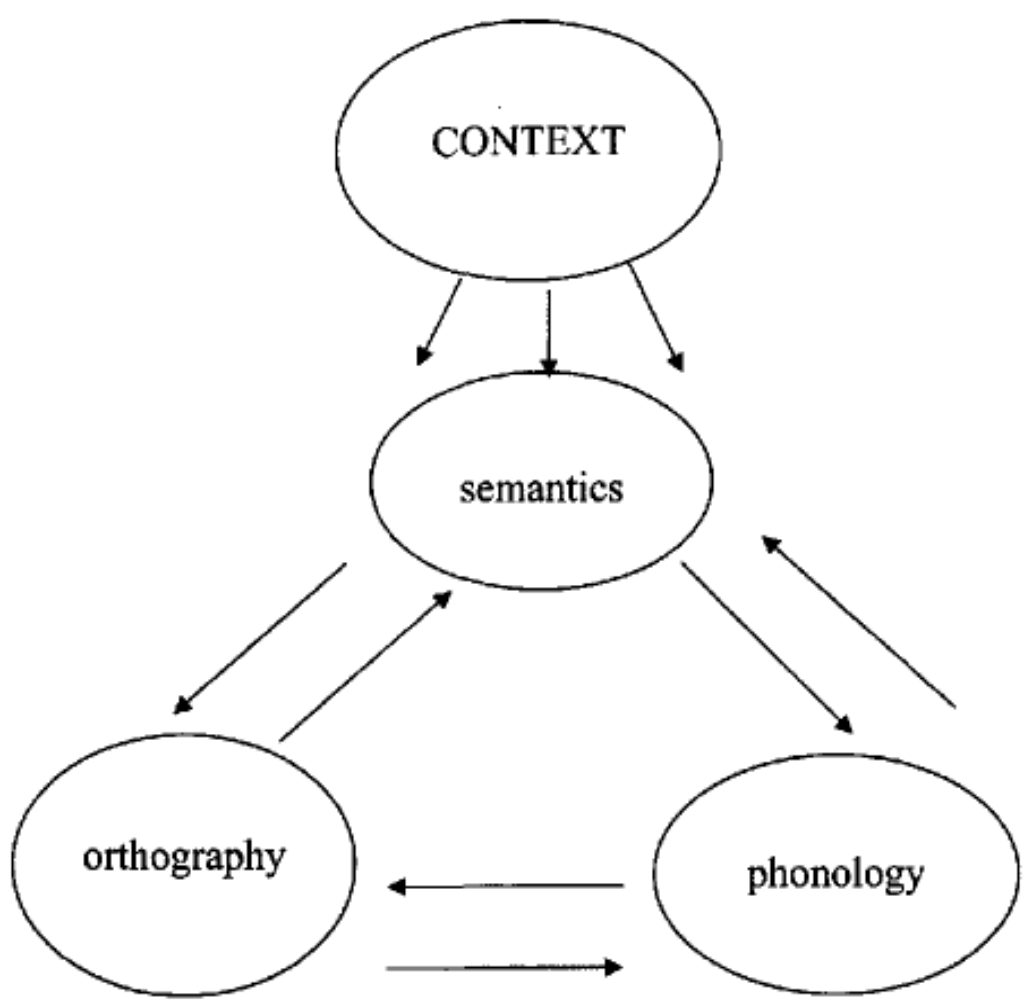

Figure 1. The Triangle Model as conceptualized by Seidenberg \& McClelland (1989). 
development of reading, they differ in whether language components develop sequentially (dual route) or simultaneously (single route).

The strength of the Triangle Model of reading lies in its developmental nature, which accounts for reading under typical conditions, atypical conditions, bilingualism, and multilingualism. Implicit in this model is the idea of a division of labor (Harm \& Seidenberg, 2004) among the language components, that changes across development, task demands, and the context in which reading occurs. This notion of a division of labor is highly attractive, because it accounts for the various compensatory strategies children might utilize when reading under a variety of conditions (e.g., learning to read two or more languages that differ in transparency, or reading vowelized versus unvowelized texts in Arabic). Moreover, the idea of a division of labor can explain how children with developmental disorders, (e.g., dyslexia) come to rely more on a semantic pathway as they read to compensate for an impaired phonological pathway.

As conceptualized, the Triangle Model suggests that young children, early in reading development, recruit all their available cognitive resources to establish a phonological pathway wherein they map sounds (phonology) on letters (orthography) to decode words and pseudowords (i.e., respectively, words and non-words that follow rules). Later in reading development, children dedicate their cognitive resources to establish a semantic pathway, wherein they map phonology and orthography via semantics. Children's establishment of a semantic pathway likely explains how they read irregular words (i.e., words that do not follow rules). Children with an intact phonological pathway do well during the initial period of learning to read as evidenced in their intact decoding abilities. If their phonological pathway is compromised, involving one or more 
of the phonological processing abilities (phonological awareness, phonological memory, and rapid naming), children tend to exhibit poorly specified phonological representations, which interfere with efficient word reading. Conversely, children whose semantic pathway is compromised could experience difficulties with reading comprehension and vocabulary knowledge. Thus, the Triangle Model provides one explanation of how children can have difficulties with either the phonological pathway (reflecting word decoding deficits) or the semantic pathway (reflecting deficits in word meaning or deficits in comprehension) or both. Given this flexibility, the Triangle Model offers a parsimonious account of reading development.

The Triangle Model has two major limitations, however. One, the model explains word reading but not reading comprehension. Although the model suggests a link between semantics and context, how semantic representations relate to other sources of language remains largely unaddressed. Two, the model grants a passive role to the developing child, because it conceptualizes reading development as the result of simple connections between units (akin to neurons in the brain) progressively strengthened with language and reading experience.

Recently, an extended version of the Triangle Model (Bishop \& Snowling, 2004) was proposed to account for reading comprehension development in children with oral language difficulties. This version can be adapted to explain how other populations of children respond when they read under less-than-optimal conditions and thereby exhibit diminished abilities (Nation \& Snowling, 2004). The model incorporates interactions between semantic representations and other components of the language system, namely grammar and discourse language processes. This version is presented here because it 
explains a wide range of reading tasks in Arabic and English. As indicated in Figure 2, this version posits interactions that involve other components of language (grammar and discourse) and demonstrates how children use grapheme-phoneme correspondence to activate semantic, morphological, and phonological representations through reliance on the context in which language occurs.

As the foregoing section proposes, learning to read is influenced by language experience that results from the interaction of various factors, mainly linguistic. Recent research evidence shows that multiple components of oral language are implicated in shaping the development of reading. These components are presented next to support the role of oral language as the prime candidate for predicting reading outcomes.

\section{Language Predictors of Reading}

This section reviews studies related to language predictors of reading during the early school years in monolingual Arabic children and bilingual English-Arabic children. It focuses on oral language as the prime candidate for predicting reading outcomes in young children.

Whereas most researchers concur about the importance of language in reading development, less agreement exists regarding how the language components, namely phonology, semantics, and morphology, develop and the role each component serves in the process of learning to read. Although the empirical support for the role of phonology and semantics in reading has increased in the past decade, similar support for the role of morphology remains modest. 


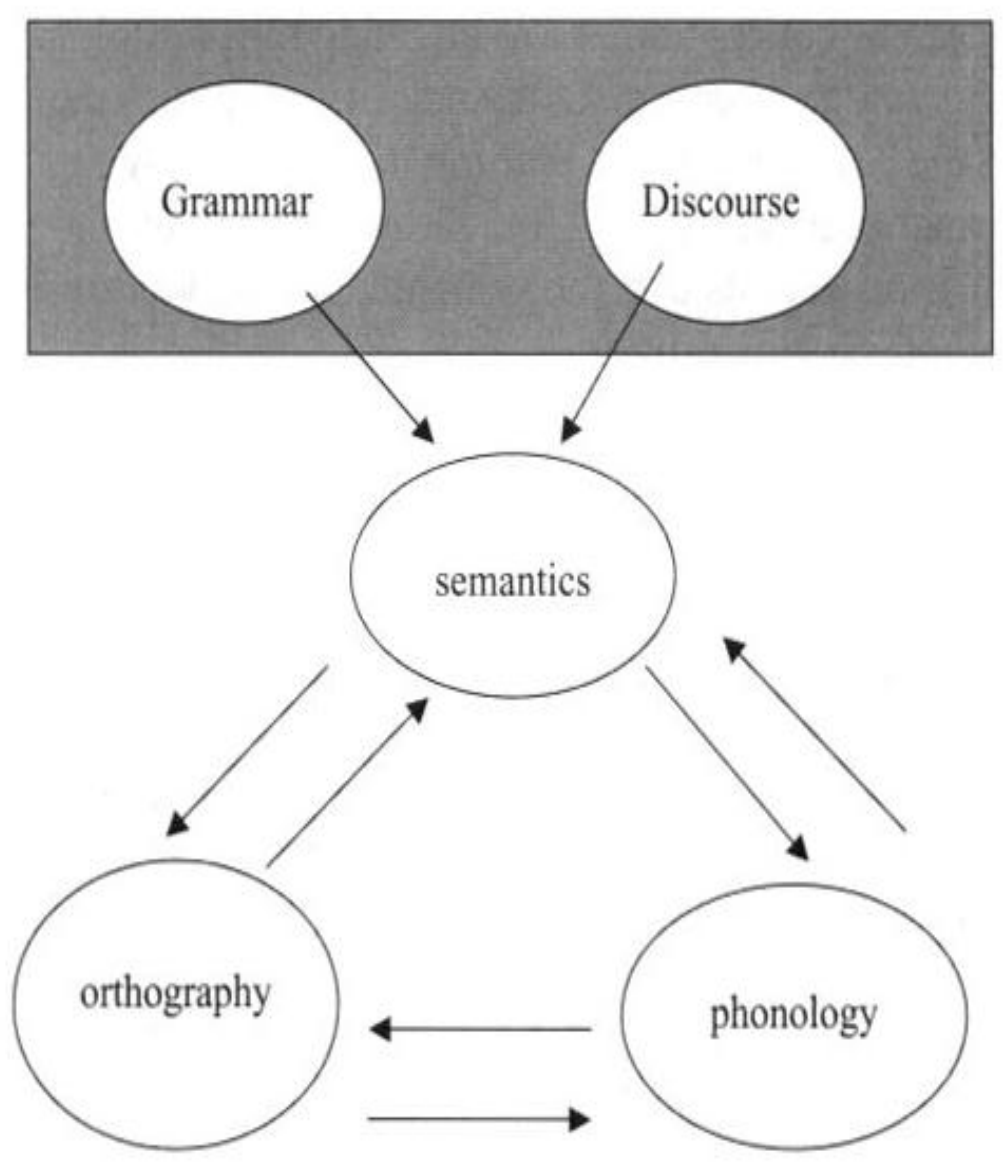

Figure 2. An extended version of the Triangle Model as conceptualized by Bishop \& Snowling (2004).

An examination of language predictors offers additional insights into reading development. When considering reading development in children, especially those who are bilingual or at risk for reading disabilities, the question arises as to whether the difficulties these children experience stem from a general language problem or from a reading problem. Therefore investigating how various components of language relate to reading is essential for a comprehensive account of reading development. 
The language components of relevance to this review are phonology, morphology, and semantics. First phonological processing is reviewed because the overwhelming majority of research has focused on its effect on reading outcomes. Next studies examining morphological awareness are presented given the importance of morphology in Arabic. Morphological awareness is followed by a review of studies that examine semantics, particularly vocabulary. Finally, this section addresses considerations related to the effects of a bilingual context on reading development. Specifically, issues of linguistic transfer and oral language proficiency are discussed because they are key players in investigating predictors of word reading and reading comprehension.

\section{Phonology}

Phonology is the study of the sounds of language and the rules for combining individual sounds, i.e., phonemes, to form words. Within phonology, phonological processing has been given considerable research attention. Many language and reading scholars argue that this aspect of phonology is universal, because it has been found to be predictive of developmental outcomes in reading across languages (Anthony \& Francis, 2005; Ziegler \& Goswami, 2005).

Phonological processing. Ample research evidence points to the robust role of phonological processing skills - a set of abilities that include phonological awareness, phonological memory, and rapid naming — in predicting reading outcomes across many languages (Goswami \& Bryant, 1990; Wagner \& Torgesen 1987; Ziegler \& Goswami, 2005). With respect to phonological awareness skills, researchers have proposed a developmental progression in learning and mastering these skills. For example, Anthony, Lonigan, Driscoll, and Burgess (2003) found that children typically progress from 
combining phonemes (e.g., blending) to deleting or manipulating phonemes (e.g. elision) as they develop, presumably the result of the cognitive load that increases according to task difficulty (Anthony \& Francis, 2005).

A strong body of evidence supports a relationship between phonological processing and reading development, suggesting a predictive role of phonological awareness in word reading in many languages including English (Snowling, 2000; Stanovich, 1986), French (Algeria, Pignot, \& Morais, 1982), and Chinese (Ho \& Bryant, 1997). For example, Snowling et al. (2000) investigated word reading, spelling, and reading comprehension in 56 English-speaking children with specific language impairment (SLI) who were followed from preschool through age 15 years. Children with SLI performed more poorly on measures of word reading, spelling, and reading comprehension as compared to their age-matched controls. The researchers found that children's reduced reading skills were commensurate with their poor phonological awareness skills. In a similar vein, Ho and Bryant (1997) examined phonological awareness development and its relationship to reading outcomes in 45 first graders and 45 second graders in Hong Kong. After controlling for the effect of age and maternal education, the researchers found that phonological awareness skills predicted children's word reading performance two and three years later.

In the case of Arabic, research suggests that phonological awareness is related to word reading (Abu-Rabia 1997; 2001; Abu-Rabia \& Taha, 2004; Abu-Rabia, Share, \& Mansour, 2003). To illustrate, Al- Mannai and Everatt (2005) examined the effect of pseudoword reading, phonological awareness, short-term memory, processing speed, and nonverbal ability on single word reading in a group of monolingual Arabic-speaking 
Bahraini children. The sample consisted of 171 students (64 first-graders, 55 secondgraders, and 52 third-graders; 84 males and 87 females) who ranged in age from 6.25 to 10.42 years. Results revealed that decoding and phonological awareness were the best predictors of variability in word reading, especially in first graders, accounting for over $40 \%$ of the variance in reading among this group of Bahraini children. In addition, performance on nonverbal intelligence tasks was a better predictor of reading skills than phonological skills for the older Bahraini children, who used unvowelized as opposed to vowelized texts (Al-Mannai \& Everatt, 2005). These findings support the single-route model of reading that posits in the absence of phonological information in unvowelized texts, older children would recruit the nonverbal skills necessary to process text features that depend on context and rich morphology.

Further support for the role of phonological awareness comes from a study with Arabic speaking children with reading disabilities. Abu-Rabia et al. (2003) investigated the effect of phonological awareness and morphological awareness on the phonological decoding abilities in 60 monolingual Arabic-speaking children (20 fifth-grade children with reading disabilities, 20 normal-reading fifth-grade children matched for chronological age, and 20 normal-reading third-grade children matched for reading level). The researchers used Analysis of Covariance measures to control for the effect of IQ and reading level. Results revealed that Arabic children with dyslexia showed poor phonological decoding and poor phonological awareness, as compared to chronological age-matched children and younger reading-matched children.

Similar conclusions were reported by Elbeheri and Everatt (2007) who investigated the relationship between phonological processing and reading ability in 331 
fourth- and fifth-grade Arabic speaking, Egyptian children some with and some without dyslexia. The children ranged in age between 9 years 4 months and 11years 6 months. Pearson's correlations revealed associations between phonological processing and reading. Chi square analysis between the dyslexic group and control group revealed higher scores for the dyslexic group on the nonverbal tasks as compared to the nondyslexic group, suggesting performance on phonological processing differentiated the two groups of readers. However, other measures of language such as morphology were not administered, so the relationship between the language components in Arabic could not be determined in this study.

Despite the evidence gathered from studies like those reviewed, a major criticism of the research on phonological awareness concerns its anglocentric nature (Share, 2008), with its heavy reliance on research conducted in the English language. For similar reasons, controversy surrounds the universality of phonological awareness (Cain \& Oakhill, 2007; Nation \& Snowling, 2004; Nation, Snowling, \& Clarke, 2007) and its predictive ability in reading in Arabic. Smythe and Everatt (2004) argued against relying solely on phonological awareness and proposed considering the transparency (the extent to which graphemes of a language map onto its phonemes) of a given language in reading acquisition and how transparency could differentially predict reading outcomes. For example reading accuracy have been found predictive of reading in nontransparent languages such as English, while measures of naming speed have been better predictors of word reading in transparent languages such as German (Ziegler \& Goswami, 2005). In the case of Arabic, which can be transparent (vowelized Arabic) or nontransparent 
(unvowelized Arabic), it is conceivable that measures of both accuracy and speed are needed to predict reading outcomes.

Other aspects of phonological processing have been linked to performance on word reading measures. For example, phonological or verbal short-term memory, which involves developing connections between visual symbols (e.g., numbers, letters, and words) and their verbal labels (i.e., pronunciations), has been associated with reading outcomes. Smythe, et al., (2003) found that measures of phonological memory differentiated poor readers from good readers in groups of English, Hungarian, and Chinese third-grade children, even though the groups varied by language background. Specifically, for the English group, memory deficits were evident in words and pseudowords; for the Hungarian group in pseudowords; and for the Chinese group in tasks that required children to retain sequences of abstract visual items.

Rapid naming, a third aspect of phonological processing, has been found to relate to word reading. Rapid naming is the rate with which a nonphonological stimulus is converted to phonological output e.g., converting a pictorial stimulus (e.g., of a cat) into a spoken word (/cat/) (Wolf \& Bowers, 1999). This aspect of phonological processing derives its importance from a theoretical model developed by Wolf and Bowers (1999) who posit that children can have differential deficits in naming speed or phonological awareness. Children who evidence both naming speed and phonological deficits present with double deficits that affect their reading outcomes. Hammill, Mather, Allen, \& Roberts (2002) investigated the role of rapid naming and phonological awareness in word identification in a sample of 200 children in grades 1-6. Using correlational analysis, they found that phonological, semantic, and rapid naming composites were related to 
word identification. In another study, Pennington, Cardoso-Martins, Green, and Lefly (2001) examined the predictors of word reading, pseudoword reading, and reading comprehension in a sample of 7 to 18 year-olds. Regression analysis results revealed that both phonological and rapid naming measures contributed unique variance to reading outcomes.

In sum, research indicates that phonological awareness, phonological memory, and naming speed are related to reading outcomes. Therefore, all three must be included in the assessment of phonological processing skills (Everatt \& Smythe, 2007).

\section{Morphology}

Morphology is the component of language concerned with the study of word form. Morphological awareness, the awareness of morphemes (the smallest units of meaning in a language) has been the most extensively researched aspect of morphology. Morphological awareness has been associated with reading outcomes and consequently necessary for understanding how reading develops (Carlisle, 1988; 2000; Treiman \& Cassar, 1996) and for predicting reading comprehension (Carlisle, 2000). This ability is considered essential for predicting reading outcomes both at the word reading level and the reading comprehension level (Ku \& Anderson, 2003).

In the English language, the relationship between morphological awareness and word reading is well established. Several studies suggest that children in the elementary grades vary significantly in their ability to manipulate morphologically complex words. Research suggests that differences in this ability reflect individual differences in word reading. Some of these differences are often linked to the difficulty of the reading task (Mahoney, Singson, \& Mann, 2000; Nagy, Berninger, \& Abbott, 2006) such as difficulty 
imposed by timing demands (e.g., Wagner \& Torgesen, 1987). Cross-linguistic research also supports the role of morphological awareness in reading. For example Ben Dror, Bentin, and Frost (1995) tested morphology, phonology, and semantics in a group of 60 fifth-graders who were learning Hebrew (20 children with reading disabilities [RD], 20 children who were chronological age- matched, and 20 children who were reading level matched). They found that children with RD performed worse than children in the other two groups. Precisely, the children's morphological awareness, measured using a morphological relatedness task in which the children had to decide whether pairs of words shared a common root, differentiated between the three groups of children. In addition to the connections between morphological awareness and word reading, relationships have been found between morphological awareness and reading comprehension, although the studies are limited in number. To illustrate, Carlisle (2000) investigated the relationship between morphological awareness and reading comprehension in third- and fifth- grade students using three different morphological awareness tasks: (a) decomposing and deriving the morphology of complex words; (b) reading morphologically complex words aloud; and (c) defining morphologically complex words. Using correlations and analysis of variance, results indicated that morphological awareness was related to reading comprehension. In addition, children's performance on the different morphological awareness measures varied as a function of task difficulty.

Similarly, Nagy et al., (2006) examined morphological awareness in 607 fourththrough ninth-grade students (182 fourth- and fifth-graders, 218 sixth- and seventhgraders, and 207 eighth- and ninth-graders). They used tasks that required the children to 
choose the appropriate suffix (suffix choice task) and to identify the actual morphological relationships from false ones in words (morphological relatedness task). Using structural equation modeling, the researchers found that for reading comprehension, reading vocabulary, spelling, and morphological awareness made a significantly unique contribution at all tested grade levels (Nagy et al., 2006).

Little evidence exists, however, to support a relationship between morphological awareness and reading comprehension in children who come from non-English-speaking homes. In a recent study, Kieffer and Lesaux (2008) investigated the relationship between morphology, vocabulary, and reading comprehension in 111 fourth- and fifthgrade students (87 Spanish-Speaking English Language Learners (ELLs) and 24 native English speakers) in an urban school district in southern California. Morphological awareness was assessed using a morphological decomposition task that required children to generate the root word from a complex word to complete a sentence. For example, children were given a sentence such as The boy is -----. Then, they were presented with the word courage and asked to use the word courageous to fit the sentence context. The researchers found that morphology related to reading comprehension in fourth- and fifthgraders, and this relationship strengthened as children progressed from fourth grade to fifth grade. Also important, the pattern of findings was similar for both groups of students, Spanish-speaking and native English speakers.

Because Arabic is a root-based language, morphological awareness should play a more potent role in Arabic than in English. For example, Abu-Rabia et al. (2003) found a significant difference in morphological awareness between the group of Arab children with reading disabilities and the group of Arab children without reading disabilities. The 
researchers measured morphological awareness through a morphological judgment task and a morphological generation task (Refer to the "Phonological Processing" section for a complete description of the study.)

In most of the studies reviewed, the tasks used to assess morphological awareness required children to provide a verbal explicit response, such as asking children to generate a response (extract a root word from a complex word) that fits the structure of an utterance. For example, children given the word beauty might be asked to complete an utterance such as: The scene was -----. It is arguable that over the course of language development, children first evidence implicit awareness of linguistic forms before they demonstrate explicit awareness of those forms (Cain \& Oakhill, 2007). If this line of reasoning is applied to language development, then it could be argued that children develop comprehension (receptive skills) before they develop production (expressive skills) (Berko-Gleason \& Bernstein-Ratner, 2009). Such considerations must be accounted for when selecting or developing language assessment measures, including morphological awareness measures.

Duncan, Casalis, and Cole (2009) accounted for both receptive and expressive comprehension in their study when they assessed both implicit and explicit morphological awareness. They developed a morphological awareness task based on the work of Mahoney et al., (2000) to examine morphological abilities in bilingual FrenchEnglish children, taking into account the children's chronological age, vocabulary, and years of schooling. The researchers used a morphological judgment task in which children judged whether word pairs were morphologically related or unrelated. Results 
revealed that children's morphological judgment ability develops over time and relates to other factors such as vocabulary and years of instruction children receive.

Overall, ample evidence exists to support morphological awareness as a potent index of reading comprehension in monolingual and bilingual children. In fact, some researchers (Carlisle, 2000; Kieffer \& Lesaux, 2008) posit that morphological awareness might have a bootstrapping effect through helping children infer the meaning of words they have not encountered before. Such an effect could be especially helpful for ELLs who typically evidence depressed vocabulary skills in their first and second language. Therefore, assessing morphological skills in children's first and second language is needed when examining factors related to reading development.

\section{Semantics}

Because reading is about accessing meaning, semantics, in addition to phonology and morphology, play an influential role in learning to read in a first and in a second language. Like morphological awareness, semantics influences readers' ability to construct meaning (Cunningham \& Stanovich, 1991; Stahl \& Fairbanks, 1986; Thorndike, 1973) as evidenced in research studies that have found a strong relationship between reading outcomes and semantic skills (Droop \& Verhooven, 2003). Therefore, a complete account of reading development must not only capture how the various language components interact to create meaning but must examine semantic skills (vocabulary and listening comprehension) development, particularly receptive vocabulary (Hammer, Lawrence, \& Miccio, 2007; Nation, et al., 2007).

Of the semantic skills, vocabulary has been the most extensively researched with evidence pointing to a reciprocal relationship between vocabulary and reading 
comprehension in native English speakers (Cain \& Oakhill, 2007; Stahl, 1999; Stahl \& Nagy, 2006; Stanovich, 1986), and ELLs (Proctor, August, Carlo, \& Snow, 2005). For example, Roth, Speece, and Cooper (2002) in their longitudinal study, followed 42 children from kindergarten through second grade. The researchers assessed the relationship between semantics and reading comprehension. They found that semantics, as measured through a receptive vocabulary task, predicted later reading comprehension.

In light of this evidence, there is a pressing need to improve the vocabulary skills for many second language learners and other struggling readers. Garcia notes this need is great for young Spanish-speaking children (2006). Recent statistics from the National Institute of Child Health and Development (2000) suggest a weak vocabulary is a major determinant of poor reading comprehension. Specifically, children lack the academic vocabulary needed to perform school tasks (Kiefer \& Lesaux, 2008; Francis et al., 2006) Academic vocabulary occurs infrequently in oral language. This deficit impedes their reading comprehension. Children who struggle in reading typically read less, which provides fewer opportunities to learn new words, which adds to the children's challenges in reading. Thus, unlike children who read a lot and as a consequence learn more words, the reverse occurs for children who struggle - a phenomenon Stanovich calls the Matthew effect (Stanovich, 1986). A general consensus exists among researchers that limited vocabulary knowledge, minimal exposure to print (Stanovich, 1986), word length and complexity (Stahl, 1999), lack of sophisticated decoding skills, and limited background knowledge contribute substantially to reading difficulties especially around fourth grade, what Chall referenced as the fourth-grade slump (Chall \& Jacobs, 2003). The relevance of these factors to reading outcomes in bilingual children is substantial, 
given that their oral language experience may be minimized due to their exposure to two or more languages.

Taken together, the studies reviewed in this section suggest that semantics, particularly academic vocabulary, is diminished in bilingual children. The evidence concerning learning to speak and read in two or more languages underscores the importance of assessing vocabulary in children's first and second language to capture their cumulative vocabulary. In addition, considering the bilingual environment and what it offers in terms of advantages and limitations is important. These considerations are discussed next.

\section{Bilingual Context}

The linguistic interdependence hypothesis put forward by Cummins (1979) and the script-dependent hypothesis proposed by Geva (2008) provide theoretical accounts for what occurs when children learn to read two or more languages. According to the linguistic interdependence hypothesis, knowledge of how to read in one language transfers when learning to read in a second language. Therefore, the strengths and difficulties children develop when learning to read in their first language influence their ability to read in their second language. By contrast, the script-dependent hypothesis maintains that reading development is constrained by the orthographic transparency and the degree of grapheme-phoneme correspondence in the language (s). Thus, the strengths and difficulties children develop when learning to read in a given language does not necessarily influence their ability to read in their second language. As children are learning to read languages that differ in orthographic transparency, they must resolve two mapping problems, one for each language. 
Research exists that supports both theories. For example, ample research exists that bilingual children in the US, whose main language is not English, are at risk for poor reading outcomes (National Center for Education Statistics, 2003). Some studies attribute this to weaknesses in phonological awareness (Durgunoglu, 2002; Geva, 2008) and morphological awareness skills that transfer from one language to another (Deacon \& Wade-Woolley, 2005; Geva 2008). Other studies link poor outcomes to the children's diminished language experience.

In spite of the evidence suggesting cross-linguistic transfer of phonological and morphological skills (Cummins, 1979), this transfer does not hold for vocabulary (Lindsey, Manis, \& Bailey, 2003). For example, a recent review by Lesaux (2006) indicates that although bilingual children perform well on word reading tasks, they are more likely than their native English-speaking peers to perform poorly on measures of reading comprehension.

Even though many researchers concur that bilingual children are more likely to have strengths in word reading accuracy and weaknesses in reading comprehension, less clear are the sources of their reading comprehension difficulties. Equally unknown are the specific components that positively influence reading comprehension in the bilingual population.

Viewed from the linguistic interdependence hypothesis and the script-dependent hypothesis, the challenges encountered by bilingual children likely stem from either the transfer across languages including deficiencies in various language components or language-specific constraints which impose limitations on learning to read. Together, they provide a comprehensive understanding of learning to read two or more languages. 


\section{What is Known about the Role of Language in Learning to Read in Arabic}

In summary, this review examined the link between oral language (phonology, morphology, and semantics) and reading (word reading and reading comprehension) in English- and Arabic-speaking children. Generally, the evidence suggests that phonological awareness is more amenable to cross-linguistic transfer than morphological awareness and vocabulary. With respect to vocabulary, its potent role in predicting reading outcomes across languages is unequivocal, although its exact role in the development of reading in Arabic is less understood. Further, morphological awareness is instrumental in the development of reading in many languages, and given that Arabic is a root-based language, morphological awareness is thought to play a significant role in reading Arabic. Although several studies investigated reading in Arabic and examined the predictive role of certain components of language in reading, lack of evidence exists that explains the interplay between various components of language when reading Arabic. Equally unknown are the mechanisms that undergird the development of reading comprehension in Arabic.

\section{Conclusion}

The importance of language components in a bilingual context notwithstanding, how the language components interact specifically within the Arabic language context is important to examine. Such knowledge could provide a means by which to understand the reading process in Arabic especially in the context of learning Arabic as a second language. However, a review of the literature on the role of Arabic language components in reading reveals a dearth of research studies in this domain, especially in bilingual children. Saiegh-Haddad and Geva's study (2008) is an exception. It investigated the 
relationship between phonological awareness, morphological awareness, and word reading in Bilingual English-Arabic children in Canada. Future research must address this gap through examining the relationship between different language components (e.g., phonology, morphology, and semantics) and various aspects of reading development (e.g., word reading accuracy and reading comprehension) in both monolingual and bilingual children.

Arabic and English differ in their orthographic depth and morphological transparency (the degree of correspondence between sounds and morphemes; transparent English versus opaque Arabic) (Saiegh-Haddad \& Geva, 2008). Therefore, the juxtaposition of English and Arabic in the same study offers the possibility to make informative comparisons of the cumulative as well as the unique contribution of language components (relevant to this review - phonology, morphology, and vocabulary) to the reading process. Such understanding has the potential to improve assessment and instruction within the broader bilingual population in the US classrooms and to identify early bilingual students who may be at risk for reading failure.

In closing, reading is a developmental process that rests on a foundation of oral language. Understanding this process requires a simultaneous understanding of the mechanisms that undergird the development of oral language including phonology, morphology, and semantics. This should be the focus of future research. 


\section{References}

Abu-Rabia, S. (1995). Learning to read in Arabic: Reading, syntactic, orthographic, and working memory skills in normally achieving and poor Arabic readers. Reading Psychology: An International Quarterly, 16, 351-394.

Abu-Rabia, S. (1997). Reading in Arabic orthography: The effects of vowels and context on reading accuracy of poor and skilled native Arabic readers. Reading and Writing: An Interdisciplinary Journal, 9, 65-78.

Abu-Rabia, S. (2001). The role of vowels in reading Semitic scripts: data from Arabic and Hebrew. Reading and Writing: An Interdisciplinary Journal, 14, 39-59.

Abu-Rabia, S., Share, D., \& Mansour, M. (2003). Word recognition and basic cognitive processes among reading-disabled and normal readers in Arabic. Reading and Writing: An Interdisciplinary Journal, 16, 423-442.

Abu-Rabia, S., \& Taha, H. (2004). Reading and spelling error analysis of native Arabic dyslexic readers. Reading and Writing: An Interdisciplinary Journal, 17, 651-689.

Alexander, P. (2005/2006). The path to competence: A lifespan developmental perspective on reading. Journal of Literacy Research, 37 (4), 413-436.

Algeria, J., Pignot, E., \& Morais, J. (1982). Phonetic analysis of speech and memory codes in beginning readers. Memory \& Cognition, 10, 451-456.

Al-Mannai, H., \& Everatt, J. (2005). Phonological processing as predictors of literacy amongst Arabic speaking Bahraini children. Dyslexia, 11, 269-291.

Ameyreh, M., \& Dyson, A. (2000). Phonetic inventories of young Arabic-speaking children. Clinical Linguistics \& Phonetics, 14 (3), 193-215.

Anthony, J., \& Francis, D. (2005). Development of phonological awareness. Current Directions in Psychological Science, 14 (5), 255-259.

Anthony, J., Lonigan, C., Driscoll, K., \& Burgess, S. (2003). Phonological sensitivity: A quasi- 
parallel progression of word structure units and cognitive operations. Reading Research Quarterly, 38 (4), 470-487.

August, D., Carlo, M., Dressler, C., \& Snow, C. (2005). The critical role of vocabulary development for English language learners. Learning Disabilities: Research and Practice, 20, 50-57.

August, D. \& Shanahan, T. (2006). Developing reading and writing in second-language learners: Lessons from the report of the National Literacy Panel on language minority children and youth. New York: Routledge, Taylor \& Francis.

Ayari, S. (1996). Diglossia and illiteracy in the Arab world. Language, Culture, and Curriculum, 9, 243-253.

Bates, E. (1978). Functionalism and the biology of language. Papers and Reports in Child Language. Stanford University, Department of Linguistics.

Ben Dror, I., Bentin, S. \& Frost, R. (1995). Semantic, phonologic, and morphologic skills in reading disabled and normal children: Evidence from perception and production of spoken Hebrew. Reading Research Quarterly, 30 (4), 876-893.

Berko-Gleason, J., \& Berstein Ratner, N. (Eds.).(2009). The development of language (7th ed.). Boston, MA: Pearson.

Bishop, D., \& Snowling, M. (2004). Developmental dyslexia and specific language impairment: Same or different? Psychological Bulletin, 130, 858-888.

Cain, K. \& Oakhill, J. (2007). Children's comprehension problems in oral and written language: A cognitive perspective. New York: Guilford Press.

Carlisle, J. (1988). Knowledge of derivational morphology and spelling ability in fourth, sixth, and eighth grades. Applied Psycholinguistics, 9, 247-266.

Carlisle, J. (2000). Awareness of the structure and meaning of morphologically complex words: Impact on reading. Reading \& Writing: An interdisciplinary Journal, 12, 169-190. 
Carlisle, J., \& Stone, A. (2005). Exploring the role of morphemes in word reading. Reading Research Quarterly, 40 (4), 428-449.

Carlo, M., August, D., McLaughlin, B., Snow, C., Dressler, C., Lippman, T., et al. (2004). Closing the gap: Addressing vocabulary needs in English-language learners in bilingual mainstream classrooms. Reading Research Quarterly, 39 (2), 188-215.

Catts, H., \& Kamhi, A. (2005). Language and reading disabilities. Boston: Allyn \& Beacon.

Chall, J., \& Jacobs, V. (2003). Poor children's fourth-grade slump. American

Educator, 27 (1), 14-15, 44.

Chomsky, N. (1957). Syntactic structures. The Hague: Mouton.

Coltheart, M., Rastle, K., Perry, C., Langdon, R., \& Ziegler, J. (2001). DRC: A dual-route cascaded model of visual word recognition and reading aloud. Psychological Review, $108,204-256$.

Cummins, J. (1979). Language functions and cognitive processing. In J.P. Das, J. Kirby and R.F. Jarman (Eds.), Simultaneous and successive processing (pp. 175-185). New York: Academic Press.

Cunningham, A., \& Stanovich, K. (1991). Assessing print exposure and orthographic processing in children: Associations with vocabulary, general knowledge, and spelling. Journal of Educational Psychology, 83, 423-441.

Dakwar, R. (2005). Children's attitudes towards the diglossic situation in Arabic and its impact on learning. Languages, Communities, \& Education, 75-86.

Daniels, P., \& Bright, W. (1996). The world's writing systems. New York: Oxford University Press.

Deacon, H., \& Wade-Woolley, L. (2005). How the relationship between morphological awareness and reading changes as language skills develop. Paper presented at the annual meeting of the Society for the Scientific Studies of Reading, Toronto, Canada. 
Deacon, T. (1997). The symbolic species: The co-evolution of language and the human brain. New York, NY: W.W. Norton.

Diamond, A. (2007). Interrelated and interdependent. Developmental Science, 10 (1), 152-158.

Droop, M., \& Verhooven, L. (2003). Language proficiency and reading ability in first- and second-language learners. Reading Research Quarterly, 38, 78-103.

Duncan, L., Casalis, S., \& Cole, P. (2009). Early metalinguistic awareness of derivational morphology: Observations from a comparison of English and French. Applied Psycholinguistics, 30 (3), 405-440.

Durgunoglu, A. (2002). Cross-linguistic transfer in literacy development and implications for language learners. Annals of Dyslexia, 2, 189-204.

Elbeheri, G., \& Everatt, J. (2007). Literacy ability and phonological processing skills amongst dyslexic and non-dyslexic speakers of Arabic. Reading and Writing: An Interdisciplinary Journal, 20 (3), 273-294.

Elman, J., Bates, E., Johnson, M., Karmiloff-Smith, A., Parisi, D., \& Plunkett, K. (Eds.). (1996). Rethinking innateness: A connectionist perspective on development. Cambridge, MA: The MIT Press.

Farran, L. (1995). Phonological assessment in the Lebanese dialect of Arabic: Test development. Unpublished Master's thesis. University of Mississippi.

Fodor, J., \& Katz, J. (Eds.). (1964). The structure of language. Englewood Cliffs, New Jersey: Prentice Hall.

Frost, R., Katz, L., \& Bentin, S. (1987). Strategies for visual word recognition and orthographical depth: A multilingual comparison. Journal of Experimental Child Psychology: Human Perception and Performance, 13(1), 104-115. 
Ferguson, C. (1959). Diglossia. Word, 15, 325-340.

Francis, D., Rivera, M., Lesaux, N., Kieffer, M., \& Rivera, H. (2006). Research-based recommendations for the use of accommodations in large-scale assessments. Portsmouth, NH: RMC Research Corporation, Center on Instruction. Retrieved June 20, 2010, from http://www.centeroninstruction.og/files/ELL1-Assessments.pdf

Geva, E. (2008). Facets of metalinguistic awareness related to reading development in Hebrew: Evidence from monolingual and bilingual children. In K. Koda and A. Zehler (Eds.), Learning to read across languages: Cross-linguistic relationships in first-and secondlanguage and literacy development (pp. 241-255). New York, NY: Routledge.

Goswami, U. (2008). Cognitive development: The learning brain. New York: Psychology Press. Goswami, U., \& Bryant, P. (1990). Phonological skills and learning to read. Hillsdale, NJ: Erlbaum.

Hammer, C., Lawrence, F., \& Miccio, A. (2004). Bilingual children's language abilities and early reading outcomes in Head Start and kindergarten. Language, Speech, and Hearing Services in Schools, 38, 237-248.

Hammill, D., Mather, N., Allen, E., \& Roberts, R. (2002). Using semantics, grammar, phonology, and rapid naming tasks to predict word identification. Journal of Learning Disabilities, 35, 121-136.

Harm, M. \& Seidenberg, M. (2004). Computing the meaning of words in reading: Co-operative division of labor between visual and phonological processes. Psychological Review, 111, $662-720$.

Ho, C., \& Bryant, P. (1997b). Phonological skills are important in learning to read Chinese. Developmental Psychology, 33, 946-951.

Hoover, H., \& Dunbar, S. (2005). The Iowa Tests of Basic Skills (ITBS). Rolling Meadows, IL: 
Riverside. Joanisse, M., Manis, F., Keating, P., \& Seidenberg, M. (2000). Language deficits in dyslexic children: Speech perception, phonology, and morphology. Journal of Experimental Child Psychology, 77, 30-60.

Kieffer, M., \& Lesaux, N. (2008). The role of derivational morphology in the reading comprehension of Spanish-speaking English language learners. Reading \& Writing: An Interdisciplinary Journal, 21, 783-804.

Lesaux, N. (2006). Building consensus: future directions for research on English language learners at risk for learning difficulties. Teachers College Record, 108 (11), 2406- 2438.

Liberman, I. (1973). Segmentation of the spoken word. Bulletin of the Orton Society, 23, 65-77.

Lindsey, K., Manis, F., \& Bailey, C. (2003). Prediction of first-grade reading in Spanishspeaking English-language learners. Journal of Educational Psychology, 95, 482-494.

Maamouri, M. (1998). Language education and human development: Arabic diglossia and its impact on the quality of education in the Arab region. Discussion paper prepared for the World Bank Mediterranean Development Forum, Marrakesh. Philadelphia: University of Pennsylvania International Literacy Institute.

Mahoney, D., Singson, D., \& Mann, V. (2000). Reading ability and sensitivity to morphological relations. Reading and Writing: An Interdisciplinary Journal, 12, 191-218.

McBride-Chang, C. (2004). Children's literacy development. London: Arnold.

Metsala, J. (1997). Spoken word recognition in reading disabled children. Journal of Educational Psychology, 89 (1), 159-173.

Nagy, W., Berninger, V., \& Abbott, R. (2006). Contributions of morphology beyond phonology to literacy outcomes of upper elementary and middle-school students. Journal of Educational Psychology, 98, 134-147.

Nation, K, \& Snowling, M. (2004). Beyond phonological skills: Broader language skills contribute to the development of reading. Journal of Research in Reading, 27, 342-356. 
Nation, K., Snowling, M., \& Clarke, P. (2007). Dissecting the relationship between language skills and learning to read: Semantic and phonological contributions to new vocabulary learning in children with poor reading comprehension. Advances in Speech-Language Pathology, 9 (2), 131-139.

National Center for Education Statistics (2003). Status and trends in the education of Hispanics. Washington, DC: U.S. Department of Education.

National Reading Panel (2000). Report of the National Reading Panel. Teaching children to read: An evidence-based assessment of the scientific research literature on reading and its implications for reading instruction. Washington, DC: National Institute of Child Health and Human Development and US Department of Education.

National Institute for Literacy (2008). Developing early literacy: Report of the National Early Literacy Panel: A scientific synthesis of early literacy development and implications for intervention. Retrieved February 25, 2010, from http://www.nifl.gov/nifl/publications/pdf/NELPReport09.pdf

Paris, S. (2005). Reinterpreting the development of reading skills. Reading Research Quarterly, $40(2), 184-202$.

Paris, S., Carpenter, R., Paris, A., \& Hamilton, E. (2005). Spurious and genuine correlates of children's reading comprehension. In S. Paris and S. Stahl (Eds.). Children's reading comprehension and assessment (pp. 131-160). Mahwah, NJ: Lawrence Erlbaum Associates.

Pennington, B., Cardoso, C., Green, P. \& Lefly, D. (2001). Comparing the phonological and double deficit hypotheses for developmental dyslexia. Reading and Writing: An Interdisciplinary Journal, 14, 707-755.

Perfetti, C. (2003). The universal grammar of reading. Scientific Studies of Reading, 7 (1), 324. 
Perfetti, C., \& Dunlap, S. (2008). Learning to read: General principles and writing systems variations. In K. Koda and A. Zehler (Eds.), Learning to read across languages: Crosslinguistic relationships in first- and second-language literacy development (pp 13-38). New York, NY: Routledge.

Perfetti, C. \& Zhang, S. (1995). Very early phonological activation in Chinese reading. Journal of Experimental Psychology: Learning, Memory, \& Cognition, 21(1), 24-33.

Pinker, S. \& Prince, A. (1988). On language and connectionism. Cognition, 28, 73-193.

Plaut, D., McClelland, J., Seidenberg, M., \& Patterson, K. (1996). Understanding normal and impaired word reading: Computational principles in quasi-regular domains. Psychological Review, 103, 56-115.

Proctor, C., August, D., Carlo, M., \& Snow. C. (2005). Native Spanish-speaking children reading in English: Towards a model of comprehension. Journal of Educational Psychology, 97 (2), 246-256.

Roth, F., Speece, D., \& Cooper, D. (2002). A longitudinal analysis of the connection between oral language and early reading. Journal of Educational Research, 95 (5), 259-272.

Saiegh-Haddad, E. (2003). Linguistic distance and initial reading acquisition: The case of Arabic diglossia. Applied Psycholinguistics, 24, 431-451.

Saiegh-Haddad, E. (2004). The impact of phonemic and lexical distance on the phonological analysis of words and pseudowords in a diglossic context. Applied Psycholinguistics, 25, $495-512$

Saiegh-Haddad, E. (2007). Linguistic constraints on children's ability to isolate phonemes Arabic. Applied Psycholinguistics, 28, 607-625.

Saiegh-Haddad, E., \& Geva, E. (2008). Morphological awareness, phonological awareness, and reading in English-Arabic bilingual children. Reading and Writing: An Interdisciplinary Journal, 21, 481-504. 
Saussure, F. D. (1915). Cours de linguistique generale. Paris: Payot.

Scarborough, H. (2001). Connecting early language and literacy to later learning (dis)abilities: Evidence, theory, and practice. In S. Neuman \& D. Dickinson (Eds.), Handbook of Family Literacy (pp. 97-110). New York: Guilford Press.

Seidenberg, M. \& McClelland, J. (1989). A distributed developmental model of word recognition and naming. Psychological Review, 96, 523-568.

Share, D. (2008). On the anglocentricities of current reading research and practice: the perils of overreliance on an outlier orthography. Psychological Bulletin, 134, 584-615.

Smythe, I., \& Everatt, J. (2004). Dyslexia - a cross linguistic framework. In I. Smythe, J. Everatt, \& R. Salter (Eds.), The International Book of Dyslexia, Part 1, London: Wiley.

Smythe, I., Everatt, J., Al-Menaye, N., He, X., Capellini, S., Gyarmathy, E., \& Siegel, L. (2008). Predictors of word-level literacy amongst grade 3 children in five diverse languages. Dyslexia, 14, 170-187.

Smythe, I., \& Everatt, J., Gyarmathy, E., Ho, C., \& Groeger, J. (2003). Short-term memory and literacy: A cross-language comparison. Educational and Child Psychology, 20, 37-50.

Snow, C. (2006). Cross-cutting themes and future research directions. In D. August \& T. Shanahan (Eds.), Developing reading and writing in second-Language Learners: Lessons from the report of the National Literacy Panel on language-minority children and youth (pp. 275-300). New York: Routledge, Taylor \& Francis.

Snowling, M. (2000). Dyslexia. Blackwell: Oxford.

Snowling, M., Bishop, D., \& Stothard, S. (2000). Is preschool language impairment as risk factor for dyslexia in adolescence? Journal of Child Psychology and Psychiatry, 41, 587-600.

Solari, E. \& Gerber, M. (2008). Early comprehension instruction for Spanish-speaking English language learners: teaching text-level reading skills while maintaining effects on word level skills. Learning Disabilities Research \& Practice, 23, 155-168. 
Stahl, S. (1999). Vocabulary development. Mahwah, NJ: Brookline Books.

Stahl, S., \& Fairbanks, M. (1986). The effects of vocabulary instruction: A model-based metaanalysis. Review of Educational Research, 56, 72-110.

Stahl, S. \& Nagy, W. (2006). Teaching word meanings. Mahwah, NJ: Lawrence Erlbaum Associates.

Stanovich, K. (1986). Matthew effects in reading: Some consequences of individual differences in the acquisition of literacy. Reading Research Quarterly, 21 (4), 360-407.

Stanovich, K. (2000). Progress in understanding reading: Scientific foundations and new frontiers. New York: Guilford Press.

Sweet, A., \& Snow, C. (2003). Rethinking reading comprehension. New York, NY: The Guilford Press.

Thorndike, R. (1973). Reading comprehension education in fifteen countries. New York, NY: Wiley.

Treiman, R., \& Cassar, M. (1996). Effects of morphology on children's spelling of final consonant clusters. Journal of Experimental Child Psychology, 63, 141-170.

Wagner, R., \& Torgesen, J. (1987). The nature of phonological processing and its causal role in the acquisition of reading skills. Psychological Bulletin, 101, 192-212.

Wagner, R. K., Torgesen, J. K., \& Rashotte, C. A. (1999). Comprehensive test of phonological processing. Austin, TX: PRO-ED.

Walley, A. (1993). The role of vocabulary in children's spoken word recognition and segmentation ability. Developmental Review, 13, 286-350.

Wilson, V., \& Rupley, W. (1997). A structural equation model for reading comprehension based on background, phonemic, and strategy knowledge. Scientific Studies of Reading, 1, 4563.

Wolf, M. (2007). Proust and the Squid: The Story and Science of the Reading Brain. 
New York: HarperCollins Publishers.

Wolf, M., \& Bowers, P. (1999). The double-deficit hypothesis for the developmental dyslexias. Journal of Educational psychology, 91 (3), 415-438.

Wolf, M., \& Vellutino, F. (1993). A psycholinguistic account of the reading process. In J. BerkoGleason and N. Bernstein Ratner (Eds.), Psycholinguistics (pp. 352-391). Boston, MA: Allyn and Bacon.

Ziegler, J., \& Goswami, U. (2005). Reading acquisition, developmental dyslexia, and skilled reading across languages: A psycholinguistic grain size theory. Psychological Bulletin, 131(1), 3-29. 


\section{CHAPTER 2}

\section{A STUDY OF THE RELATIONSHIP BETWEEN ORAL LANGUAGE AND READING DEVELOPMENT IN BILINGUAL ENGLISH AND ARABIC CHILDREN}

Reading development is a language-based process (Catts \& Kamhi, 1999; Nation \& Snowling, 2004) that begins at birth and continues through the lifespan (Alexander, 2005/2006; Wolf, 2007). Central to this definition is the idea that the language (s) in which children learn to read determines the different patterns of strengths and weaknesses children bring to the learning task. Perfetti (2003) illustrates this same notion through the language constraint on reading. Accordingly, the connection that readers make between a graphic form and meaning is mediated through language. Therefore, the idea that learning to read is predicated on a foundation of oral language means that both the speech that children hear, and the language they use to construct meaning from their everyday experiences are implicated in reading development. As such, children learn to map graphemes to phonemes (speech) as well as graphemes to meaning (language). This holds true for learning to read across world languages studied to date including alphabetic languages such as English and Arabic, as well as logographic languages (traditionally perceived as pictographic) such as Chinese and Japanese (Perfetti \& Dunlap, 2008).

However, in spite of the importance of both speech and language in reading, the overwhelming majority of the research evidence stresses the fundamental role speech skills (phonology) play in reading development (Adams, 1990; Brady \& Shankweiler, 1991; Goswami \& Bryant, 1990; Liberman, 1973; Wagner \& Torgesen, 1987) with comparatively little attention paid to other language components. Such evidence comes 
from cross-linguistic research indicating that phonology is paramount to reading development across languages that differ in their orthographic transparency (see Ziegler \& Goswami, 2005 for a review).

The importance of phonology notwithstanding, research indicates that the evidence that links phonology to reading is not sufficient to explain the development of reading comprehension (Cain \& Oakhill, 2007). Phonology must be understood through its connection to other language components such as semantics (meaning) in monolingual (Catts \& Hogan, 2003) and bilingual children (Hammer, Miccio, \& Lawrence, 2004). Thus, the hypothesis that there is more to reading than a single language component bolsters the claim that reading development depends on the orchestration of multiple components of oral language (Nation \& Snowling, 2004). The current study supports this claim by challenging the notion that phonology, compared to other components of language, plays a superior role in the process of learning to read in English and Arabic. This study examined the relationship between oral language and reading in young children. Specifically, it sought to determine the language predictors of reading outcomes in young bilingual children who learn English and Arabic as their first and second language, respectively.

\section{Theoretical Framework}

The current study is cast in an interactive model of reading — an extended version of the Triangle Model of reading (Bishop \& Snowling, 2004) that relies on the role experience plays as a mechanism for reading and language development. This model is also supported by the developmental-interactionist framework (Diamond, 2007), which 
considers that various components of language play an important role in shaping reading developmental outcomes.

The next section provides background for the study. This consists of a brief overview that includes (a) the points of convergence between oral language and written language, and (b) similarities and differences between Arabic and English in phonology, morphology, vocabulary, cross-linguistic transfer, and reading fluency.

\section{Where Oral Language and Written Language Converge}

The ultimate goal of reading is the comprehension of text. Learning to read requires understanding how written language encodes oral language. According to Perfetti (2003), the close relationship between oral language and reading is attributable to the Universal Language Principle, which posits that the written form of any language must map onto its oral form. Further, Perfetti argues, what is being mapped is not only characters and graphemes to phonemes; rather what is being mapped is meaning, and this mapping holds irrespective of the language in which reading occurs (Perfetti \& Dunlap, 2008).

World languages present young readers with two main problems as they engage in mapping written language onto oral language. This consists of a phonological problem, which requires the mapping of graphemes onto phonemes; as well as a semantic or meaning problem, which entails the mapping of graphemes onto units of meaning like morphemes (smallest units of meaning) and the linguistic-conceptual objects (words and concepts) (Perfetti \& Zhang, 1995). Therefore, both phonology and semantics are implicated in reading development. What is unknown is how phonology and semantics 
interact with other components of language (e.g., morphology, syntax, pragmatics) and the extent to which they develop in a sequential manner (Pinker \& Prince, 1988) or a simultaneous manner (Perfetti, 2003; Seidenberg \& McClelland, 1989).

Consistent with the extended Triangle Model (Bishop \& Snowling, 2004), this study subscribes to the idea that learning to read consists of simultaneous parallel mapping of phonology and semantics in the service of comprehension. This mapping recruits children's knowledge of phonology and morphology at the word level and their knowledge of other language components and social-cultural conventions (Perfetti \& Dunlap, 2008) at the sentence and text levels.

One important factor that affects children's ability to map written language onto oral language is the transparency of language. Transparency refers to the extent to which the orthography of a writing system maps onto its phonology (e.g., grapheme-to-phoneme correspondence). Transparency plays an important role in reading development in monolingual and bilingual children across languages (Koda \& Zehler, 2008; Zielger \& Goswami, 2005), and can differ across, as well as within, world languages (Share, 2008). Generally, world languages either are considered transparent or non-transparent. In transparent languages like German, this grapheme-to-phoneme correspondence is straightforward as evidenced in the early mastery of phonological processing skills during the early years of reading development (Wimmer \& Goswami, 1994). By contrast, in non-transparent languages such as English, grapheme-to-phoneme correspondence is one-to-many and the mastery of phonological processing skills does not occur until later 
in the early school years, which could interfere with the development of reading (Ziegler \& Goswami, 2005).

An exception is seen in the Semitic language of Arabic, defined as transparent or non-transparent depending on whether vowelized (with diacritic markers) or unvowelized (without diacritical markers) Arabic is used. Moreover, because of its diglossic nature, Arabic is highly shaped by the linguistic distance between the spoken vernacular Arabic (SVA) and Modern Standard Arabic (MSA). This linguistic distance affects all components of language, including phonology, morphology, and semantics and as a consequence, interferes with the reading process (Saiegh-Haddad, 2003).

The research base on Arabic reading development is limited, making unclear the mechanisms of the relationship between oral language and reading. Further, the notion of linguistic distance becomes more influential in the case of bilingual English-Arabic children - the population in this study. These bilingual children are exposed to at least two variants of Arabic, MSA and SVA, in addition to English. Moreover, English and Arabic differ in their transparency: English is phonologically opaque (one-to-many correspondence between graphemes and phonemes; e.g., mint and pint); and Arabic is phonologically transparent (in vowelized Arabic, a one-to-one correspondence exists between graphemes and phonemes, whereby each diacritic marker denotes a single speech sound; e.g., kataba). Within MSA, children are exposed to vowelized and unvowelized words and texts. As this population learns how to read, bilingual children must map different written forms (vowelized Arabic; unvowelized Arabic; and English) onto different forms of oral language (SVA, used in everyday conversation; MSA, used 
during formal instruction in school; and spoken English, used in all oral language contexts). Taken together, these factors render learning to read in two languages when one is Arabic, a complex process.

\section{Similarities and Differences in Reading in Arabic versus English}

Understanding cross-linguistic linkages between English and Arabic requires the examination of similarities and differences between these two languages. The first step in learning to read in Arabic and English consists of learning grapheme-to-phoneme correspondences and manipulating the sounds of the language, which develop in a similar fashion in the two languages, that is via direct experience with the oral language (AbuRabia 1997). This is especially true for most beginning readers of Arabic, as children often learn to read vowelized words and text that rely on diacritical markers to denote short vowels.

Learning to read in Arabic is different from learning to read in English, however. This is due mainly to children's late formal and systematic exposure to written Arabic or MSA compared to the early print exposure as typically found in children who come from European-American middle class families. Because MSA is taught to children in schools, children first exposed to Arabic may encounter difficulties in learning to read due to their lack of familiarity with the written form of the language and to the pronounced differences between SVA and MSA, which render learning MSA similar to learning a second language (Ayari, 1996). Further, Arabic and English differ with respect to language components (of relevance to this study phonology, morphology, and vocabulary), cross-linguistic transfer, and reading fluency. These are presented next. 


\section{Phonology}

Phonology, the study of the sound system of a language, differs in Arabic and English. Adding to the challenge for children learning to speak Arabic are the phonological differences affecting three consonants in MSA that are absent in SVA.

These are the Voiceless / $\Theta /$ as in thalj (ice), voiced /th/ as in thubaba (fly) and emphatic voiced /th/ as in Tha:bit (officer). Such differences between the spoken and written forms of Arabic do not exist in English.

In addition to sound differences, Arabic and English differ with respect to transparency. Arabic is considered phonologically transparent when children read fully vowelized texts; in this regard, Arabic differs from opaque English, because English lacks a one-to-one grapheme-to-phoneme correspondence. Also Arabic is considered opaque when children read unvowelized texts without vowel diacritics. To read vowelized texts in Arabic, children resort to bottom-up processes using decoding abilities, just as in English. To read unvowelized texts, however, children use top-down processes, relying on their knowledge of the context, morphological knowledge, and syntactic knowledge to compensate for the lack of vowels (Abu-Rabia, 2001).

Further differences between English and Arabic lie in the strategies children utilize in various word reading tasks. In Arabic, children use different strategies as they read both vowelized and unvowelized texts, often relying on contextual cues in texts or sentences to achieve word recognition (Abu-Rabia, 2001). By contrast, word recognition in English is achieved through context-free orthographic and spelling representations independent from grapheme-to-phoneme correspondence (Stanovich, 2000). 
Overall, a consensus among Arabic scholars exists that children rely on phonological processing skills (phonological awareness, phonological memory, and naming speed) when learning to read Arabic (Abu-Rabia, 1997; 2001; Abu-Rabia \& Taha, 2004; Elbeheri \& Everatt, 2007). Research evidence suggests that phonological processing, including phonological awareness, phonological memory, and naming speed, are the manifestations of comparable underlying cognitive processes in the two languages (L1 and L2) of bilingual children (Elbeheri \& Everatt, 2007) and must be assessed in either language (L1 or L2).

Morphology

Differences between English and Arabic are evident in other components of language such as morphology. Morphemes are the smallest units of meaning in a language and morphological awareness refers to the ability to reflect on and manipulate morphemes (Carlisle, 2000). English and Arabic differ in their use of morphological processes. English has a transparent morphology, i.e., the sound and meaning of a complex word is easily inferred from its internal morphological structure (Elbro \& Arnbak, 1996). English, a concatenative language, has a linear morphological structure. Therefore, children who learn English, generate new words from free stems using linear morphological processes, such as prefixes and suffixes, often retaining the structure of the stem and sparing the continuous representation of the root.

Unlike English, Arabic is a non-concatenative language with an opaque morphology. Word derivation is linear and non-linear and word formation involves the simultaneous affixation of a consonantal root that carries the meaning of the word, and a 
pattern that consists of vowel template (Abu-Rabia, 1997). The root and pattern are bound morphemes that cannot stand on their own as independent words; for example the consonantal root $K T B$, which conveys the concept "to write," is combined with the vocalic pattern template $a a$ to make the word kataba. The affixation of the root into fixed slots in word patterns results in a discontinuous representation of the root.

The role of morphology in reading has been central across languages such as English (Carlisle, 2000; Mahoney, Singson, \& Mann, 2000) and Arabic (Abu-Rabia, Share, \& Mansour, 2003; Abu-Rabia \& Taha, 2004; Saiegh-Haddad \& Geva, 2008). Morphological awareness continues to develop throughout the elementary school years (Ku \& Anderson, 2003) and has been found to contribute independently to reading above and beyond phonological awareness in English and Hebrew (Fowler \& Liberman, 1995). Further, morphological awareness is correlated with language and reading measures such as word reading (Deacon \& Kirby, 2004), pseudoword reading (Nagy, Berninger, \& Abbott, 2006), reading morphologically complex words (Saiegh-Haddad \& Geva, 2008), vocabulary (Ku \& Anderson, 2003), and reading comprehension (Deacon \& Kirby, 2004).

In terms of assessment, morphological awareness is assessed at two different levels. At the implicit level, children must recognize that word pairs are morphological related (Duncan, Casalis, \& Cole, 2009). At the explicit level, children must generate a response through morphological decomposition tasks (Carlisle \& Stone, 2005). Implicit awareness of linguistic forms developmentally precedes explicit awareness of those forms (Gombert, 1992). Thus, it is recommended that implicit awareness be assessed 
prior to assessing explicit awareness in bilingual children (Ku \& Anderson, 2003) especially with children who are at risk for oral language deficits, like the bilingual English-Arabic children in the current study.

Given the importance of morphological awareness in reading, its assessment should provide an understanding of reading development in bilingual children $(\mathrm{Ku} \&$ Anderson, 2003), especially in those who evidence reduced vocabulary. Bilingual children often resort to morphological abilities to bootstrap their language skills as they search for word meanings (Droop \& Verhooven, 2003). Results of studies with bilingual children show that recognizing morphological units in L1 can facilitate vocabulary learning in L1 and L2 (Ku \& Anderson, 2003). Likewise, in alphabetic languages, studies of L1 derivational morphology in English indicate that knowledge of morphological relations among words results in vocabulary expansion in L1 and L2 due to reliance on morphological processes (Ku \& Anderson, 2003).

\section{Vocabulary}

As demonstrated with morphology, vocabulary plays a paramount role in reading. This role is substantiated in the research on word reading accuracy and word recognition (Stahl, 1999; Stanovich, 2000; Cunningham \& Stanovich, 1991; Perfetti, 1985). A sizable body of work points to vocabulary as one major determinant of reading comprehension (Hammer, Miccio, \& Lawrence, 2004; Nagy, Herman, \& Anderson, 1985; Roth, Speece, \& Cooper, 2002; Thorndike, 1973; Torgesen, Wagner, Rashotte, Burgess, \& Hecht, 1997). Evidence suggests that a distinctive characteristic of second language learning is a reduced vocabulary (Droop \& Verhooven, 2003) with a general consensus that bilingual 
children tend to have reduced vocabulary in their first and second language (Hammer et al., 2004). In fact, researchers recommend that bilingual children should have their vocabulary tested in their first and second languages to gain a more complete assessment of their vocabulary (Hammer et al., 2004).

Cross-linguistic Transfer

When examining the relationship between language and reading across languages, one important factor to consider is cross-linguistic transfer. This refers to the extent to which skills from the first language (L1) transfer to the second language (L2). Research indicates that the degree to which transfer occurs between linguistic components, such as phonology, morphology, and semantics, depends on the languages under consideration. For example, phonological processing skills transfer from one alphabetic language to another (Durgunoglu, 2002; Durgunoglu, Nagy, \& Hansen-Bhatt, 1993). This transfer is also reported from non-alphabetic languages such as Chinese to alphabetic languages such as English (Perfetti, 2003) and from English to Arabic (Saiegh-Haddad \& Geva, 2008).

However, little evidence exists to support transfer of morphological skills from English to Arabic, especially when considering the different morphological processes used in these two languages (English and Arabic; McCarthy, 1985). The little available evidence points to a lack of transfer of morphological skills from Arabic to English (Saiegh-Haddad \& Geva, 2008).

In terms of vocabulary, research studies demonstrate lack of transfer of vocabulary words from L1 to L2 (Hammer et al., 2004). Therefore, assessing vocabulary 
abilities in both L1 and L2 is needed to capture children's vocabulary abilities in the two languages. In the case of diglossic Arabic, transfer of vocabulary skills has not been tested empirically. However, indirect evidence points to limited transfer of vocabulary abilities from SVA to MSA due to the linguistic distance phenomenon that pervades in Arabic (Saiegh-Haddad, 2003; 2004; 2007).

\section{Reading Fluency}

In addition to the identified contributions of various components of language to word reading and reading comprehension, research evidence indicates that reading fluency is implicated in learning to read across languages (Breznitz, 2001). Reading fluency involves the integration of information from phonological, morphological, semantic, and orthographic processes (Wolf \& Katzir-Cohen, 2001) and encompasses rate, accuracy and comprehension (Wolf \& Bowers, 1999).

One way to assess reading fluency at the word level is to ask children to read words accurately and quickly. Saiegh-Haddad and Geva (2008) assessed reading fluency by asking children to read morphologically complex words accurately and quickly; their goal was to examine the contribution of phonological and morphological processes (predictors) to reading single words. They found that morphological awareness predicted complex word reading fluency in Arabic and English. However, it was unclear whether vowelized or unvowelized words were used, for research has established that children tend to rely on different strategies as they read vowelized versus unvowelized words in Arabic. Therefore, reading fluency could differ substantially depending on the target words being used (i.e., vowelized words versus unvowelized words). 


\section{Measuring the Relationship between Language and Reading}

As the foregoing section indicates, several factors must be examined to get a comprehensive view of the relationship between language and reading in English-Arabic bilingual children. Equally important is what measures are used to assess word reading and reading comprehension, and another essential aspect to consider when examining oral language components and reading outcomes is oral language proficiency. Bilingual children vary in their second language oral proficiency and this variation is attributable to instructional factors, age of exposure to second language (e.g., Arabic), and individual differences in rate of learning first and second language.

Furthermore, research indicates that assessment measures differ in the degree to which they focus on certain skills (e.g., word reading and decoding versus oral language proficiency) and their relation to outcome measures such as reading comprehension. For example, Cutting and Scarborough (2006) compared three measures frequently used to assess reading comprehension in the US. These are the comprehension subtest of the Gates-MacGinitie Reading Test-Revised (G-M; MacGinitie, MacGinitie, Maria, \& Dryer, 2000), the Wechsler Individual Achievement Test (WIAT; Wechsler, 1992), and the Gray Oral Reading Test-Third Edition (GORT 3; Wiederholt \& Bryant, 1992). The researchers found that word reading/decoding and oral language proficiency contributed differentially to different measures. Specifically, word reading and decoding skills accounted for $11.9 \%$ of the variance in the WIAT scores as compared to $7.5 \%$ and $6.1 \%$ in the GORT-3 and G-M scores, respectively. Conversely, oral language proficiency accounted for $15 \%$ of the variance in the G-M scores as compared to only $9 \%$ in the 
GORT-3 scores and 9\% in the WIAT scores. Because bilingual English-Arabic children in the current study represented a wide distribution in second language oral proficiency, the Gates-MacGinitie was a more desirable measure for the assessment of vocabulary and reading comprehension abilities in Arabic.

\section{The Present Study}

The connections between oral language components, namely phonology, morphology, and vocabulary, and reading outcomes at the word and text levels, are well established. However, how the language components interact and the role each component plays in the reading process in English and Arabic remains largely underinvestigated. An exception was Saiegh-Haddad and Geva's study (2008) which investigated the relationship between morphological awareness, phonological awareness, and reading in 43 bilingual English-Arabic children in Canada in third through sixth grades. Saiegh-Haddad and Geva found that phonological skills, but not morphological skills, predicted word reading across English and Arabic and that morphological awareness within both languages predicted complex word reading fluency. Their study was important because it shed light on the cross-linguistic relationship between phonological and morphological skills to reading in Arabic. However, other language components, such as semantics (vocabulary) were not assessed in either Arabic or English. Furthermore, they assessed word reading accuracy and complex word reading fluency but not reading comprehension. Although they assessed phonological awareness, Saiegh-Haddad and Geva did not consider other related sub-skills such as phonological memory and naming speed in their examination of phonological processing skills. 
The current study examined the link between oral language and reading in bilingual English-Arabic children in the US. It sought answers to six research questions:

(1) Is there a relationship between children's phonological awareness in English and Arabic? (2) Is there a relationship between children's morphological awareness in English and Arabic? (3) Does the contribution of children's phonological skills versus their morphological skills vary as a function of the reading task in English and Arabic? (4) Does morphological awareness in one language predict word reading in the other language above and beyond cross-language phonological processing and vocabulary and within language morphological awareness? (5) Does morphological awareness predict reading comprehension above and beyond phonological processing and vocabulary within English and Arabic languages? (6) Does the relationship between vocabulary and reading comprehension hold across high and low vocabulary groups after controlling for chronological age?

\section{Method}

\section{Study Context}

This study was conducted in the spring of 2010 over a period of four weeks at the end of the school year. The site of the study was a school located in a suburb of a major city in the Southeastern portion of the US. It is a charter school that adopts an expeditionary learning model with a focus on hands-on activities and projects as a means for learning. It attracts teachers and parents interested in diversity in home language, ethnicity, and culture. 
One unique aspect of this school is its emphasis on teaching Arabic as a second language in the primary and elementary grades. In fact, it is the only public charter school in the state and one of a few schools in the nation to teach Arabic daily in the primary grades. In terms of instructional method, the school's Arabic department consists of four Arabic teachers who focus daily on oral language use, though writing and spelling are sometimes used. Teachers also introduce spelling and reading simple paragraphs or stories using pictorial stimuli to aid children's comprehension of text. Limited emphasis is placed on reading and writing, especially with emergent readers or those who are considered beginners in the Arabic language.

As indicated by school demographic data, the school serves children from various socioeconomic and educational backgrounds; the majority of parents have at least a college degree. Furthermore, not all parents are speakers or users of Arabic. Many parents are native speakers of English, Urdu, Turkish, Tamil, or French. See Table 1 for demographic characteristics of the children and parents in the study.

\section{Participants}

The participants were 83 bilingual English-Arabic children in third, fourth, and fifth grades (35 males and 48 females). Participants were children (a) who had attended the school for at least three consecutive years, (b) who had received formal Arabic 
Table 1

Demographic Characteristics of the Children in the Study

\begin{tabular}{cc}
\hline Variable & M (SD) or Frequency (Percentage) \\
\hline Grade & \\
3 & $33(39.8 \%)$ \\
4 & $28(33.7 \%)$ \\
5 & $22(26.5 \%)$ \\
Age in years & $9.84(.91)$ \\
Gender & \\
Female & $48(57.8 \%)$ \\
Male & $35(42.2 \%)$ \\
Ethnicity & \\
Asian & $29(34.9 \%)$ \\
Black & $14(16.9 \%)$ \\
Hispanic & $1(1.2 \%)$ \\
Mixed & $9(10.8 \%)$ \\
White & $30(36.1 \%)$ \\
\hline
\end{tabular}

Note. Total children $(n=83)$.

instruction for 40 minutes per day, four days per week, (c) whose parents signed a consent form to participate in the study; and (d) who signed their own assent to participate. Excluded from the study were children identified (a) with known developmental disorders or learning disabilities, (b) as at risk for learning disabilities, and 
(c) as English language learners as indicated by school demographic data. All children whose parents consented to participate also gave their assent and were included in the study. A total of eleven children who met inclusionary criteria did not participate in the study: Three children whose parents returned the signed consent forms and declined to participate; and eight children whose parents did not return the signed consent forms.

\section{Data Collection}

Students were tested in the school over a period of four weeks in the spring of 2010. Assessment tasks were administered in both English and Arabic and consisted of individual and group assessments. The researcher trained the examiners (two university researchers and two graduate students) to administer the English tests. In addition, the researcher completed a self-training in the Arabic measures. Each child was assessed on two different days within the same week. English tasks were administered on the first day by the two university researchers and two graduate research assistants. Arabic tasks were administered on the second day by the researcher. The order of the tasks within the same language was counterbalanced to maximize random distribution of measurement error and to ensure that the order of administration of the measures did not influence student performance in either language. Student verbal responses were audio recorded to ensure the accuracy of manual scoring.

Administration of the individual assessments took place in a quiet room inside the school and near the classrooms. Children were given breaks during the testing session as needed. The group assessment took place in the children's classrooms. Children were tested in small groups, with each group consisting of 10 to 20 children. Assent was 
obtained from each child prior to the administration of each assessment. Only children who gave their assent participated in the individual and group assessments.

To examine the relationship between oral language and reading seven domains were assessed in both English and Arabic: (1) phonological processing (all three aspects of phonological processing were administered in English; only phonological awareness aspect was administered in Arabic); (2) morphological awareness; (3) word reading; (4) pseudoword reading; (5) complex word reading fluency; (6) vocabulary; and (7) reading comprehension.

\section{Measures}

\section{English Measures}

Six measures were used. For five of the six measures, subtests were administered individually to each child. For the first two measures (phonological processing and morphological awareness), the examiner orally presented the stimuli to the child and the child provided oral responses. For the other three measures (word reading, pseudoword reading, and derived word reading fluency), the examiner provided the child with a list of words or pseudowords and the child read them aloud. Total administration time for the five English individual measures was approximately 40 minutes. A brief description of each measure follows.

English phonological processing. The Comprehensive Test of Phonological Processing (CTOPP; Wagner, Torgesen, \& Rashotte, 1999; Blending, Elision, phonological memory, and naming speed subtests). The CTOPP is a published, normreferenced test. The norming sample consisted of 1,656 individuals in 30 states whose 
characteristics paralleled those reported by the Census Bureau (1997) in terms of gender, race, geographic region, rural and urban residence, family income, ethnicity, parent education, and disability (Wagner, Torgesen, \& Rashotte, 1999). Internal reliability estimates of composite scores exceed .83 . Test-retest reliability estimates gathered over a 1-year period ranged from .70 to .97 for individual subtests and from .78 to .95 for composite scores.

The Blending subtest required the child to blend individual phonemes to make syllables or words. The examiner presented orally each set of individual phonemes and asked the child to produce a whole word by combining the speech sounds (e.g., /c/, /a/, $/ n /, / d /, / y /$ are combined to produce the word $c a n d y)$. This subtest consists of six practice items and 20 test items that progress in length and phonological complexity. A score of 0 was given for incorrect or partially correct responses and a 1 for correct responses.

The Elision subtest assessed the child's ability to repeat verbally presented words back to the examiner. The child was required to repeat a target word (s) while omitting a specified phonological unit such as a speech sound or a syllable (e.g., say the word toothbrush without saying/tooth/ or say the word cup without saying $/ k /$ ). This subtest consists of six practice items and 20 test items. Raw scores were computed based on correct responses on each task. A score of 0 was given for incorrect or partially correct responses and a 1 for correct responses.

The Phonological Memory subtest was administered using two tasks: forwarddigit span and nonword repetition. In the forward-digit span, a series of numbers is presented in a specified forward order via an audiorecording, progressing gradually in 
length. The child was asked to repeat the series of digits as presented (e.g., say 836 ). In the nonword repetition, a list of nonwords was presented via an audiorecording. The child was asked to repeat the list of nonwords as presented (e.g., say nigong). Raw scores were computed based on correct responses on each task. A score of 0 was given for incorrect or partially correct responses and a 1 for correct responses.

The Naming Speed subtest is a timed task. It consists of Rapid Color Naming and Rapid Object Naming subtests. The Rapid Color Naming subtest required the child to rapidly name a series of different colored blocks presented in rows on two pages (e.g., blue red green black brown yellow red black blue). Two forms were used: Form A and Form B. Each form consists of four rows, each of which depicts a sequence of nine colored blocks. The Rapid Object Naming subtest required the child to rapidly name a series of objects presented in rows on two pages. Two forms were used: Form A and Form B. Each form consists of four rows, each of which depicts a sequence of nine objects. A raw score was computed based on the time it took the child to name a page of colors or objects. Administration of the Phonological Memory and the Naming Speed subtests took approximately 15 minutes.

English Morphological Awareness. This test consists of a list of 20 highfrequency word pairs used in Duncan et al. (2009) and adapted from Mahoney et al. (2000). This experimental measure assesses the child's implicit ability to determine if word pairs are morphologically related. In each word pair, the child was given the following directions: "In this game, I'm going to give you two words that are a little bit like each other. You have to tell me each time whether the words I say are from the same 
family or not. Let's practice: kind and kindness, are they from the same family? Teach and teacher?" (Duncan et al., 2009, p. 413). The examiner provided the child with corrective feedback for the three practice items. Three additional trials were provided to children who experienced difficulty understanding the task. A score of 0 was given for incorrect or partially correct responses and a 1 for correct responses. Raw score was calculated based on the correct number of morphologically related pairs identified. Administration time was approximately 5 minutes. A copy of this subtest is found in Appendix A.

The Wide Range Achievement Test-Revised (WRAT-R; Wilkinson \& Robertson, 1984; Word Reading Subtest). This test is a published, norm-referenced test. The norming sample consists of 5,600 subjects between ages 5 and 74 years. No alpha coefficients or split-half reliability is reported. Test-retest reliability coefficients range from .79 to .97 . This subtest assessed word decoding ability through word recognition. The examiner presented the child with a list of 42 isolated words (e.g., how, animal, even, spell) that progressed gradually in phonological complexity in terms of syllabic structure and length. The child received a 0 for partially correct or incorrect items, and a 1 for correct items. Raw score was calculated based on the total number of words correctly read. This subtest took approximately10 minutes to administer.

The Woodcock Reading Mastery Test-Revised/Norming Update. (Woodcock, 1987/1998; Word Attack subtest). This subtest is part of a published, norm-referenced assessment test. The norming sample consists of 3,700 participants ranging in age from 5 to 75 years. Split-half reliability Test median is .91, and clusters median is .95 . The Word 
Attack subtest assesses children's ability to read pseudowords using decoding and structural analysis skills. The examiner presented the child with a list of 45 isolated pseudowords (e.g., weaf, depine) that progressed in length and complexity of syllabic structure. The child was required to read all pseudowords. The child received a 0 for partially correct or incorrect items, and a 1 for correct items. Raw score was calculated based on the total correct words read. This subtest took approximately 10 minutes to administer.

English Complex Word Reading Fluency. This measure is adapted from SaieghHaddad and Geva (2008). It assessed the child's rate and accuracy of reading morphologically related words. The examiner asked the child to read a list of 20 highfrequency morphologically related or unrelated words accurately and rapidly. Stimuli for this measure consisted of the word pairs in the English morphological relatedness measure used in Duncan et al (2009), which is described in the preceding section. Accuracy scores were computed by summing the total number of correctly read words. Fluency scores were computed by measuring the time it took the child to read the word pairs from the list. Total score on this measure was obtained by computing the total number of correctly read words per minute. This measure took approximately 5 minutes to administer. A copy of this subtest is found in Appendix B.

The remaining English measure is the Iowa Tests of Basic Skills (ITBS), a norm referenced achievement test. Student scores were obtained from the school's archival data. Because this study was designed to examine the relationship between language (e.g., vocabulary) and reading, only the Vocabulary and Reading Comprehension subtests 
of the ITBS were used. For the vocabulary subtest, the child was presented with a word in sentence or phrase context and was asked to select the word that means the same as the target word from an array of four choices (multiple-choice format). For the Reading Comprehension subtest, the child was asked to read passages that varied in length (four lines to a full page) and topic (e.g., social studies, fiction, biographies). The child was then asked to select the correct answer to comprehension questions from an array of four choices (multiple-choice format). At least two thirds of the passages required the child to draw inferences and generalize about what he/she had read. The ITBS was administered by the school staff in September of 2009. Scores were obtained from the school's records in May 2010.

\section{Arabic Measures}

A total of six Arabic measures that parallel the English measures were administered to ensure the children were tested in the same domains in both Arabic and English. Five of the measures were adapted from Saiegh-Haddad and Taha (2008), who have published extensively in Arabic (Abu-Rabia \& Taha, 2004; Saiegh-Haddad, 2003; 2004; 2007). These five measures were administered individually to each child. Total administration time was approximately 45 minutes. The sixth measure was administered to the children in groups. Each group administration took 50 minutes to complete.

Because of the lack of norm-referenced tests in Arabic, experimental measures were developed or adapted for this study based on published Arabic and English assessments. All Arabic measures parallel the English measures in content, administration, and response elicitation methods. Instructions for all Arabic measures 
were presented in English and then in Arabic to ensure children's understanding of the task. A brief description of these measures follows.

Arabic phonological awareness. The Blending and Elision subtests assessed phonological awareness skills. They parallel the English CTOPP test described in the English measures section. The Blending subtest assessed the child's ability to blend individual phonemes. The stimuli for the Blending subtest were adapted from a segmentation task developed by Taha and Saiegh-Haddad (2008) and consisted of two practice items and 20 target items that progressed in length and phonological complexity. The examiner presented orally each set of individual phonemes and asked the child to blend the speech sounds to make syllables or words (e.g., " $b$ ", " $a$ ", " $y$ ", " $t$ " are combined to produce the word bayt [house]). A score of 0 was given for incorrect or partially correct responses and a 1 for correct responses. Raw scores were computed based on correct responses. It took approximately five minutes to administer. The list of the two practice words and 20 target words that make up this subtest is presented in Appendix C.

The Elision subtest assessed the child's ability to repeat verbally-presented words. The stimuli for this subtest were adapted from Saiegh-Haddad and Geva (2008) and consisted of two practice items and 40 target items that progressed in phonological complexity (i.e., progressed from using larger phonological units to smaller phonological units). The examiner orally presented each target word and the child repeated the target word omitting the specified phonological unit, such as a phoneme or a syllable (e.g., say the word barmil without saying /bar/ or say the word samir without saying $/ s /$ ). This 
subtest consists of two practice items and 40 test items. A score of 0 was given for incorrect or partially correct responses and a 1 for correct responses. Raw scores were computed based on correct responses on this subtest. This subtest took approximately 10 minutes to administer. A list of the two practice items and 40 target items is presented in Appendix D.

Arabic Morphological Awareness. This measure, developed by Taha and SaieghHaddad (2008), assesses a child's implicit Morphological Awareness knowledge. Words used were phonologically transparent. They consisted of two morphemes and had four patterns: agentive (e.g., ka:teb [writer]), passive adjective (e.g., maktu:b [written]), place adverbial (e.g., maktab [office]) and reciprocal verbal (e.g., ka:taba [corresponded]) (Saiegh-Haddad \& Geva, 2008, p. 488). These words were frequent in stem and derived forms and had a word unit of 30 or below. The examiner orally presented 20 pairs of words. The child was given these instructions, "You will hear pairs of words that sound alike. Listen carefully and tell me whether the words that I say are from the same family or not." The child responded yes if the word pair was morphologically related, and no if the word pair was morphologically unrelated. Three pairs of high-frequency words, of each stem and derived form, were presented as practice items. Three additional trials were provided if the child experienced difficulty understanding the task. A score of 0 was given for incorrect or partially correct responses and a 1 for correct responses. Alpha reliability coefficient for the Arabic morphological task was .76. Raw scores were computed based on correct responses on this subtest. It took about 10 minutes to administer. A copy of this subtest is found in Appendix E. 
Arabic Word Reading. Taha and Saiegh-Haddad (2008) developed his measure. The child was asked to read aloud a list of 40 vowelized and 40 unvowelized words that progressed in length and complexity. The vowelized Arabic word list consisted of words without inflectional endings. The child read words presented in six rows on one page. For unvowelized word reading, the examiner presented the child with an unvowelized Arabic word list of 40 words without inflectional endings. The child was asked to read the words presented. A score of 0 was given for incorrect or partially correct responses and a 1 for correct responses. Raw scores were computed based on correct responses on this subtest. It took about 10 minutes to administer. A copy of the vowelized word reading subtest and a copy of the unvowelized word reading subtest are found in Appendix F.

Arabic Pseudoword Decoding. Taha and Saiegh-Haddad (2008) developed this measure. It assesses the child's ability to decode pseudowords (nonwords). Children were asked to read a list of 41 pseudowords that progressed in length and phonological complexity. Pseudowords were presented in vowelized Arabic without inflectional endings (e.g., Thamir instead of Thamiron). A score of 0 was given for incorrect or partially correct responses and a 1 for correct responses. Raw scores were computed based on correct responses on this subtest. This subtest took about 10 minutes to administer. A copy of this subtest is found in Appendix G.

Arabic Complex Word Reading Fluency. This measure was adapted from SaieghHaddad and Geva (2008). It assessed the child's rate and accuracy of reading morphologically related words. Stimuli for this measure consisted of the word pairs used in the Arabic morphological relatedness measure described in the morphological 
awareness measure section. Accuracy scores were computed by adding the number of words read correctly. Fluency scores were computed by measuring the time it took the child to read the word pairs. The final score on this measure was computed by dividing the accuracy score by the fluency score. This measure took about 5 minutes to administer. Arabic Vocabulary and Reading Comprehension. An adaptation of the GatesMacGinitie Reading Test, Fourth Edition, Level 2 (GMRT; MacGinitie, MacGinitie, Maria, \& Dryer, 2000) was used for this study. Level 2 was selected because it included pictures along with sentences and short paragraphs with the pictures guiding the child as the child read the words and text. This reliance on pictures as a source for extracting meaning parallels the instruction received at school. This feature is missing from Level 3 and Level 4 versions of the Gates-MacGinitie test. The researcher provided the children with a response form with multiple choice questions. Vocabulary was assessed using 64 vocabulary items. Each item included a pictorial stimulus with four word choices. The child was asked to circle the word that depicts the picture.

The adaptation of the Gates-MacGinitie test into Arabic proceeded as follows. First, the test items were translated from English to Arabic, and then back-translated from Arabic to English and back to Arabic to ascertain the intended meaning of each item was preserved. A panel of four native Arabic speakers, which included the researcher, performed translation of the test. All members had graduate college degrees and had received Arabic instruction through college. Panel members translated sections of the test and then shared their translations. The follow up discussion focused on the commonalities and differences in their translations. Once a translation was agreed upon 
by the panel, it was deemed adequate to include in the test. This assessment used a multiple choice format.

Reading comprehension was assessed using cloze tests. Each cloze test consisted of 28 items. For each item, one or two sentences were presented along with three picture stimuli. The child was asked to circle the picture that best represented the meaning of the sentence. A score of 0 was given for incorrect (e.g., did not mark the target word) or partially correct responses (e.g., marked two responses including the target word) and a 1 for correct responses. Raw scores were computed based on correct responses on this subtest. This test took approximately 50 minutes to administer. A copy of this test is found in Appendix $\mathrm{H}$.

\section{Data Management}

During data collection, the researcher distributed all testing and scoring materials to the examiners in the morning and picked them up at the end of the day to ensure confidentiality and appropriate storage of information. One graduate research assistant checked each student's folder to ensure all testing materials had been returned and individual subtests had been completed. At the conclusion of data collection, all data including audiotapes and testing materials were locked in a file cabinet. To ensure anonymity, after the assessments were completed, all names on the test record forms were replaced with identification numbers. To maintain confidentiality, only the research team had access to the assessment data and personal information. All data and information were kept in a locked file in the researcher's office. 


\section{Data Analysis}

Data screening was the first step in the data analysis process. Screening included using SPSS to inspect descriptive statistics for out-of-range values and for plausibility of means and standard deviations and outliers. Screening involved evaluating missing data, checking plots for nonlinearity and heteroscedasticity, identifying skewness and kurtosis, transforming variables as warranted, and evaluating variables for multicollinearity and singularity (Tabachnick \& Fidell, 2007).

Descriptive statistics were used to present demographic information, distribution (kurtosis and skewness), and dispersion (mean, standard deviation, and range, frequency, and percentage) of scores in both English language and reading measures and Arabic language and reading measures. Demographic variables included grade, age, gender, ethnicity, mother's education, partner's education, mother's home language use, or partner's home language use.

Three different types of analyses were used: partial correlation (first analysis), regression analyses, each consisting of one dependent variable (DV) and two or more independent variables (IVs) (second and third), and Analysis of Covariance (fourth), which consists of one DV, one IV, and one covariate.

The first analysis consisted of partial correlations between the Arabic and English language and reading measures, controlling for age. The Arabic measures consisted of language (morphological awareness, phonological awareness [blending and elision] and vocabulary) and reading (complex word reading fluency, vowelized word reading, unvowelized word reading, and reading comprehension). The English measures consisted 
of language (morphological awareness, phonological processing [phonological awareness, phonological memory, and rapid naming]) and reading (word reading, word attack, and complex word reading fluency).

The second analysis examined language predictors of reading using simultaneous multiple regression, as compared to a sequential multiple regression, because all components of language, including phonological, morphological, and vocabulary components are considered equally important in reading. This analysis explored the degree of relationship between the DVs (Arabic vowelized word reading, Arabic unvowelized word reading, Arabic pseudoword decoding, Arabic complex word reading fluency, English word reading, English pseudoword decoding, English complex word reading fluency, and Arabic reading comprehension) and the IVs (English phonological awareness composite, English phonological memory, English rapid naming composite, English morphological awareness, Arabic blending, Arabic Elision, and Arabic morphological awareness), the proportion of the variance in the DV predicted by the regression, and the relative importance of the various IVs to reading.

Then, a series of hierarchical linear regressions were used to examine whether morphological awareness in one language was a unique predictor of word and pseudoword decoding in the other language after controlling for cross-language phonological processing/awareness and vocabulary, and within language morphological awareness. 
A series of hierarchical linear regression analyses were also used to examine the predictive ability of morphological awareness in reading comprehension with English and Arabic, above and beyond phonological processing/awareness and vocabulary.

The final analysis examined whether the relationship between vocabulary and reading comprehension held across language groups. An analysis of covariance (ANCOVA) was conducted to examine whether the effect of the independent variable (vocabulary) on the dependent variable (reading comprehension) remained unchanged across the high vocabulary group and the low vocabulary group within the sample, while controlling for chronological age.

\section{Results}

Table 1 shows frequency of demographic variables of the children in the study followed by percentages of these variables in parentheses. One exception is age in years, for which the mean is presented in parentheses followed by standard deviation. Table 2 shows frequency of parent and partner education and parent and partner home language use variables $(n=64)$. Frequency is followed by percentage in parentheses. As this table indicates, the majority of parents and their partners were highly educated: approximately $36 \%$ of mothers and $39 \%$ of mothers' partners had graduate school education level; and $50 \%$ of mothers and approximately $38 \%$ of mothers' partners had 4 -year college education level. Results also indicate that approximately $61 \%$ of mothers and $60 \%$ of mothers'partners spoke English in the home. Comparatively, Arabic was spoken by approximately $14 \%$ of mothers and $16 \%$ of mothers' partners only. Table 3 presents means, standard deviation, and range of scores for all tasks administered in this study. As 
indicated in Table 3, children's distribution of scores on the Arabic vocabulary measure was positively skewed. Therefore, standardized scores (z-scores) were alternatively used to correct for such skewness. None of the other measures were skewed markedly. This could be related to the fact that the majority of children come from homes in which the parents spoke English or a combination of English and another language (e.g., Arabic,

Table 2

Demographic Characteristics: Parent and Partner Education and Home Language Use

\begin{tabular}{|c|c|c|c|}
\hline Variable & $\begin{array}{l}\text { Frequency } \\
\text { (Percentage) }\end{array}$ & Variable & $\begin{array}{l}\text { Frequency } \\
\text { (Percentage) }\end{array}$ \\
\hline \multicolumn{2}{|l|}{ Parent Education } & \multicolumn{2}{|l|}{ Partner Education } \\
\hline Elementary & $0(0 \%)$ & Elementary & $1(1.6 \%)$ \\
\hline $\begin{array}{l}\text { High School or } \\
\text { Equivalent }\end{array}$ & $5(7.8 \%)$ & $\begin{array}{l}\text { High School or } \\
\text { Equivalent }\end{array}$ & $7(10.9 \%)$ \\
\hline $\begin{array}{l}\text { Community } \\
\text { College }\end{array}$ & $4(6.3 \%)$ & $\begin{array}{l}\text { Community } \\
\text { College }\end{array}$ & $7(10.9 \%)$ \\
\hline 4-year College & $32(50 \%)$ & 4-year College & $24(37.5 \%)$ \\
\hline Graduate School & $23(35.9 \%)$ & Graduate School & $25(39.1 \%)$ \\
\hline \multicolumn{2}{|c|}{ Mother Home Language Use } & \multicolumn{2}{|c|}{ Partner Home Language Use } \\
\hline Arabic & $9(14.1 \%)$ & Arabic & $10(15.6 \%)$ \\
\hline English & $39(60.9 \%)$ & English & $38(59.4 \%)$ \\
\hline Other & $16(25 \%)$ & Other & $16(25 \%)$ \\
\hline
\end{tabular}

Note. Total parents $(n=64)$.

Urdu, French, Tamil). Inspection of the scores on the Arabic measures reveals comparable means and standard deviation scores on the vowelized word reading accuracy and unvowelized word reading accuracy measures. This could be attributable to the 
instructional approach used to teach reading in the school, which focused on teaching sight words in addition to decoding skills using diacritical markers.

The study addressed six research questions. Results for each research question are presented next.

Research Question 1: Is there a relationship between children's phonological awareness in English and Arabic?

The first research question investigated whether there is a relationship between children's phonological awareness in English and Arabic. Partial correlations were used to explore the relationship between language and reading measures in Arabic and English while controlling for chronological age (see Table 4). Preliminary data screening was performed to ensure no violation of the assumptions of normality, linearity, and homoscedasticity. Data screening was conducted using SPSS histograms, expected normal probability plot and detrended normal probability plot, and scatterplots. Results revealed positive partial correlations between Arabic elision and English Phonological Awareness Composite, $r=.47, p<.001$ and between Arabic blending and English Phonological Awareness Composite, $r=.43, p<.001$. Results also indicated a positive partial correlation between Arabic phonological awareness (elision and blending) and other aspects of English phonological processing. Specifically, Arabic elision was positively correlated with English phonological memory, $r=.27, p<.05$, and Arabic blending was positively correlated with English phonological memory, $r=.34, p<.01$, after controlling for chronological age. 
Research Question 2: Is there a relationship between children's morphological awareness in English and Arabic?

The second research question examined whether there is a relationship between children's morphological awareness in English and Arabic. As indicated in Table 4, partial correlations between Arabic and English morphological awareness measures, controlling for age, revealed no significant relationship, $r=-.04, p>.05$.

Research Question 3: Does the contribution of children's phonological skills versus their morphological skills vary as a function of the reading task in English and Arabic?

The third research question examined the contribution of phonological skills and morphological skills as a function of the reading task. Simultaneous multiple regression analyses were conducted. For Arabic, the dependent variables (DVs) were Arabic vowelized word reading accuracy, Arabic unvowelized word reading accuracy, Arabic pseudoword decoding, Arabic complex word reading fluency, and Arabic reading comprehension. The independent variables (IVs) were Arabic morphological awareness, Arabic phonological awareness (elision), and Arabic phonological skills (blending). For English, the DVs were English word reading, English pseudoword decoding, English complex word reading fluency, and English reading comprehension. The IVs were English phonological awareness composite and English morphological awareness. Results indicated that Arabic phonological skills—-both elision and blending — but not Arabic morphological skills, predicted Arabic word reading and Arabic pseudoword decoding; they explained $67 \%$ of the variance in Arabic vowelized word reading accuracy, $71 \%$ of the variance in Arabic unvowelized reading accuracy, and 64\% of the 
variance in Arabic pseudoword decoding. Furthermore, Arabic phonological awareness skills (elision) and Arabic morphological awareness skills predicted, and explained $67 \%$ of the variance in Arabic complex word reading fluency. Neither Arabic phonological nor Arabic morphological awareness skills contributed significantly to children's Arabic reading comprehension skills (See Table 5). Results also revealed that English phonological awareness skills predicted English word reading, English pseudoword decoding, and English complex word reading fluency. They explained $51 \%$ of the variance in English word reading, 44\% of the variance in English pseudoword decoding, and $30 \%$ of the variance in English complex word reading fluency. However, English morphological but not English phonological awareness skills predicted, and explained $42 \%$ of the variance in English reading comprehension skills (see Table 6).

Research Question 4: Does morphological awareness in one language predict word reading in the other language above and beyond cross-language phonological processing and vocabulary and within language morphological awareness?

The fourth research question assessed whether morphological awareness skills in one language were a unique predictor of word reading in the other language above and beyond cross-language phonological processing and vocabulary and within language morphological awareness. To answer this question, a series of hierarchical multiple regressions was performed. For Arabic, the DVs included Arabic vowelized word reading accuracy, Arabic unvowelized word reading accuracy, Arabic pseudoword decoding, and Arabic complex word reading fluency. In each of these equations, the IVs included chronological age, Arabic morphological awareness, Arabic vocabulary, English 
phonological awareness, English phonological memory, English rapid naming, and English morphological awareness (see Tables 7, 8, 9, and 10). For English, the DVs were English word reading, English pseudoword decoding, and English complex word reading fluency. Of note, children's standard scores on the ITBS vocabulary and reading comprehension were only available for third- and fifth-grade students, $\mathrm{N}=55$. 
Table 3

Variable Mean and Standard Deviation Scores

\begin{tabular}{|c|c|c|c|}
\hline Variable & Mean & SD & Range \\
\hline \multicolumn{4}{|l|}{ Arabic Language Measures } \\
\hline Elision & 22.63 & 6.76 & $5-37$ \\
\hline Blending & 14.17 & 3.53 & $3-20$ \\
\hline Morphological Awareness & 14.89 & 3.55 & $6-20$ \\
\hline Vocabulary & 0.00 & 1.76 & $-3.43-6.85$ \\
\hline \multicolumn{4}{|l|}{ Arabic Reading Measures } \\
\hline Vowelized Reading Accuracy & 20.15 & 11.47 & $0-38$ \\
\hline Unvowelized Reading Accuracy & 21.19 & 11.52 & $0-37$ \\
\hline Pseudoword Decoding & 20.93 & 11.41 & $0-39$ \\
\hline Complex Word Reading Fluency & 12.44 & 10.14 & $0-58.82$ \\
\hline Reading Comprehension & 10.73 & 3.16 & $3-20$ \\
\hline \multicolumn{4}{|l|}{ English Language \& Cognitive } \\
\hline \multicolumn{4}{|l|}{ Measures } \\
\hline Phonological Awareness Composite & 53.38 & 12.29 & $33-93$ \\
\hline Phonological Memory Composite & 5.88 & 1.55 & $3-10$ \\
\hline Rapid Naming Composite & 4.02 & 2.04 & $1-9$ \\
\hline Morphological Awareness & 2.48 & 1.67 & $0-5$ \\
\hline Vocabulary & 200.00 & 29.00 & $134-262$ \\
\hline \multicolumn{4}{|l|}{ English Reading Measures } \\
\hline Word Decoding (WRAT-3) & 76.76 & 13.98 & $45-111$ \\
\hline Pseudoword Decoding (WRMT-R) & 108.45 & 10.58 & $67-137$ \\
\hline Complex Word Reading Fluency & 1.58 & .51 & $0-2.86$ \\
\hline Reading Comprehension & 202.78 & 30.84 & $150-268$ \\
\hline
\end{tabular}

Note. Standardized z-scores were used to report means (Zero) and standard deviations for Arabic vocabulary. 


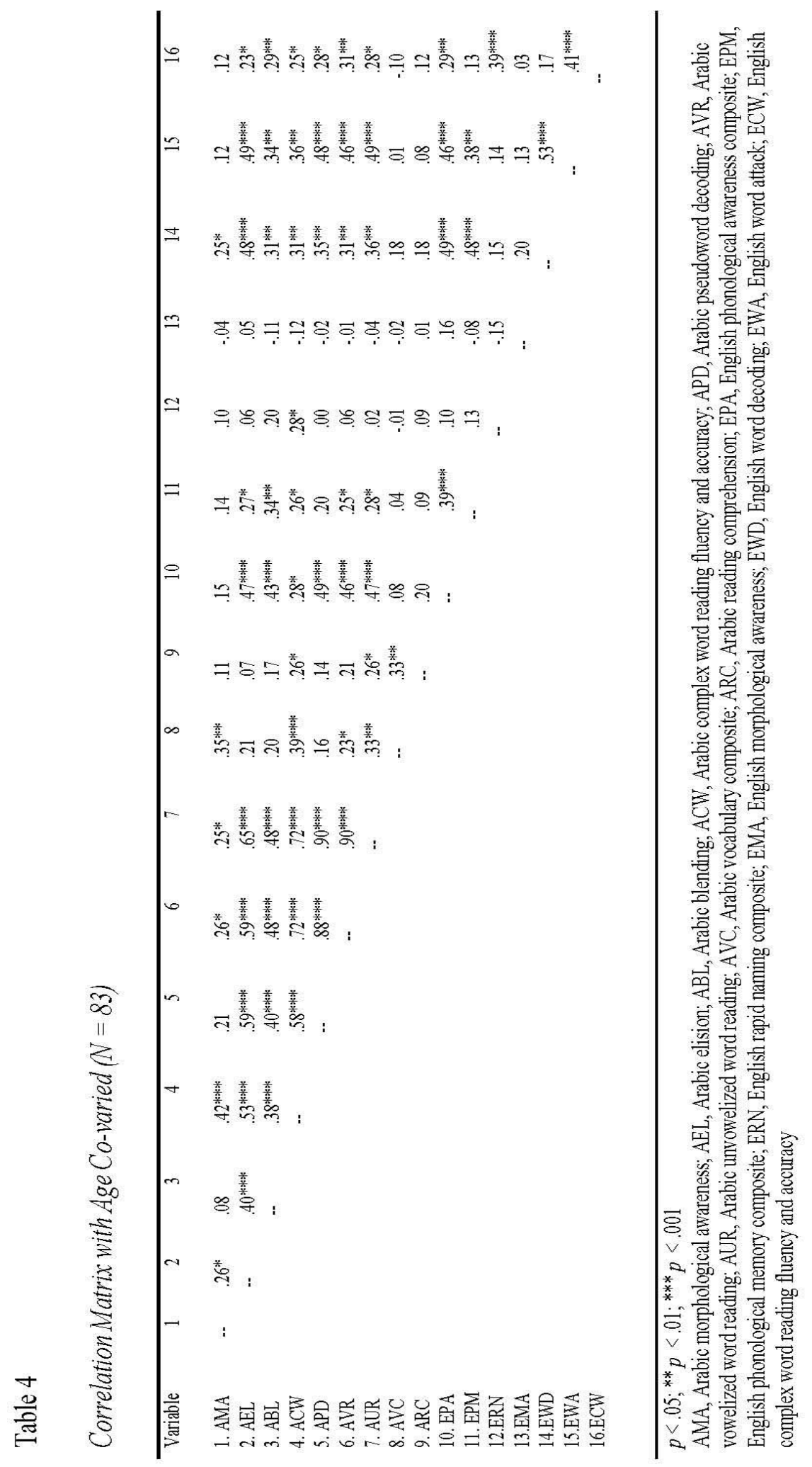




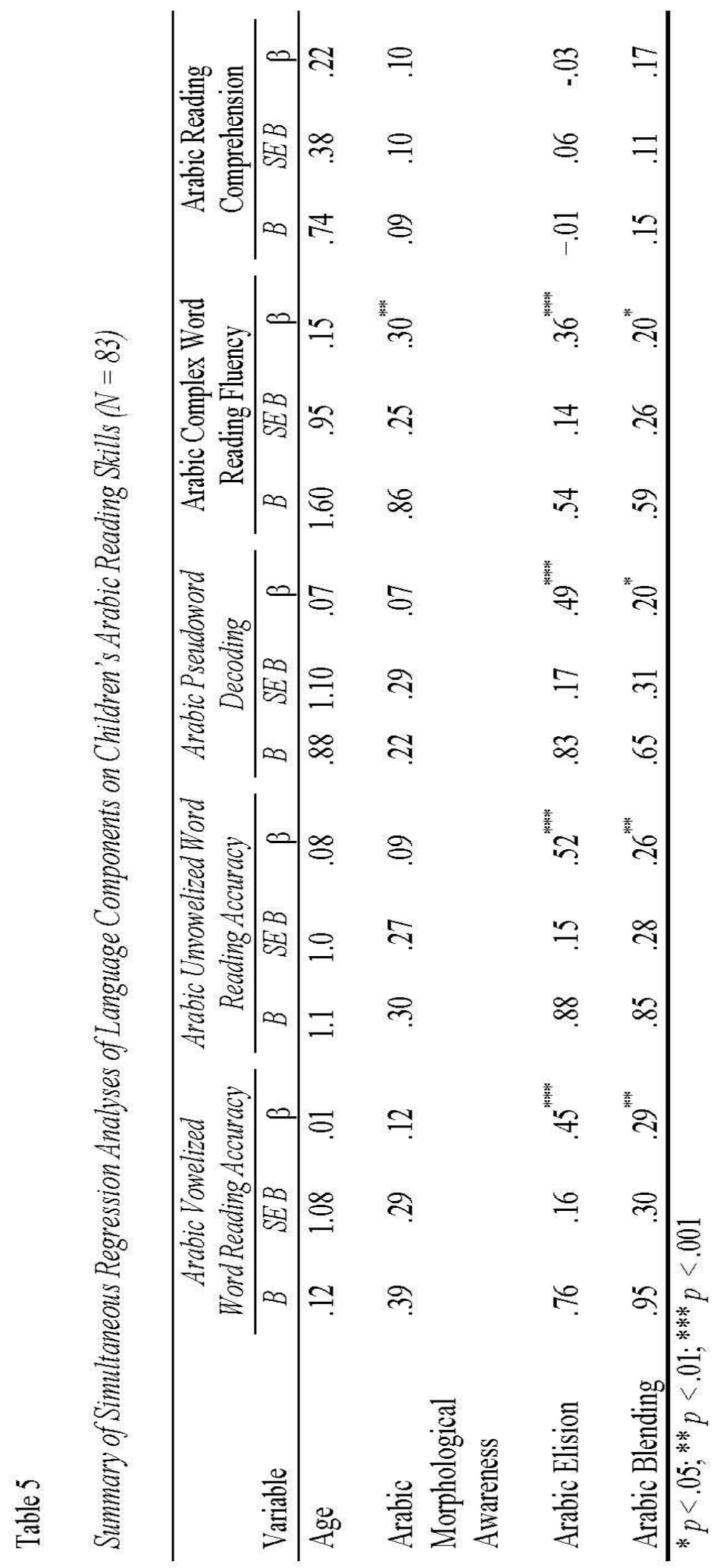




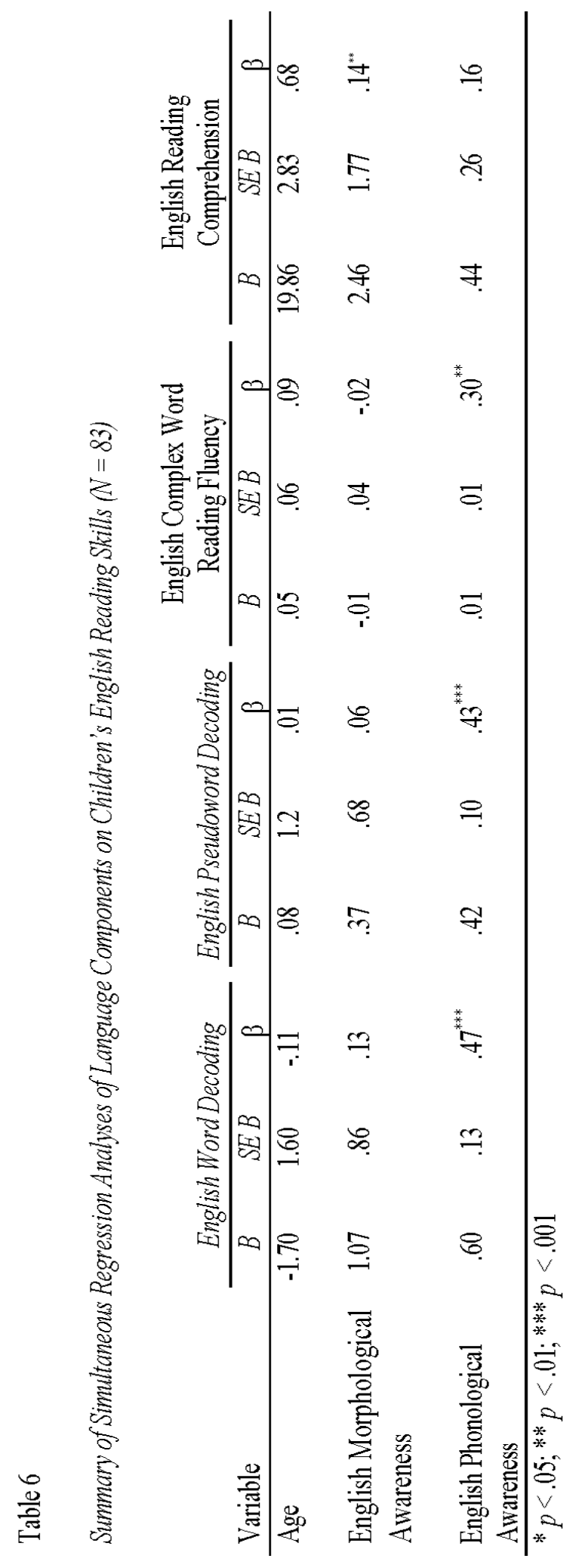




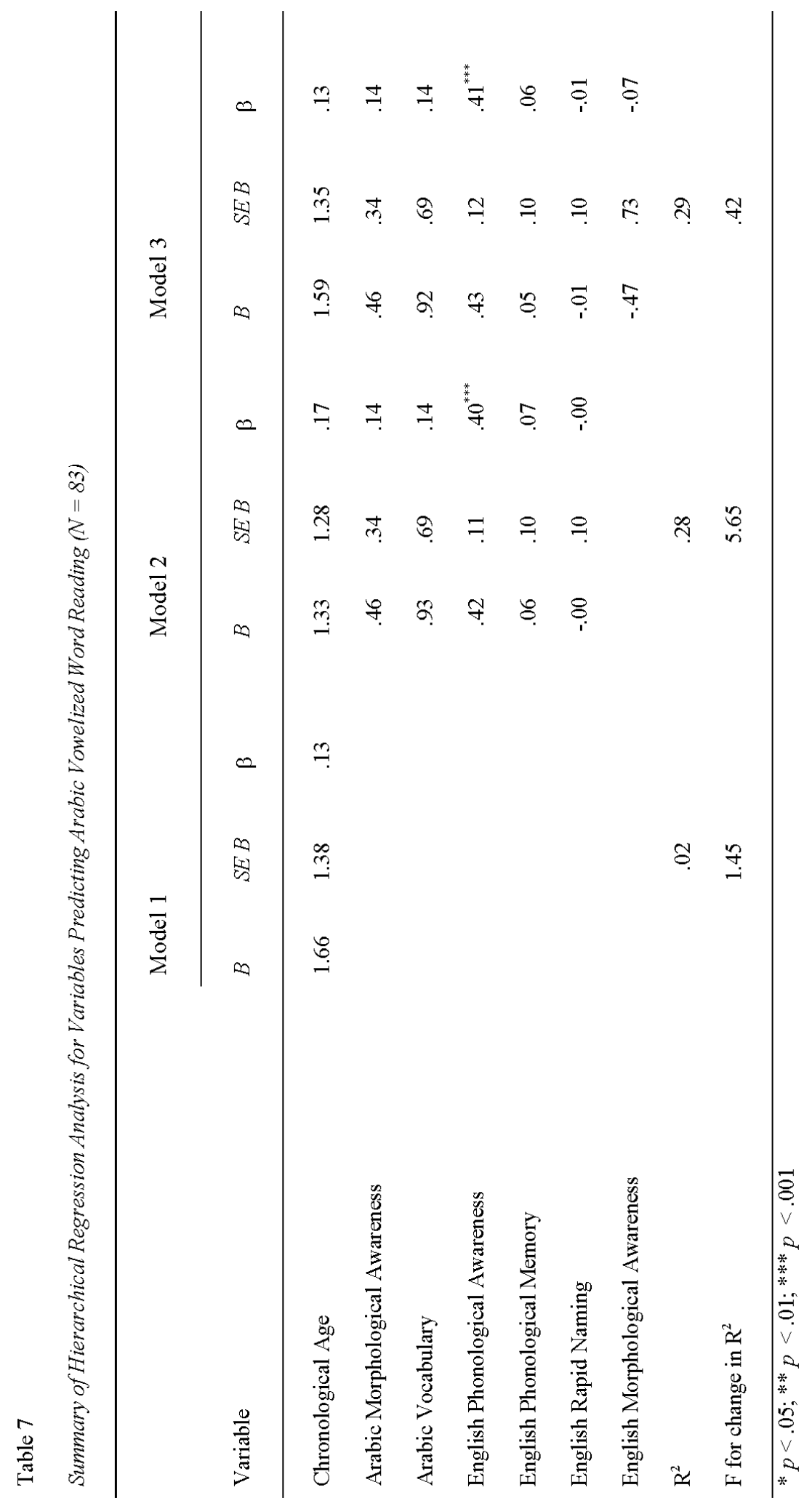




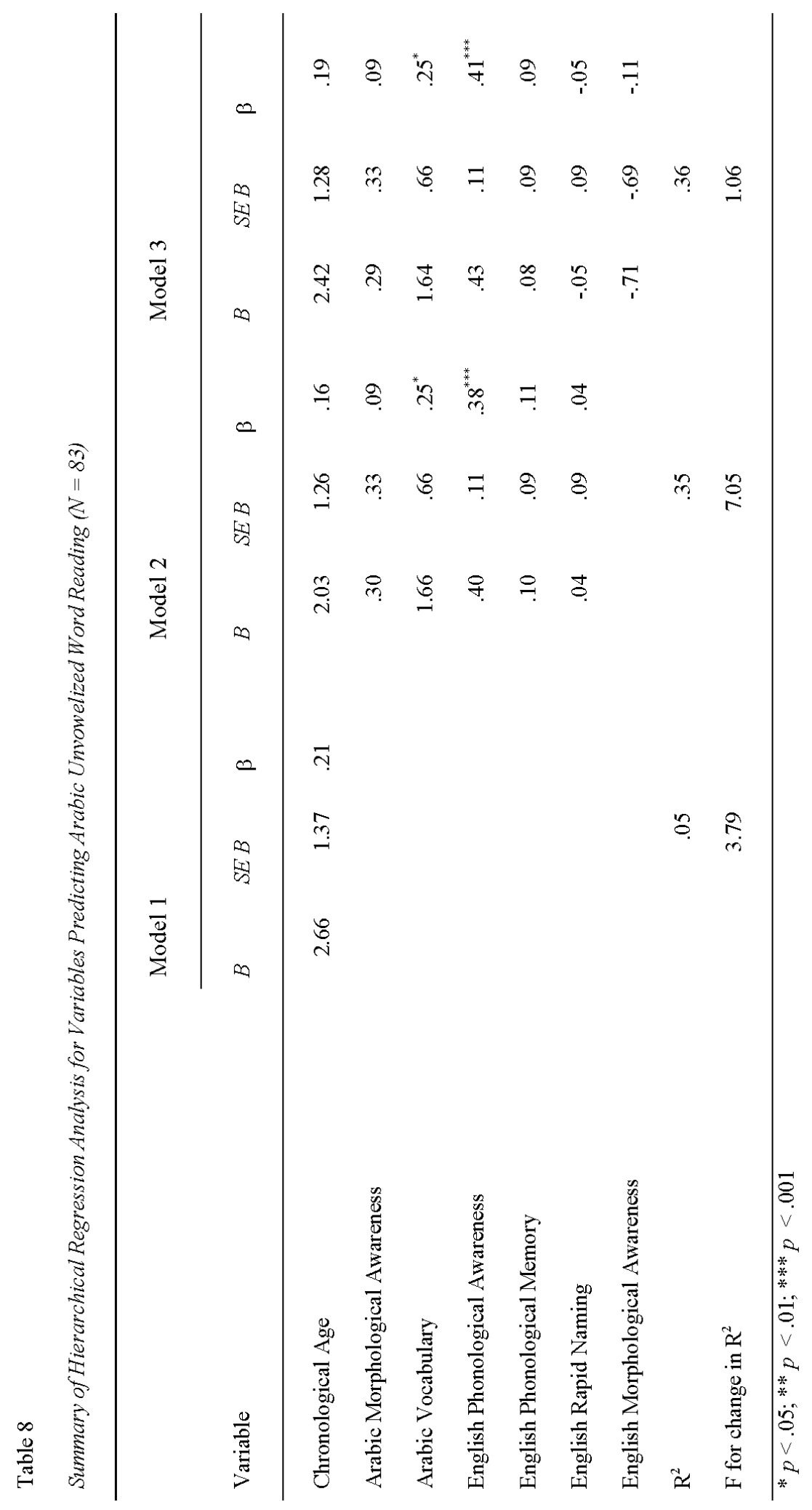




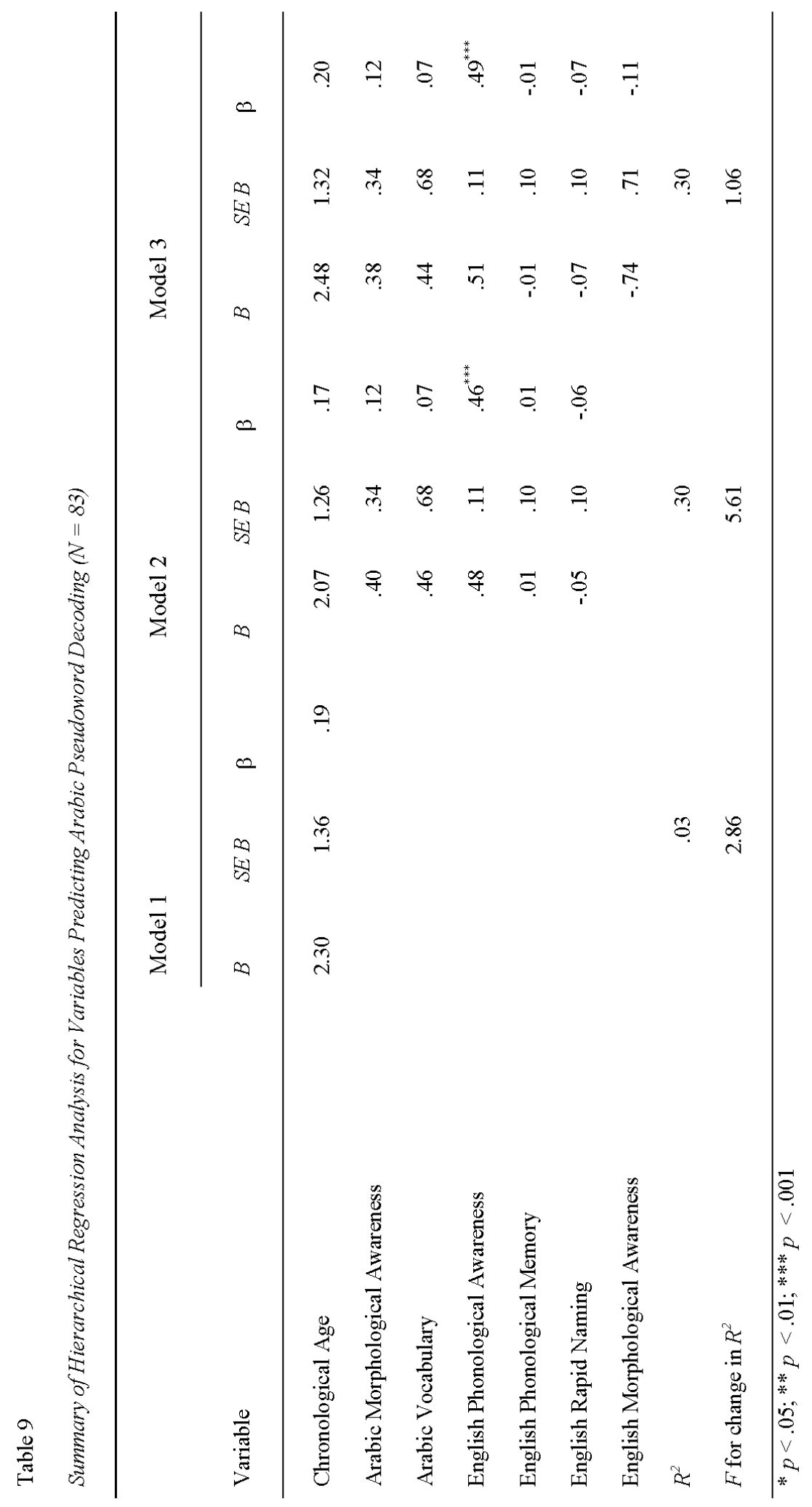




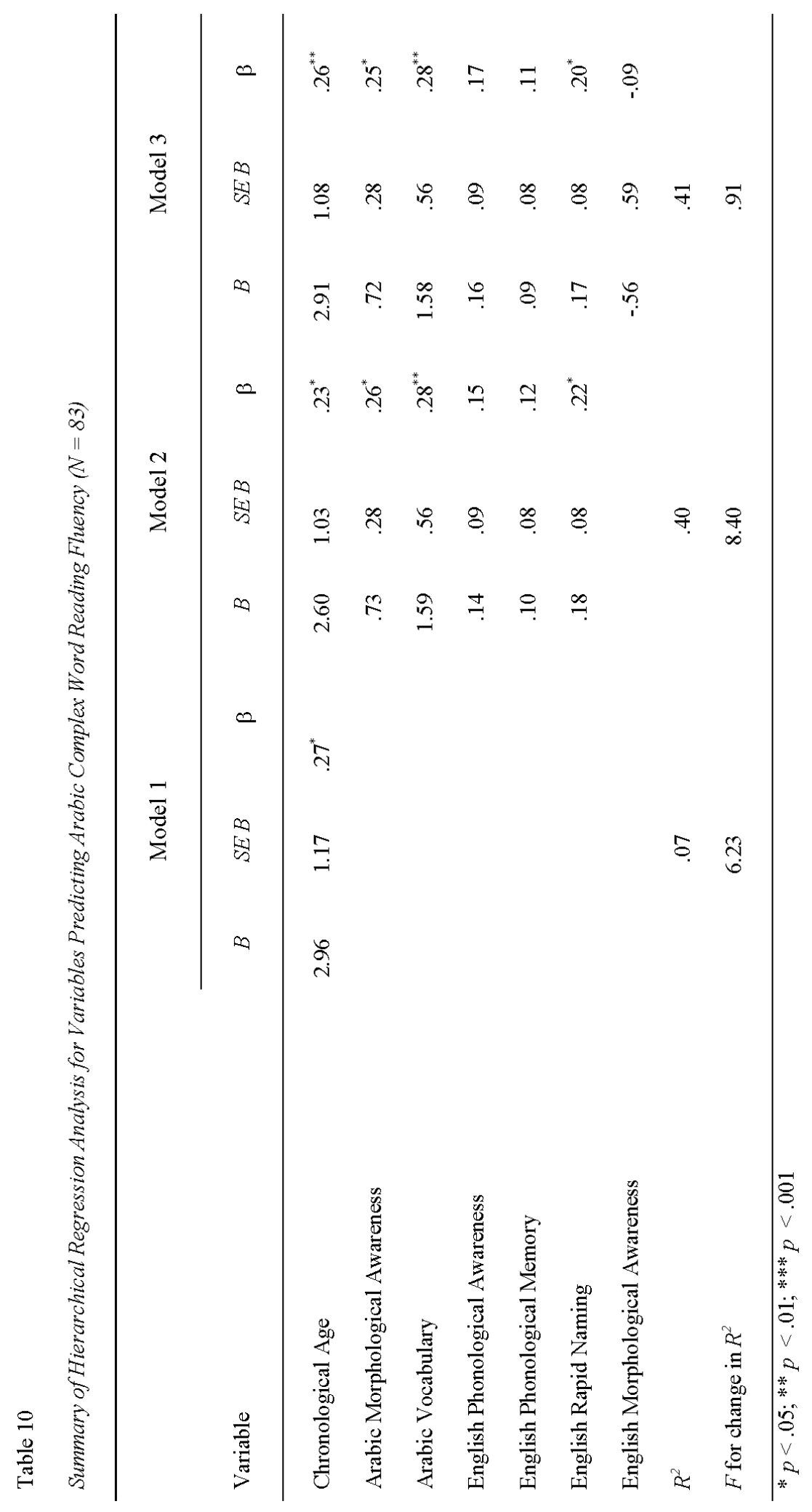


Correlation analyses revealed multicollinearity among the IVs. Therefore, to meet regression assumptions, chronological age was taken out of the regression equation in the remaining analyses for the fourth research question and analyses were conducted separately for third-grade and fifth-grade. Because of the new sample size in each group ( $\mathrm{N}=33$ for third grade; and $\mathrm{N}=22$ for fifth grade), and in order to reduce the number of IVs in each analysis, the elision and blending subtests of Arabic phonological awareness were collapsed into a single variable: Arabic phonological awareness composite variable. Arabic blending and elision were selected because extant research in English indicates that blending and elision could be conceptualized as belonging to the same underlying construct (Anthony \& Francis, 2005). Inspection of table 4 reveals that Arabic blending and Arabic elision were moderately correlated, $r=.40, p<.001$. So for each equation, the IVs were English morphological awareness, English vocabulary, Arabic phonological awareness composite, and Arabic morphological awareness (see Tables 11, 12, 13, 14, 15, and 16).

The first in a series of hierarchical multiple regressions examined whether English morphological awareness predicted Arabic vowelized word reading accuracy, after controlling for the influence of chronological age, Arabic morphological awareness, Arabic vocabulary, and English phonological processing. At step 1, chronological age was entered, explaining $1.8 \%$ of the variance in Arabic vowelized word reading accuracy, $\mathrm{F}(1,81)=1.45, \mathrm{p}>.05$; at step 2, Arabic morphological awareness, Arabic vocabulary, and English phonological processing were entered, explaining $28.4 \%$ of the variance in Arabic vowelized word reading accuracy, $F(6,76)=5.02, \mathrm{p}<.001$. After entry of 
English morphological awareness at step 3, the total variance explained by the model as a whole was $28.8 \%, F(7,75)=4.33, p<.001$. Thus, English morphological awareness explained an additional $.4 \%$ of the variance in Arabic vowelized word reading accuracy after controlling for the above mentioned variables, $\mathrm{R}$ squared change $=.004, F$ change $(1,75)=.42, p>.05$. In the final model, English morphological awareness was not significant, with a beta value $(\beta=-.07, p>.05$; see Table 7$)$.

The second analysis examined whether English morphological awareness predicts Arabic unvowelized word reading accuracy. The IVs were chronological age, Arabic morphological awareness, Arabic vocabulary, and English phonological processing. At step 1, chronological age was entered, explaining $4.5 \%$ of the variance in Arabic unvowelized word reading accuracy; at step 2, Arabic vocabulary, English phonological processing, and Arabic morphological awareness were entered, explaining 35\% of the variance in Arabic unvowelized word reading accuracy. This model was significant. After entry of English morphological awareness at step 3, the total variance explained by the model as a whole was $36 \%, F(7,75)=5.94, p<.001$. Thus, English morphological awareness explained an additional $1 \%$ of the variance in Arabic unvowelized word reading accuracy after controlling for the above mentioned variables, $\mathrm{R}$ squared change $=01, F$ change $(1,75)=1.10, p>.05$. In the final model, English morphological awareness was not significant, with a beta value $(\beta=-.11, p>.05)$ (see Table 8$)$. 


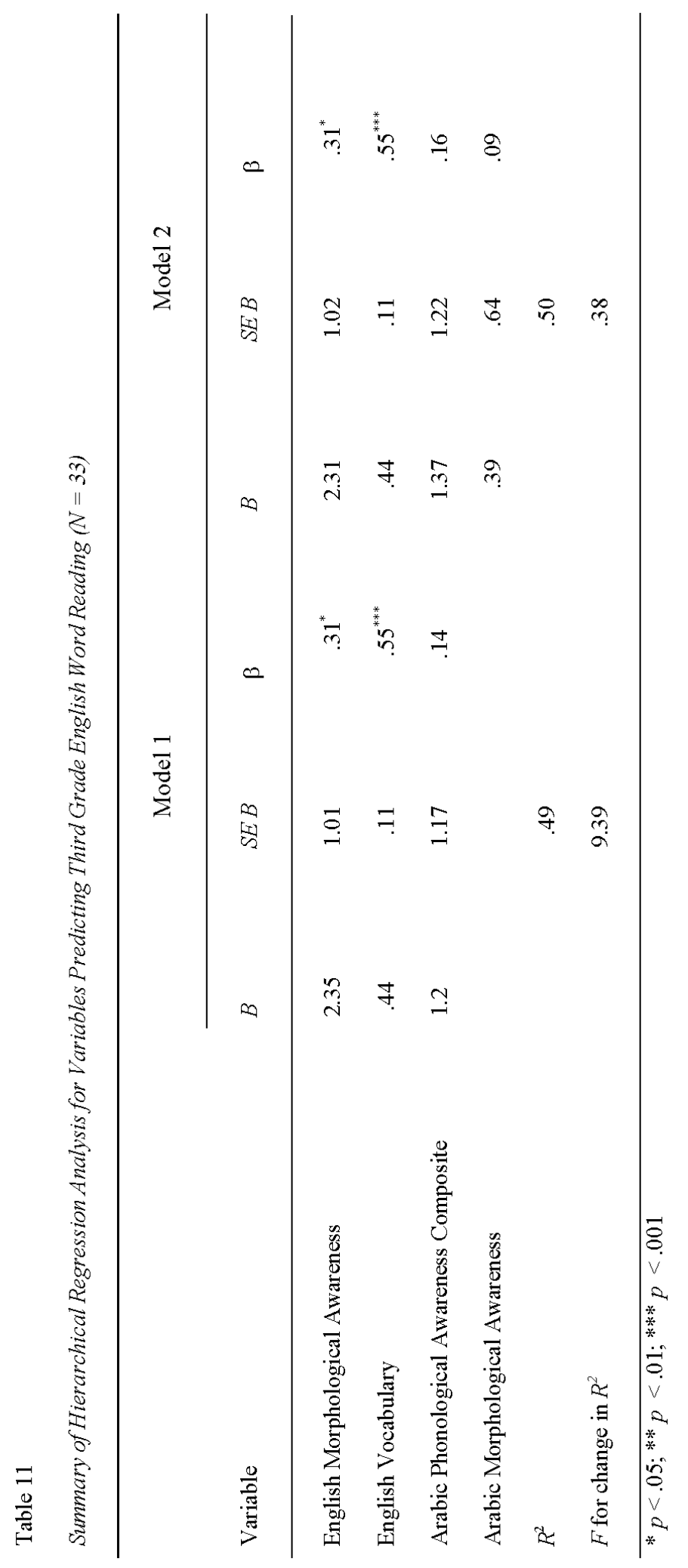




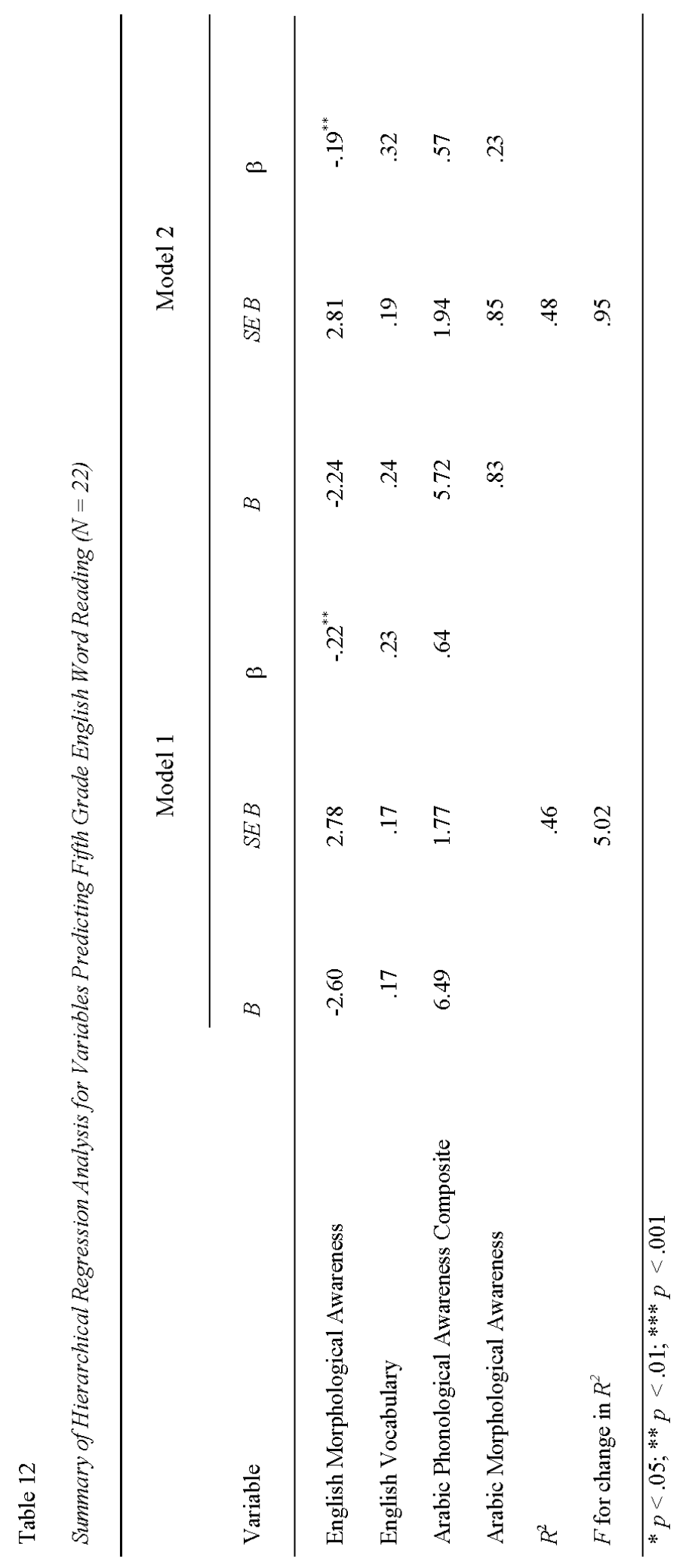




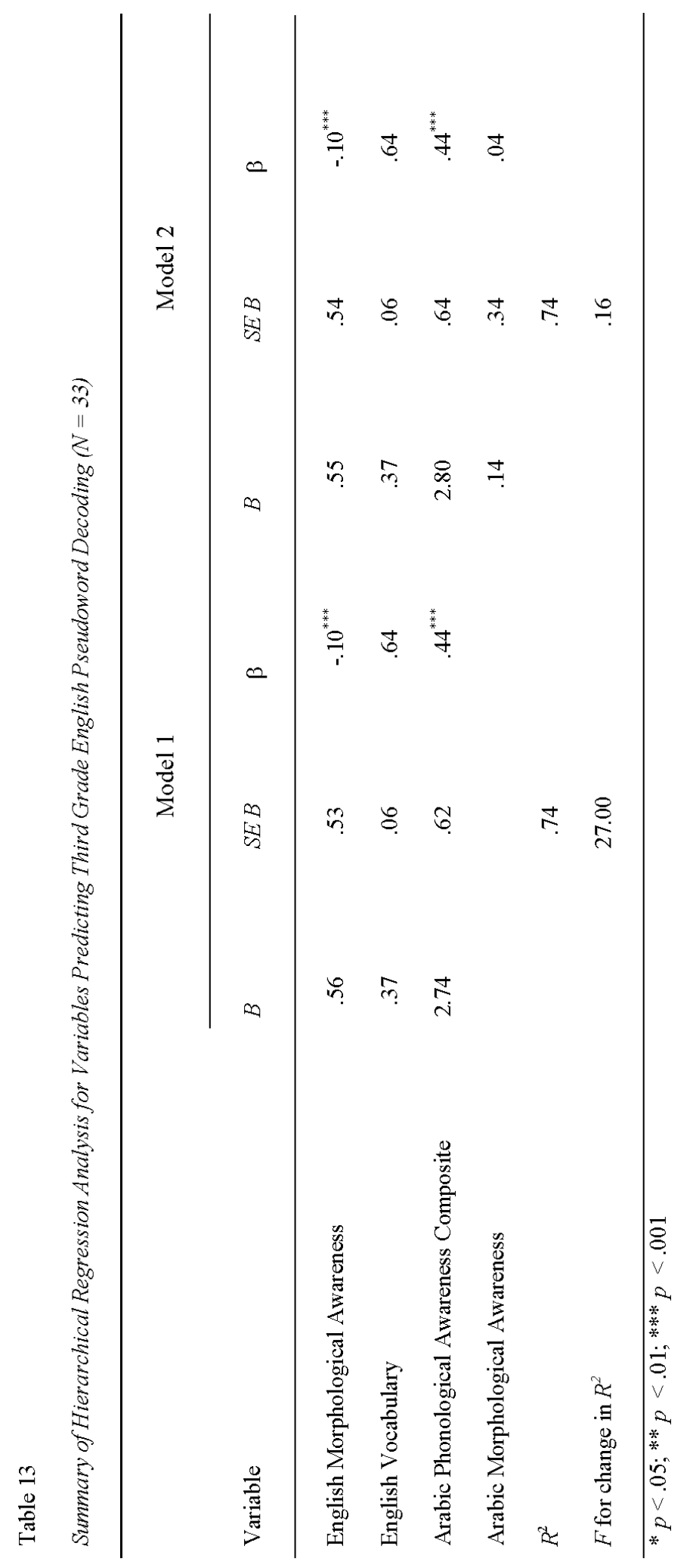




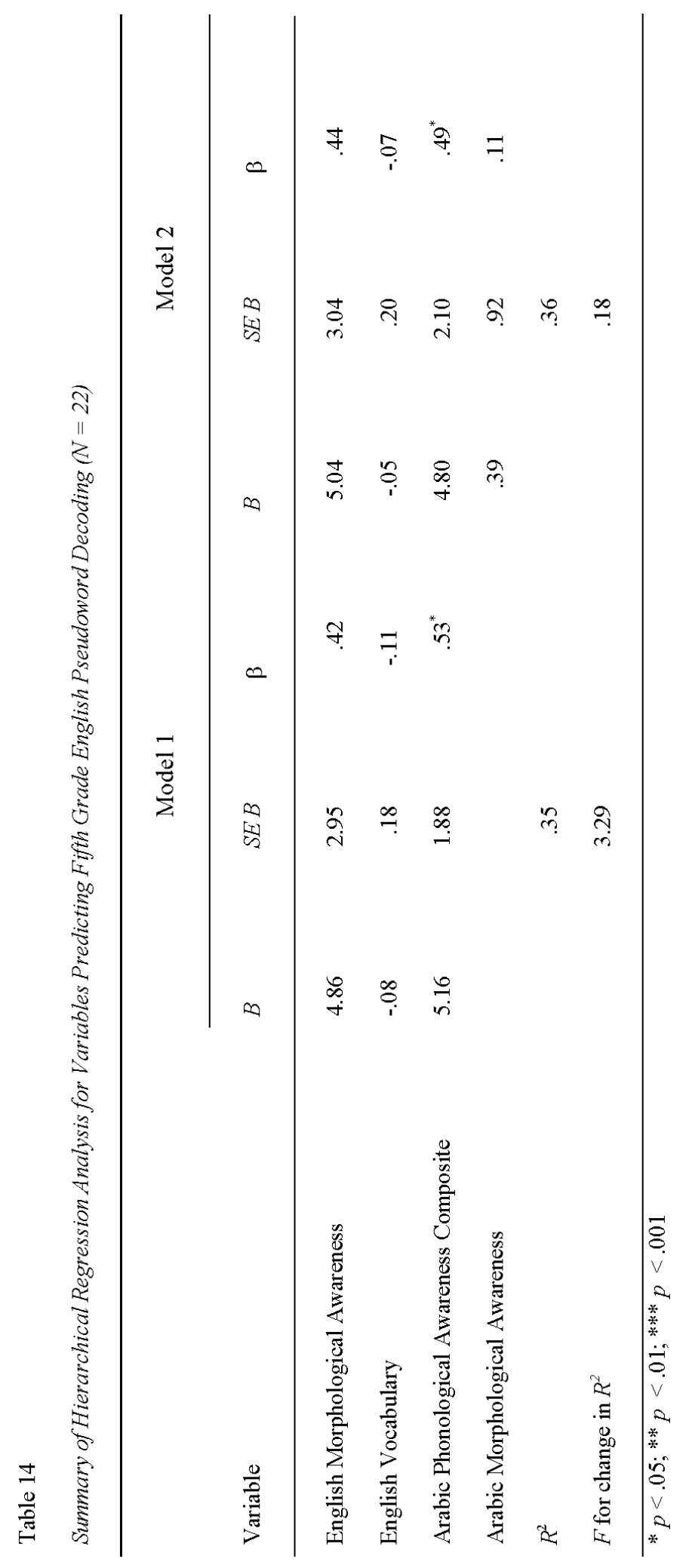




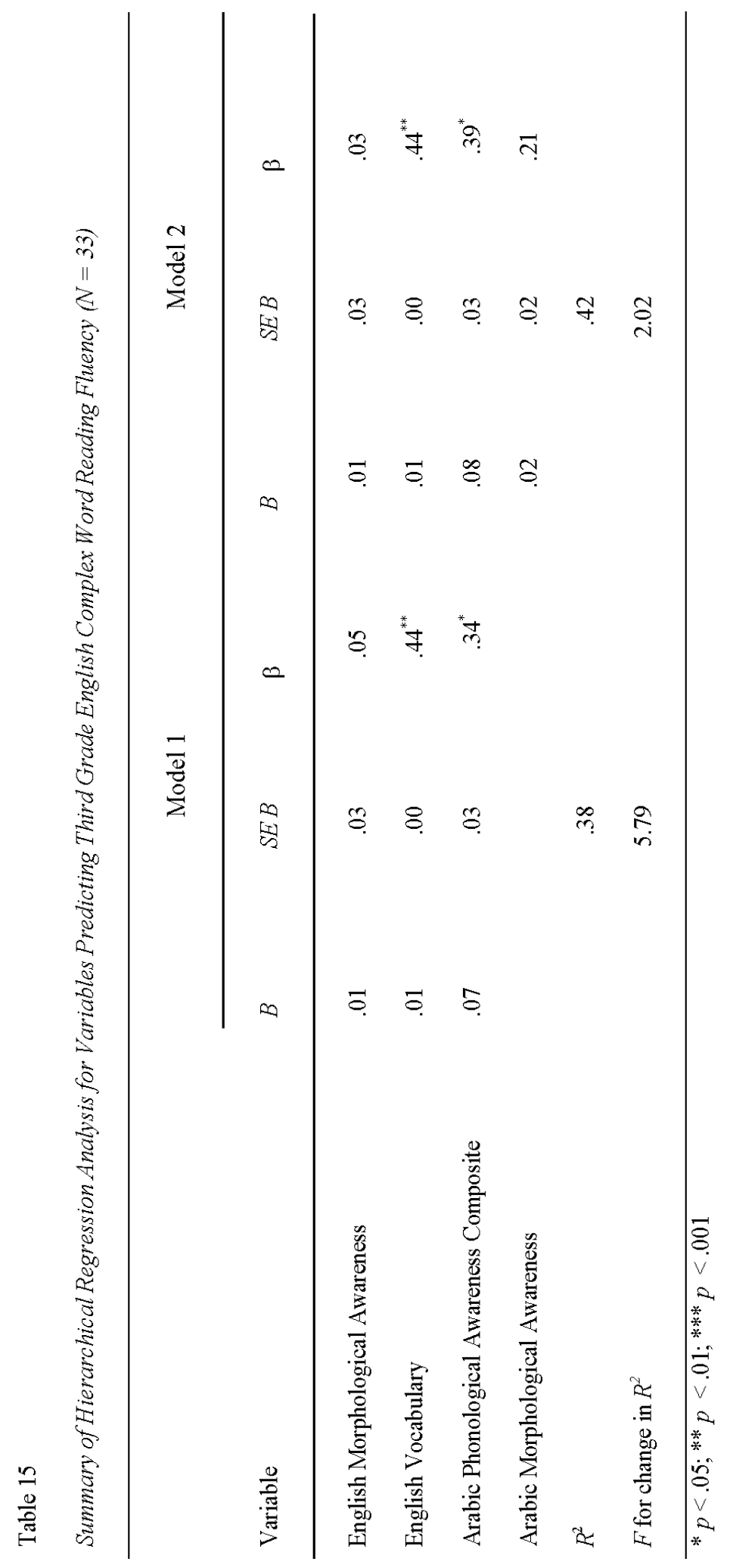




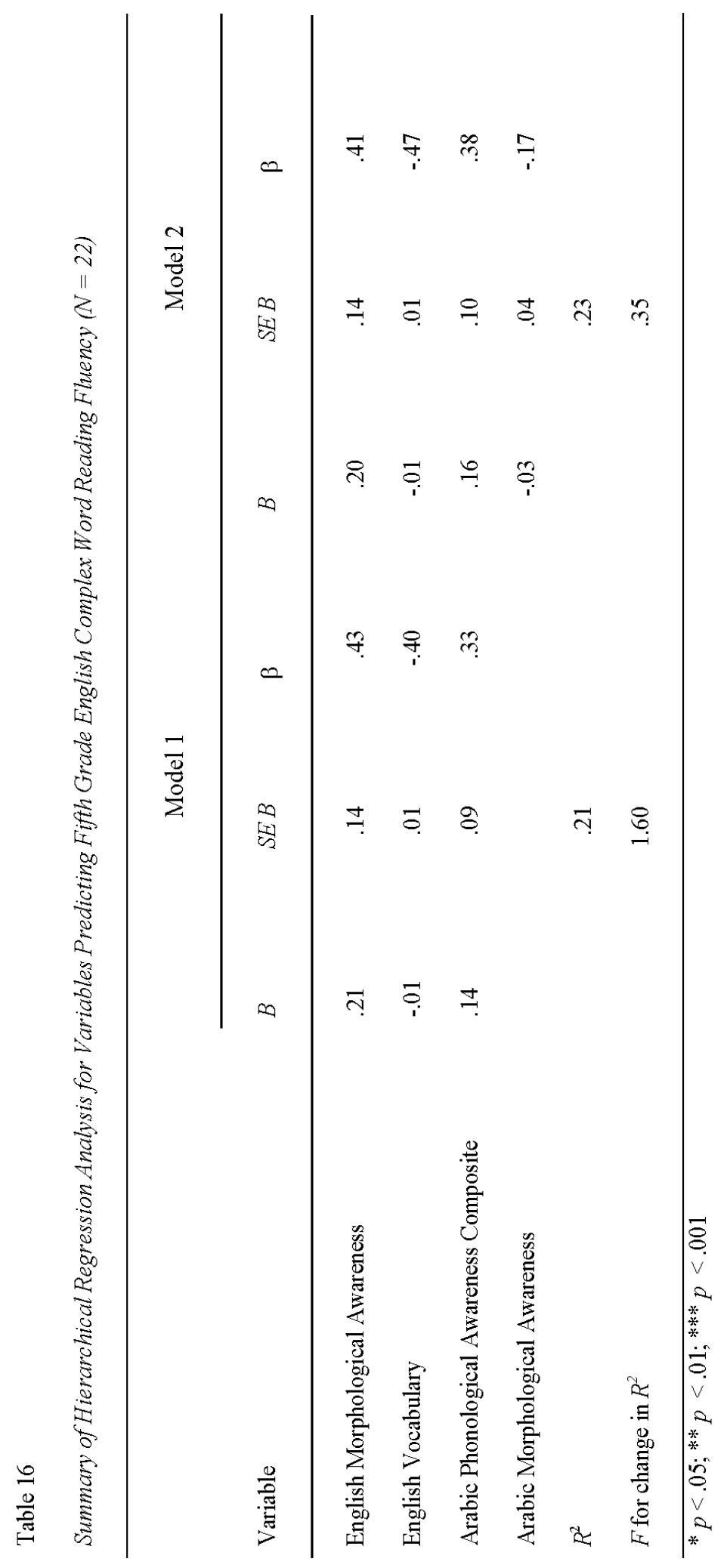


The third analysis was performed to assess the ability of English morphological awareness to predict Arabic pseudoword decoding. The IVs were chronological age, Arabic morphological awareness, Arabic vocabulary, and English phonological processing. At step 1, chronological age was entered, explaining 3.4\% of the variance in Arabic unvowelized word reading accuracy; at step 2, Arabic vocabulary, English phonological processing, and Arabic morphological awareness were entered, explaining $29.5 \%$ of the variance, $F(6,76)=5.29, p=<.001$ in Arabic pseudoword decoding. After entry of English morphological awareness at step 3, the total variance explained by the model as a whole was $F(7,75)=4.69, p<.001$. Thus, English morphological awareness explained an additional $.5 \%$ of the variance in Arabic pseudoword decoding after controlling for the above mentioned variables, $\mathrm{R}$ squared change $=.01, F$ change $(1,75)$ $=1.06, p>.05$. In the final model, English morphological awareness was not significant, with a beta value $(\beta=-.11, p>.05)$ (see Table 9).

The fourth analysis was performed to assess the ability of English morphological awareness in predicting Arabic complex word reading fluency. The IVs were chronological age, Arabic morphological awareness, Arabic vocabulary, and English phonological processing. At step 1, chronological age was entered, explaining $7.1 \%$ of the variance in Arabic complex word reading fluency, $F(1,81)=6.23, p<.05$; at step 2, Arabic vocabulary, English phonological processing, and Arabic morphological awareness were entered. They explained approximately $40 \%$ of the variance in Arabic complex word reading fluency, $F(6,76)=8.51, p<.001$. After entry of English morphological awareness at step 3, the total variance explained by the model as a whole 
was $41 \%, F(7,75)=7.42, p<.001$. Thus, English morphological awareness explained an additional $1 \%$ of the variance in Arabic complex word reading fluency after controlling for the above mentioned variables, $\mathrm{R}$ squared change $=.01, F$ change $(1,75)$ $=.91, p>.05$. In the final model, the contribution of English morphological awareness to the model was not significant, with a beta value $(\beta=-.10, p>.05)$ (see Table 10).

The fifth analysis was conducted separately for third grade and fifth grade and without chronological age because chronological age was found to be highly correlated with ITBS vocabulary. This analysis was performed to assess the ability of Arabic morphological awareness to predict English word reading accuracy (WRAT-3 standard score). The IVs were English morphological awareness, English vocabulary, and Arabic phonological awareness. For third grade, at step 1, English morphological awareness, English vocabulary, and Arabic phonological awareness were entered, explaining 49\% of the variance in English word reading accuracy, $F(3,29)=9.39, p<.001$. After entry of Arabic morphological awareness at step 2, the total variance explained by the model as a whole was $50 \%, F(4,28)=6.99, p<.001$. Thus, Arabic morphological awareness explained an additional 1\% of the variance in English word reading accuracy after controlling for the above mentioned variables, $\mathrm{R}$ squared change $=.007, F$ change $(1,28)$ $=.38, p>.05$. In the final model, the contribution of Arabic morphological awareness to the model was not significant, with a beta value $(\beta=.09, p>.05)$ (see Table 11). For fifth grade, at step 1, English morphological awareness, English vocabulary, and Arabic phonological awareness were entered, explaining $46 \%$ of the variance in English word reading accuracy, $F(3,18)=5.02, p<.05$. After entry of Arabic morphological 
awareness at step 2, the total variance explained by the model as a whole was $48 \%, F$ (4, $17)=3.99, p<.05$. Thus, Arabic morphological awareness explained an additional $2 \%$ of the variance in English word reading accuracy after controlling for the above mentioned variables, $\mathrm{R}$ squared change $=.03, F$ change $(1,17)=.95, p>.05$. In the final model, the contribution of Arabic morphological awareness to the model was not significant, with a beta value $(\beta=.23, p>.05)($ see Table 12$)$.

The sixth analysis was performed for third grade and fifth grade separately to assess the ability of Arabic morphological awareness to predict English pseudoword decoding. The IVs were English morphological awareness, English vocabulary, and Arabic phonological awareness. For third grade, at step 1, English morphological awareness, English vocabulary, and Arabic phonological awareness were entered, explaining $74 \%$ of the variance in English pseudoword decoding, $F(3,29)=26.97, p<$ .001. After entry of Arabic morphological awareness at step 2, the total variance explained by the model as a whole was $74 \%, F(4,28)=19.68, p<.001$. Thus, Arabic morphological awareness did not explain any additional variance in English pseudoword decoding after controlling for the above mentioned variables, $\mathrm{R}$ squared change $=.00, F$ change $(1,28)=.16, p>.05$. In the final model, Arabic morphological awareness was not significant, with a beta value $(\beta=.04, p>.05)$ (see Table 13). For fifth grade, at step 1, English morphological awareness, English vocabulary, and Arabic phonological awareness were entered, explaining 35\% of the variance in English pseudoword decoding, $F(3,18)=3.29, p<.05$. After entry of Arabic morphological awareness at step 2 , the total variance explained by the model as a whole was $36 \%, F(4,17)=2.40, p$ 
$>$.05. Thus, Arabic morphological awareness did not explain any additional variance in English pseudoword decoding after controlling for the above mentioned variables, R squared change $=.01, F$ change $(1,17)=.18, p>.05$. In the final model, Arabic morphological awareness was not significant, with a beta value $(\beta=.11, p>.05)$ (see Table 14).

The seventh analysis was conducted for third grade and fifth grade separately. It was performed to assess the ability of Arabic morphological awareness to predict English complex word reading fluency, after controlling for the influence of chronological age, English morphological awareness, English vocabulary, and Arabic phonological awareness. For third grade, at step 1, English morphological awareness, English vocabulary, and Arabic phonological awareness were entered, explaining $38 \%$ of the variance in English complex word reading fluency, $F(3,29)=5.79, p<.01$. After entry of Arabic morphological awareness at step 3, the total variance explained by the model as a whole was $42 \%, F(4,28)=5.00, p>.01$. Thus, Arabic morphological awareness explained an additional 4\% of the variance in English complex word reading fluency after controlling for the above mentioned variables, R squared change $=.04, F$ change $(1$, $28)=2.02, p>.05$. In the final model, Arabic morphological awareness was not significant, with a beta value $(\beta=.21, p>.05)$ (see Table 15). For fifth grade, at step 1 , English morphological awareness, English vocabulary, and Arabic phonological awareness were entered, explaining $21 \%$ of the variance in English complex word reading fluency, $F(3,18)=1.59, p>.05$. This model was not significant. After entry of Arabic morphological awareness at step 2, the total variance explained by the model as a 
whole was $23 \%, F(4,17)=1.24, p>.05$. Thus, Arabic morphological awareness did not explain any additional variance in English complex word reading fluency after controlling for the above mentioned variables, $\mathrm{R}$ squared change $=.02, F$ change $(1,17)$ $=.35, p>.05$. In the final model, Arabic morphological awareness was not significant, with a beta value $(\beta=-.17, p>.05)$ (see Table 16).

Research Question 5: Does morphological awareness predict reading comprehension above and beyond phonological processing and vocabulary within English and Arabic languages?

The fifth research question examined whether morphological awareness skills predicted reading comprehension above and beyond phonological processing and vocabulary within Arabic and English languages. To answer this question, a series of hierarchical regression analyses were performed. For Arabic, the DV was Arabic reading comprehension and the IVs were chronological age, Arabic phonological awareness, Arabic vocabulary composite, and Arabic morphological awareness. For English, the DV was English reading comprehension and the IVs were chronological age, English phonological awareness composite, English phonological memory composite, English alternate rapid naming composite, English vocabulary, and English morphological awareness.

The first analysis was conducted to examine whether Arabic morphological awareness predicted Arabic reading comprehension after the effect of chronological age, Arabic phonological awareness, and Arabic vocabulary were taken into account. These variables were used as controls because they have been found to be predictive of reading 
comprehension (either directly, e.g., vocabulary, or indirectly through their effect on word reading, which has been associated with reading comprehension, e.g., phonological awareness) across languages. Therefore, controlling for their effect should shed light on the unique contribution made by morphological awareness in predicting reading comprehension in Arabic. At step 1, chronological age was entered, explaining 5.8\% of the variance in Arabic reading comprehension, $F(1,81)=4.98, p<.05$. At step 2 , Arabic phonological awareness and Arabic vocabulary were entered, explaining $16 \%$ of the variance in Arabic reading comprehension, $F(3,79)=5.11, p<.01$. After entry of Arabic morphological awareness at step 3, the total variance explained by the model as a whole was $16 \%, F(4,78)=3.86, p<.01$. Thus, Arabic morphological awareness did not contribute any additional variance in Arabic reading comprehension after controlling for the above mentioned variables, R squared change $=.00, F$ change $(1,78)=.01, p>.05$. In the final model, English morphological awareness was not significant, with a beta value $(\beta=-.01, p>.05)($ see Table 17$)$.

To determine whether morphological awareness predicts reading comprehension after the effect of phonological processing, and vocabulary have been taken into account in English, a hierarchical regression was conducted for third grade and fifth grade separately and without chronological age. For third grade, at step 1, English phonological processing (awareness, memory, and rapid naming) and English Vocabulary were entered, explaining $44 \%$ of the variance in English reading comprehension, $F(4,28)=$ $5.54, p<.01$. After entry of English morphological awareness at step 2, the total variance explained by the model as a whole was $44 \%, F(5,27)=4.30, p<.01$. Thus, English 
morphological awareness did not contribute any additional variance in English reading comprehension after controlling for the above mentioned variables, $\mathrm{R}$-squared change $=$ $00, F$ change $(1,27)=.10, p>.05$. In the final model, English morphological awareness was not significant, with a beta value $(\beta=-.04, \mathrm{p}>.05)$ (see Table 18 ).

For fifth grade, at step 1, English phonological processing (awareness, memory, and rapid naming) and English Vocabulary were entered, explaining $87 \%$ of the variance in English reading comprehension, $F(4,17)=28.17, p<.001$. After entry of English morphological awareness at step 2, the total variance explained by the model as a whole was $88 \%, F(5,16)=24.41, p<.001$. Thus, English morphological awareness contributed 2\% additional variance in English reading comprehension after controlling for the above mentioned variables, $\mathrm{R}$ squared change $=.02, F$ change $(1,16)=2.10, p$ > .05. In the final model, English morphological awareness was not significant, with a beta value $(\beta=.18, \mathrm{p}>.05)($ see Table 19$)$.

Research Question 6: Does the relationship between vocabulary and reading comprehension hold across high and low vocabulary groups after controlling for chronological age?

The sixth research question examined whether the relationship between vocabulary and reading comprehension holds across language groups. Vocabulary was selected as IV due to the strong research support linking vocabulary to reading comprehension, particularly in bilingual children. Because random assignment of children to groups was impossible in this study, an analysis of covariance (ANCOVA) was used (Cook \& Campbell, 1979) to examine whether there is a difference between 
different levels of the IV (vocabulary) in their ability to predict the DV, while controlling for chronological age. First, the sample was split into two groups using a median split: a high vocabulary group, which consists of children who scored above the median on the Arabic vocabulary measure; and a low vocabulary group, which consists of children who scored below the median on the Arabic vocabulary measure. Next, a one-way betweengroups analysis of covariance was conducted to compare the effect of vocabulary in predicting reading comprehension between hi- and low-vocabulary groups, while taking into account the effect of chronological age as a covariate. Preliminary analyses were conducted to ensure that there was no violation of the ANCOVA assumptions. Since the covariate used was chronological age, the assumptions of measurement and reliability of the covariate, and correlations among the covariates were not violated. The assumption of equality of variance was not violated as indicated by Levene's Test of Equality of Error Variances table, $\mathrm{p}>.05$. The linearity assumption was assessed using scatterplot to test whether there is a linear relationship between the covariate and the DV. This assumption was not violated. The homogeneity of regression slopes was assessed statistically by checking whether there is interaction between the covariate (chronological age) and the DV (reading comprehension). The interaction term was not statistically significant, meaning this assumption was not violated.

Results from ANCOVA indicated that, after adjusting for the effect of chronological age, there was no significant difference between the hi-vocabulary group and the low vocabulary group in reading comprehension, $F(1,80)=1.74, p>.05$. Results also showed a small effect size (Cohen, 1988) with only $4.9 \%$ of the variance in 


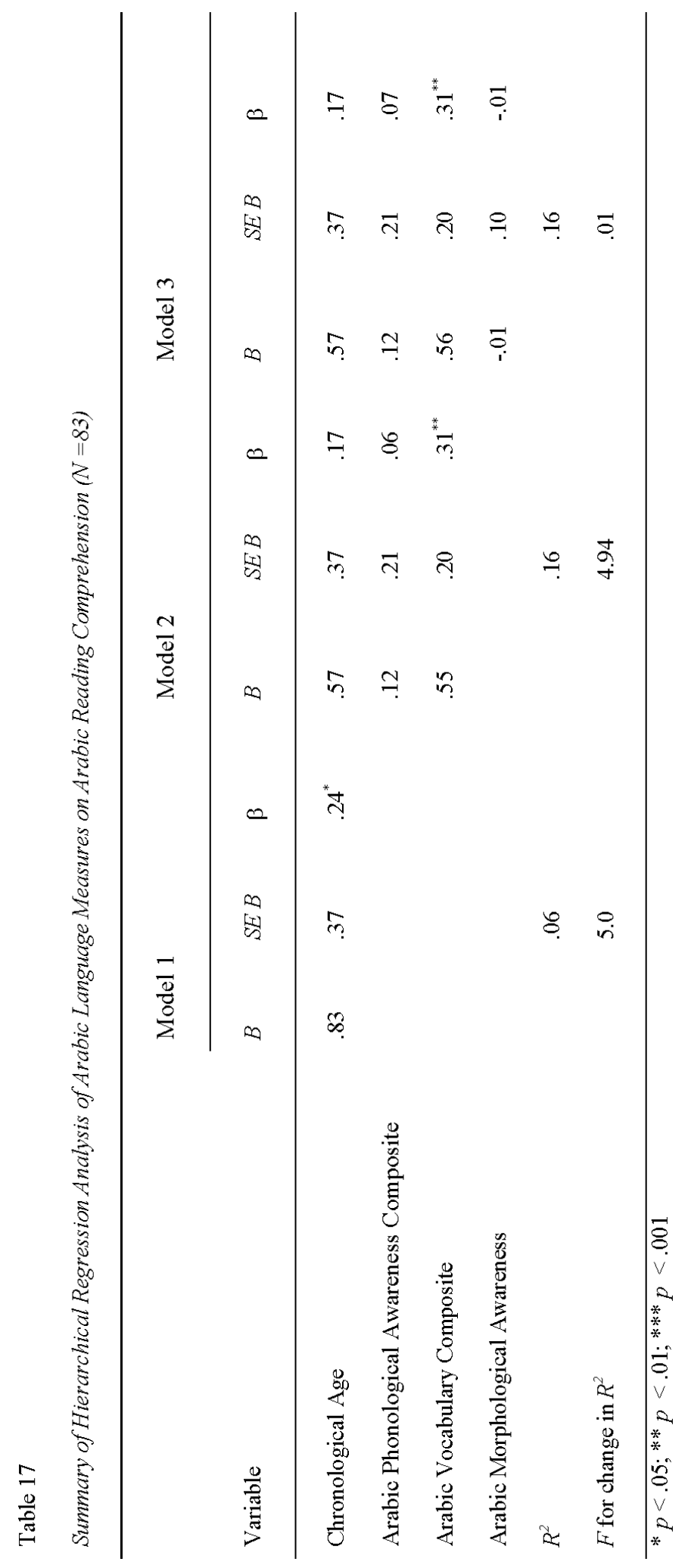




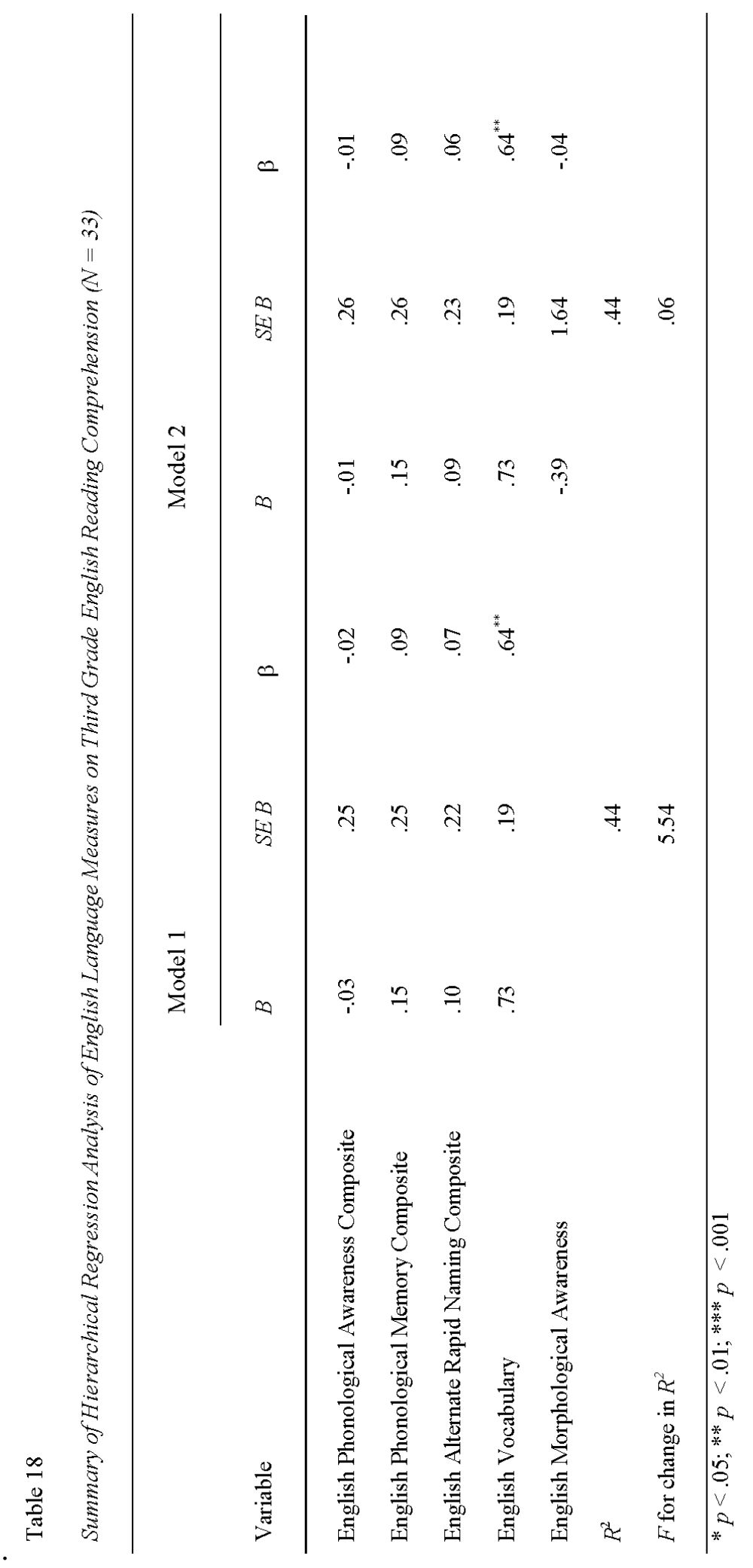




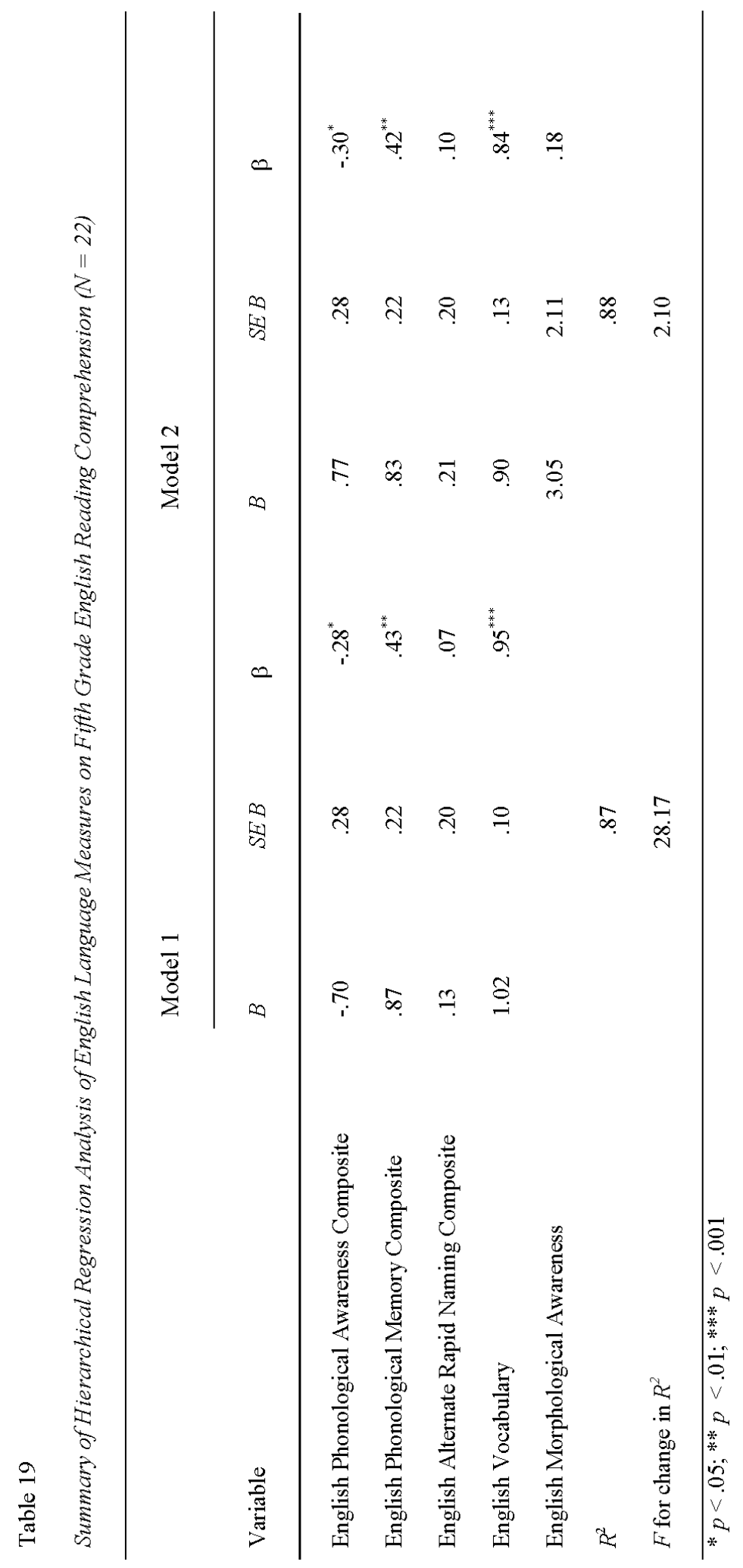


reading comprehension was explained by chronological age, partial Eta Squared value of $.049, p>.05$

The last analysis examined whether the effect of vocabulary on reading comprehension was moderated by another variable. Guided by theoretical and empirical support for the role of unvowelized reading accuracy in reading comprehension in Arabic (Abu-Rabia \& Taha, 2004), this last ANCOVA examined whether there is a difference in scores on the unvowelized reading accuracy measure between hi-vocabulary and lowvocabulary groups, while controlling for chronological age. Results indicated that the two groups were statistically different, $F(1,78)=4.42, p<.05$ in their ability to predict reading comprehension (See Table 20). These results suggest that the predictive ability of vocabulary in reading comprehension could be driven by children's ability to read unvowelized words.

Table 20

Analysis of Covariance of Arabic Reading Comprehension Scores with Chronological Age as the Covariate

\begin{tabular}{lcccc}
\hline \multicolumn{1}{c}{ Source } & $\mathrm{df}$ & $F$ & $p$ & $\eta^{2}$ \\
\hline Chronological Age & 1 & 5.20 & .03 & .06 \\
Arabic Vocabulary & 1 & 0.84 & .36 & .01 \\
Arabic Unvowelized Word Reading & 1 & 4.42 & .04 & .05 \\
Arabic Vocabulary $\times$ Arabic Unvowelized & 1 & 2.23 & .14 & .03 \\
Word Reading & & & & \\
Error & 78 & & &
\end{tabular}




\section{Discussion}

This study examined the relationship between oral language and reading outcomes in bilingual English-Arabic children who attended a charter school and received consistent instruction in English (first language) and Arabic (second language). The study builds on a recent study by Saiegh-Haddad and Geva (2008) that investigated the relationship between phonological awareness, morphological awareness, and word reading in bilingual English-Arabic children in Canada. It shares with the study by Saiegh-Haddad and Geva a focus on phonological and morphological awareness as predictors of word reading, pseudoword decoding, and complex word reading fluency. However, this study extends the study of Saiegh-Haddad and Geva (2008) by investigating the role of vocabulary and reading comprehension in English and in Arabic. Further, this study adds to the emerging body of evidence that bolsters the paramount role language plays in reading development. Results support the extended Triangle Model of Reading (Bishop \& Snowling, 2004) which emphasizes the role experience plays in the development of language and reading and the dynamic division of labor among the various components of language in the process of learning to read. Results also concur with the interactionist-developmental position on learning (Diamond, 2007) that underscores the interdependence between various language components, namely phonology, morphology, and semantics, in shaping reading developmental outcomes.

What follows is a discussion of the findings of the study. It begins with a brief mention of the measurement issues that emerged in the study, followed by other related 
issues that are considered important in the assessment, instruction, and intervention research with bilingual children.

\section{Measurement Issues}

Several measurement issues are important to consider when interpreting the results of this study. For example, there were substantial differences in how vocabulary was measured in the two languages, English and Arabic. In Arabic, vocabulary was assessed using an Arabic version of the Gates-MacGinitie Test which consisted of two parts: the first part deals with phonological and semantic aspects shared among words; the second part relies primarily on semantic associations among words. It is important to note that pictorial stimuli were provided to facilitate the semantic identification of test items. In English, vocabulary assessment was part of the ITBS that assessed general vocabulary skills and relied strictly on children's ability to read test items. Children had to select the most appropriate answer that matched target words or sentences.

Furthermore, expressive vocabulary, associated with highly specified phonological, morphological, and semantic representations (Cain \& Oakhill, 2007), was not assessed in this study. Similar issues surround the measurement of morphology and the typological differences between English and Arabic, influencing task equivalence across the two languages.

Another issue concerns the differences in task instructions that the examiner presented to the children when assessing Arabic (timed) versus English (untimed) word reading and nonword reading. For instance, in Arabic, the examiner said "Here is a list of words that do not have meaning and you have not seen before. Using a loud voice, please 
read these words quickly and accurately. Start reading when I ask you to.” In English, the examiner said "I want you to read some words that are not real words. I want you to tell me how they sound." Although only accuracy scores (raw scores) were reported for word reading and pseusoword reading in Arabic, these two measures were timed in Arabic but not in English, which could have influenced the results across Arabic and English.

Differences in morphological awareness measures were another source of methodological concern. The current study used a morphological relatedness measure, whereas the Saiegh-Haddad and Geva's study used both morphological relatedness and morphological decomposition measures that were combined into a single morphological awareness composite. This led to considerable variability within the group of children tested in the Saiegh-Haddad and Geva's study, which in turn resulted in differences in results across the two studies. In the present study, phonological awareness was the only predictor of English word reading and Pseudoword decoding, whereas in Saiegh-Haddad and Geva's study, both phonological and morphological awareness predicted English word reading and Pseudoword decoding.

Likewise, the way in which language proficiency was measured could have shaped the results. Arabic oral language proficiency was measured using an adaptation of the Gates-MacGinitie Test of Reading. Although research indicates this test is highly sensitive to children's English oral language proficiency (Cutting \& Scarborough, 2006), it is unknown whether the adapted measure for this study captured children's oral language proficiency in Arabic, because its utility in Arabic has not been substantiated empirically. 
Lastly, most of the English assessment measures were norm-referenced, whereas all of the Arabic assessment measures were experimental. This renders the interpretation of the current results difficult, particularly around the construct of cross-linguistic transfer between English and Arabic, thereby limiting the results' generalizability to other bilingual English-Arabic children in the US.

\section{Conceptual and Practical issues}

This study addressed six research questions. The findings associated with each are summarized below and connected to the broader language context. The section ends with a presentation of the study's limitations and future research directions.

The first research question investigated whether there is a relationship between phonological awareness in English and Arabic. These findings indicate that there is a relationship between phonological awareness skills in the two languages, corroborating the findings reported by Saiegh-Haddad and Geva (2008). Also, these findings are in line with previous research in the Semitic language of Hebrew (Geva \& Wang, 2001) as well as other alphabetic languages (Durgunoglu, 2002).

By contrast, results of the second research question revealed that morphological awareness in English and morphological awareness in Arabic did not correlate with each other. However, morphological awareness correlated with phonological awareness within each language, English and Arabic. The lack of correlation between English morphological awareness and Arabic morphological awareness, but evidence of phonological-morphological associations within the same language supports the view that reading development may be constrained by the typology of the language. Perhaps 
this finding is driven by differences in the morphological structure of the two languages. Arabic, a non-concatenative language, employs both linear (e.g., inflectional using affixes and stems) and non-linear (e.g., derivational using consonantal root and vocalic pattern) morphological structure; whereas, English, a concatenative language, employs a predominant linear morphological structure. In the current study, a derivational morphological task was used as opposed to an inflectional morphological task because of its importance in predicting reading outcomes in both English and Arabic (Carlisle, 2000; Abu-Rabia 2001). When considering derivational morphological processes, children when reading Arabic face the demands of mounting a consonantal root onto a fixed vowel word pattern. Conversely, children when reading English must manipulate word stems that undergo a slight change in the process of deriving morphemes. Thus the construct of morphological awareness is not identical in English and Arabic.

The third research question investigated whether phonological and morphological skills differed in their contribution to reading as a function of the reading task. The four reading tasks investigated were vowelized and unvowlized word reading accuracy, word reading and pseudoword decoding, word reading fluency, and reading comprehension. The results indicated that Arabic phonological awareness explained a unique variance in Arabic vowelized and unvowelized word reading accuracy and Arabic pseudoword decoding. Similarly, English phonological awareness explained unique variance in English word reading accuracy and English Pseudoword decoding. These findings concur with Saiegh-Haddad and Geva (2008) who found that Arabic phonological awareness predicted Arabic vowelized word reading and Arabic pseudoword decoding. Likewise, 
English phonological awareness predicted English word reading and English pseudoword decoding. However, unlike Saiegh-Haddad and Geva's study, the current study examined phonological and morphological contributions to both vowelized and unvowelized word reading accuracy and revealed that phonological awareness explained a unique variance in unvowelized word reading accuracy as well. These findings align with those reported by Abu-Rabia, Share, and Mansour (2003) which indicated that phonological awareness skills were associated with both reading vowelized as well as unvowelized words and texts. Arguably, children who read Arabic rely on contextual cues and rich Arabic morphology regardless of the words being read (vowelized or unvowelized).

Predictors of Arabic complex word reading fluency were Arabic elision and Arabic morphological awareness. English phonological awareness predicted English complex word reading fluency. In both Arabic and English, phonological awareness explained a unique variance in complex word reading fluency. The lack of contribution of morphological awareness in English could be due to the ceiling effect obtained on this measure. In this task, children had to identify whether pairs of English words were morphologically related or not, a relatively easy task for most children in the study. Findings related to reading comprehension differed in Arabic and English. In Arabic, neither phonological nor morphological awareness predicted reading comprehension. However, in English, morphological awareness predicted English reading comprehension. There are two possible explanations for the differences in the findings. One, different derivational morphological tasks were used in the two languages. Because English is a concatenative language, a reader employs linear 
morphological processes, whereby word stems remain essentially unchanged and easier to identify as compared to derivational morphology tasks used in Arabic, a nonconcatenative language, a reader applies non-linear processes. Two, the differences could be attributed to the differences in the children's proficiency in the two languages. English is the first language for most children in the study; therefore, it is likely that their vocabulary in English is better than their vocabulary in Arabic. Perhaps a certain threshold level in vocabulary is needed (better English command or language proficiency) before the contribution of any morphological processes could be observed. Thus given the children's higher language proficiency in English compared to Arabic, English morphological awareness was established already.

The fourth research question assessed whether English morphological awareness predicts word and pseudoword reading above and beyond Arabic morphological awareness, Arabic vocabulary, and English phonological processing. The findings from the first three hierarchical regression analyses indicate that English morphological awareness did not add to the prediction of Arabic vowelized word reading accuracy, Arabic unvowelized word reading accuracy, Arabic Pseudoword decoding, or Arabic complex word reading fluency beyond Arabic morphological awareness, Arabic vocabulary, and English phonological processing. This finding is consistent with those reported by Saiegh-Haddad and Geva (2008). The one exception was for Arabic unvowelized word reading accuracy, which was not examined in their study. One reason for why English morphological awareness did not predict reading outcomes could be related to task difficulty. As mentioned in the methodological issues section, 
morphological awareness in English consisted of a morphological relatedness task, in which children had to determine whether pairs of words are related or not related. The majority of the children across the three grades performed well on this task; therefore little variability was observed, resulting in a reduced ability to predict reading outcomes. Importantly, the results from this analysis indicate that only English phonological awareness predicted Arabic vowelized word reading and Arabic pseudoword decoding, whereas both English phonological awareness and Arabic vocabulary predicted Arabic unvowelized word reading; and English phonological awareness, English rapid namimg, and Arabic vocabulary predicted complex word reading fluency. Because reading unvowelized words is more difficult than reading vowelized words and pseudowords because unvowelized words lack phonological information typically available through diacritics, children had to recruit other components of language (e.g., vocabulary), particularly as the difficulty of the reading task increased (e.g., complex word reading fluency) to help children extract meaning from text. This lends support to the extended Triangle Model of Reading and the idea of a division of labor among the language components in the service of word reading and reading comprehension.

The remaining analyses conducted to address the fourth research question targeted the third-graders and fifth-graders separately. Thus scores for 55 of the 83 children were analyzed. Scores were not available for the fourth graders. Arabic morphological awareness did not predict performance on English word reading accuracy, English Pseudoword decoding, or English complex word reading fluency above and beyond English morphological awareness, English vocabulary, and Arabic phonological 
awareness. However, English vocabulary and English morphological awareness predicted English word reading accuracy, English Pseudoword decoding, and English complex word reading fluency. These findings differ from Saiegh-Haddad and Geva's findings. In their study, Arabic morphological awareness predicted English word reading accuracy, English pseudoword decoding, and English complex word reading fluency. One interpretation of these findings for third grade is English morphological awareness and English vocabulary predicted reading outcomes because of the children's proficiency in English. Arabic was their second language and English was their first language; therefore the third-graders had poorly specified phonological representations in Arabic. As the single-route model suggests, the third graders recruited other language components from their first language to bootstrap poor phonological skills in their second language. Another interpretation relates to the differences in the morphological structure of Arabic and English and to the differences in task complexity between the current study and the Saiegh-Haddad and Geva (2008) study.

For fifth-graders, phonological processing predicted a unique variance in English word reading accuracy and English complex word reading fluency. For both the thirdgraders and fifth-graders, Arabic morphological awareness did not predict English word reading or English complex word reading fluency. However, for fifth-graders but not third graders, phonological awareness predicted English word reading and English complex word reading fluency. This could be attributed to the relatively better (almost perfect) performance on the morphological awareness task of the fifth-graders as compared to the third-graders, possibly due to the ease of the Arabic morphological 
relatedness task, which required children to indicate if pairs of words are morphologically related.

Findings from the fifth research question indicated that morphological awareness within each language did not predict reading comprehension above and beyond phonological awareness and vocabulary. Possibly task demands contributed to these findings. As noted previously, morphological awareness was assessed using a morphological relatedness task, which is a recognition task. Most children scored well in both languages on this task. The reduced variability on this measure explains the lack of significant results. Rather than morphological awareness, vocabulary predicted reading comprehension within Arabic and English. These findings concur with the extant research regarding the role vocabulary plays in reading comprehension processes across languages. Although research on the role vocabulary plays in Arabic reading is lacking, evidence from investigations of learning to read English suggests that vocabulary plays a paramount role in reading comprehension, especially in the early school years (Cain \& Oakhill, 2007; Seigneuric \& Ehrlich, 2005) In fact, some researchers posit that the relationship between vocabulary and reading comprehension is reciprocal and continues to develop during the elementary and middle school years in first language English speakers (de Jong \& Van der Leij, 1999).

The sixth and last research question investigated whether the relationship between language and reading comprehension in Arabic differed across high- and low-vocabulary groups. The two groups differed significantly in their Arabic reading comprehension scores. This difference was driven by children's ability to read Arabic unvowelized 
words. These findings support the importance of the print context when reading in Arabic; the value of the print context is substantiated in research on Arabic reading development and linked to enhanced reading comprehension (for a review, see AbuRabia \& Taha, 2004). Readers must rely on the context to decipher the meaning of words, because unvowelized word reading lacks diacritical markers. This finding is in line with the extended Triangle Model of reading that illustrates the role of context and the contribution of various language components to reading comprehension (Bishop \& Snowling, 2004). Of note, the researcher used a median split to group children in hivocabulary and low-vocabulary groups. Results indicated that the two groups differed in their reading comprehension scores, revealing a small effect size (Cohen, 1988). However, it could be that this difference was epiphenomenal given the effect of other independent measures on the dependent variable was not examined. Despite the identified limitations of using median split to transform a continuous variable into a categorical variable (Stevens, 1996; Tabachnick \& Fidel, 2007), median split has been used widely in research studies with intact groups (e.g., classrooms) when random assignment of participants to groups could not be achieved.

It is important to underscore the fact that the first two research questions and analyses used to answer those questions were correlational in nature. Therefore, the present findings can only inform the reader about associations among independent variables and dependent variables, and not about causal relationships among those variables. Equally important is to consider that one major limitation of using regression 
analyses is that they only capture manifest variables, but not latent variables (Tabachnick \& Fidell, 2007).

To review, this study examined the relationship between language and reading in bilingual English-Arabic children. Taken together, the results of this study point to the importance of speech and language in predicting reading outcomes in bilingual EnglishArabic children. Whereas speech is critical to word recognition and during the initial period of learning to read, language is paramount to reading comprehension across the lifespan. Furthermore, the findings suggest that for bilingual English-Arabic children, different language components may be implicated in the development of word reading and in reading comprehension processes. These findings are consistent with tenets of the extended Triangle Model of reading (Bishop \& Snowling, 2004).

Likewise, the findings are compatible with the developmental-interactionist theory of learning (Diamond, 2007). This theory asserts there is neither a central executive nor a single cause of typical or atypical reading development. Rather throughout development there is a spectrum of abilities (Snowling, 2000) that manifests across the language components at different times as strengths and weaknesses. Viewed from this theoretical perspective, the bilingual children in this study present with their own strengths and weaknesses. Their poorly specified phonological representations likely are due to (a) Arabic diglossia, (b) differential strengths in their first and second language due to bilingualism, and (c) the school's instructional approaches. Combined, these factors interact with developmental and environmental forces (e.g., biological, socialcultural) to shape the children's reading outcomes. Depending on task demands and 
children's developmental levels, different language components are called upon to aid bilingual children in the process of gaining meaning from text.

\section{Limitations}

The present study presents with several limitations. One, the cross-sectional design did not permit the examination of differences in the children's reading development. Because the study captured a snapshot of children's reading development at one time point, perhaps it was not representative of children's overall reading performance.

Two, the sample size was small, precluding generalizations to other bilingual English-Arabic children in the US. This was particularly the case in the last few analyses when the sample of third and fifth graders was divided into two groups (fourth graders scores were not available), one for each grade: third and fifth grades, thereby resulting in a limited number of cases per analysis and reducing the power to detect a statistically significant difference.

Three, the length and rigor of Arabic learning prior to and during the last three years as well as English language proficiency could have influenced the results. Although the researcher controlled for the effect of Arabic language exposure via ensuring that students had been receiving Arabic instruction for at least three years, it remains possible that the study's results were influenced by the instruction these students received.

Four, the operationalization of bilingualism and context in this study was limited. The way in which bilingualism was used to identify study participants possibly added to the heterogeneity of the sample. Children were considered bilingual if English was their 
first language and they learned Arabic as a second language in the school. However, the influence of Arabic as a second language may have been minimized due to the focus of Arabic instruction on the oral aspect of language at the expense of written language, including spelling and reading. This issue becomes even more important because home literacy practices varied across the children's homes. As the demographic data indicate, for the majority of participating families, Arabic was not the main language spoken in the home, even if one or both parents spoke and/or read Arabic. With respect to the term context, its use was confined to the reading (word, sentence, or text) or language (Arabic or English) context. A more encompassing definition of context such as social-cultural context must be used to capture differences in children's exposure to and patterns of use of one language versus another or one form of Arabic versus another (MSA versus SVA). Five, most children spoke English as their first language and Arabic as their second language, and their exposure to Arabic differed in frequency and contexts of use (MSA versus SVA). For example, children were exposed to Arabic in school only or in school and home. Most children had poorly specified phonological representations for either form of Arabic, MSA and SVA. It is likely that a different pattern of results would be observed if children had Arabic as their first language.

\section{Future Directions}

This section highlights several areas that deserve attention in future research. These include the place of Arabic in reading research, the role of instruction, the role of social-cultural context, and the role of early intervention. 


\section{The Place of Arabic in Reading Research}

This study is the first to address the relationship between language and reading in bilingual English-Arabic children in the US. As the findings suggest, the process of reading Arabic involves both bottom-up and top-down processes with much reliance on the context (word or sentence), even among the third graders - the youngest children in this sample. Additionally, given Arabic-specific characteristics such as diacritics (Share, 2008), the predominance of the homograph phenomenon (words that look the same but sound and mean different) every second or third word in unvowelized Arabic (AbuRabia, 1997/2001), and diglossia (Saiegh-Haddad, 2003), the study of Arabic might offer unique insights into the development of reading, in both typical and atypical populations of learners. As these characteristics are not central to English or other European languages, studying the relationship between language and reading in Arabic provides an ideal ground to test further the tenability of the extended Triangle Model of Reading and to inform a comprehensive theory of reading development that does not rely exclusively on anglocentric research (Share, 2008). Future research must examine the relationship between language and reading using the following: (a) comprehensive measures of semantics including receptive vocabulary, expressive vocabulary, polysemy (multiple meanings of words), semantic breadth and semantic depth, and listening comprehension measures; (b) comparable measures in English and Arabic that are sensitive to oral language proficiency; (c) a more carefully designed morphological awareness measure that includes words of various degrees of complexity, both in terms of length and word 
frequency in children's lexicons; and (d) a diverse sample of children from various socioeconomic backgrounds and parent education.

Although evidence exists that phonological processing skills are universal, especially phonological memory and naming speed, support exists that these skills may be influenced by typological factors. Thus, a comprehensive measure of phonological processing in Arabic (similar to the English CTOPP) would elucidate this issue of transferability of phonological processing across languages such as English and Arabic. Also longitudinal examinations are needed of the dynamic interplay between the language components and how they influence reading development.

\section{The Role of Instruction}

Future examination of the role of instruction in learning to read in Arabic is warranted. The current results indicated that various language components were implicated in reading vowelized and unvowelized Arabic. Given that both vowelized and unvowelized Arabic were taught in this school and instruction varied slightly based upon the particular teacher (in addition to the use of MSA for instruction, teacher's SVA was occasionally infused in the classroom), the effect of specific instruction and how it might have influenced reading outcomes in this sample remains unknown. Future research should address how instructional variables interact with child variables (e.g., cognitive profile, language profile, home literacy practices, parent beliefs, home language preference, and home language use) to shape language and reading outcomes.

One important direction for future research concerns the question of whether bilingual education is the ideal choice for children who are exposed to two or more 
languages in the US schools. Research evidence exists to support teaching bilingual children in their first and second language (August \& Shanahan, 2006) and the importance of conceptual knowledge development in children's first language (ArabMoghaddam \& Senechal, 2001). Importantly, however, recent research with ELLs underscores that proficiency in children's second (instructional) language plays a more powerful role in shaping reading outcomes compared to proficiency in children's first language (Scarcella, 2003; Slavin \& Cheung, 2005). Further, research evidence with Spanish-speaking ELLs suggests that teaching ELLs academic vocabulary in their second language (English) is associated with high academic achievement (Francis et al., 2006). With respect to bilingual children who learn Arabic, the research addressing which type of education (bilingual or monolingual) is associated with better reading outcomes is lacking. Looking within Arabic, it would be reasonable to assume that both forms of Arabic (SVA and MSA) play a role in the development of reading. Whereas SVA is needed for multiple purposes such as generational transmission of cultural values and norms, social-communicative purposes, and national identity; MSA is paramount for the continuity of that knowledge across generations. Furthermore, MSA is the medium for studying Arabic language evolution and Arabic language change (as written language has been shown to be less vulnerable to language loss than any oral/spoken language). Future studies should address how early intervention aimed at teaching reading in MSA could lead to positive literacy outcomes. 


\section{The Role of Social-Cultural Context}

Another major direction for future research in Arabic is to go beyond the reading context (word, sentence, or text) to explore the broader social context and the reasons for specific patterns of language use. Parental preference for one language over another and/ or patterns of use of MSA versus SVA need to be examined in future research. Diglossia is a fundamental characteristic of Arabic and is shaped by social-cultural-historical factors that affect the linguistic distance between oral and written language. Diglossia likely leads to difficulties in learning to read, as children who learn diglossic languages like Arabic are more likely to develop poorly specified linguistic representations compared to children who learn non-diglossic languages. Therefore, understanding social-cultural mechanisms of Arabic language use (e.g., opportunity to learn, availability of resources, instructional approaches, teacher development, parent education and beliefs regarding first and second language learning, and home literacy practices) should shed light on the relationship between the oral and written language forms in Arabic. Understanding the circumstances under which children learn language and learn to read are essential for a fuller understanding of the development of reading and reading disabilities in bilingual and monolingual Arabic children.

\section{The Role of Early Intervention}

The majority of research studies on Arabic reading and language development have been conducted with predominantly monolingual school age children. There is much to learn about the development of and reading in Arabic in both monolingual and bilingual children. Although research studies on Arabic early reading and language 
development are lacking, the little available evidence underscores the benefits of early intervention in improving reading outcomes in children who are learning Arabic as their first language (Abu-Rabia, 2000; Feitelson, Goldstein, Iraqi, \& Share,1993; Levin, Saiegh-Haddad, Hende, \& Ziv, 2008), bolstering "the importance of starting small" (Elman et al, 1996, p. 340). Research studies aimed at examining the burgeoning of language and how language mediates the development of reading in Arabic in the early preschool years should be a future research goal.

\section{Conclusion}

This study examined the relationship between phonological, morphological, and semantic (vocabulary) language components and reading outcomes at the word and text comprehension levels in bilingual English-Arabic children. The children attended a charter school and learned English and Arabic as their first and second language, respectively. Consistent with Saiegh-Haddad and Geva (2008), the results revealed associations between phonological awareness skills across English and Arabic. These associations did not hold for morphological awareness skills. Results also revealed that for Arabic and English, phonological awareness predicted word reading accuracy and vocabulary predicted reading comprehension. These findings challenge the notion that phonological awareness must be taught to young children prior to other language components. Rather, the findings support the idea that learning to read is highly shaped by the contributions of multiple components of language that work in concert to enable 
developing children to make meaning from text. Therefore, the process of teaching young children how to read must address all components of language, in addition to phonology.

Consistent with the extended Triangle Model of reading (Bishop Snowling, 2004), this study underscores the importance of experience in learning to read. Some children had diminished experience in Arabic due to their heterogeneous language backgrounds and to Arabic instruction that occurred in a context of restricted oral language experience (given that some children were exposed to Arabic only in school) and reduced exposure to reading, writing, and spelling. As the results suggest, depending on the language and reading task, children relied on a division of labor among various language components to meet the task demands. These conclusions support the importance of language in predicting reading outcomes in bilingual English-Arabic children, whereby enhanced language skills are protective factors and poor language skills are risk factors (Snowling, 2000). 


\section{References}

Abu-Rabia, S. (1997). Reading in Arabic orthography: The effects of vowels and context on reading accuracy of poor and skilled native Arabic readers. Reading and Writing: An Interdisciplinary Journal, 9, 65-78.

Abu-Rabia, S. (2000). Effects of exposure to literary Arabic on reading comprehension in a diglossic situation. Reading \& Writing: An Interdisciplinary Journal, 13 (1-2), 147-157.

Abu-Rabia, S. (2001). The role of vowels in reading Semitic scripts: data from Arabic and Hebrew. Reading and Writing: An Interdisciplinary Journal, 14, 39-59.

Abu-Rabia, S., Share, D., \& Mansour, M. (2003). Word recognition and basic cognitive processes among reading-disabled and normal readers in Arabic. Reading \& Writing, 16, 423-442.

Abu-Rabia, S., \& Taha, H. (2004). Reading and spelling error analysis of native Arabic dyslexic readers. Reading and Writing: An Interdisciplinary Journal, 17, 651-689.

Adams, M. (1990). Beginning to read: Thinking and learning about print. Cambridge, MA: MIT Press.

Alexander, P. (2005/2006). The path to competence: A lifespan developmental perspective on reading. Journal of Literacy Research, 37 (4), 413-436.

Anthony, J., \& Francis, D. (2005). Development of phonological awareness. Current Directions in Psychological Science, 14 (5), 255-259.

Arab-Moghaddam, N., \& Sénéchal, M. (2001). Orthographic and phonological processing skills in reading and spelling in Persian/English bilinguals. International Journal of Behavioral Development, 25(2), 140-147.

August, D., \& Shanahan, T. (2006). Developing literacy in second-language 
learners: Report of the National Literacy Panel on language-minority children and youth. Mahwah, NJ: Erlbaum.

Ayari, S. (1996). Diglossia and illiteracy in the Arab world. Language, Culture, and Curriculum, 9, 243-253.

Bishop, D., \& Snowling, M. (2004). Developmental dyslexia and specific language impairment: same or different? Psychological Bulletin, 130, 858-888.

Brady, S. \& Shankweiler, D. (1991). Phonological processes in literacy. Hillsdale, NJ: Erlbaum.

Breznitz, Z. (2001). The determinants of reading fluency: A comparison of dyslexic and average. In M. Wolf (Ed.), Dyslexia, Fluency, and the Brain. Timonium, MD: York Press.

Cain, K. \& Oakhill, J. (2007). Children's comprehension problems in oral and written language: A cognitive perspective. New York: Guilford Press.

Carlisle, J. (2000). Awareness of the structure and meaning of morphologically complex words: Impact on reading. Reading \& Writing: An interdisciplinary Journal, 12, 169-190.

Carlisle, J., \& Stone, A. (2005). Exploring the role of morphemes in word reading. Reading Research Quarterly, 40 (4), 428-449.

Catts, H., \& Hogan, T. (2003). Language basis of reading disabilities and implications for early identification and remediation. Reading Psychology, 24, 223-246.

Cohen, J. (1988). Statistical power analysis for the behavioral sciences (2nd ed.), Hillsdale, New Jersey: Lawrence Erlbaum.

Cook, T, \& Campbell, D. (1979). Quasi-Experimentation: Design and Analysis for Field Settings. Rand McNally: Chicago, Illinois.

Cunningham, A., \& Stanovich, K. (1991). Assessing print exposure and orthographic 
processing in children: Associations with vocabulary, general knowledge, and spelling. Journal of Educational Psychology, 83, 423-441.

Cutting, L., \& Scarborough, H. (2006). Prediction of reading comprehension: Relative contribution of word recognition, language proficiency, and other cognitive skills can depend on how comprehension is measured. Scientific Studies of Reading, 10 (3), 277299.

Deacon, H., \& Kirby, J. (2004). Morphological awareness: Just “:more phonological”? The role s of morphological and phonological awareness in reading development. Applied Psycholinguistics, 25, 223-238.

De Jong, P., \& Van der Leij., A. (1999). Specific contributions of phonological abilities to early reading acquisition. Results from a Dutch latent variable longitudinal study. Journal of Educational Psychology, 91, 450-76.

Diamond, A. (2007). Interrelated and interdependent. Developmental Science, 10 (1), $152-158$.

Droop, M., \& Verhooven, L. (2003). Language proficiency and reading ability in firstand second-language learners. Reading Research Quarterly, 38, 78-103.

Duncan, L., Casalis, S., \& Cole, P. (2009). Early metalinguistic awareness of derivational morphology: Observations from a comparison of English and French. Applied Psycholinguistics, 30 (3), 405-440.

Durgunoglu, A. (2002). Cross-linguistic transfer in literacy development and implications for language learners. Annals of Dyslexia, 2, 189-204.

Durgunoglu, A., Nagy, W., \& Hansen-Bhatt, B. (1993). Cross-language transfer of phonological awareness. Journal of Educational Psychology, 85, 453-465. 
Elbeheri, G., \& Everatt, J. (2007). Literacy ability and phonological processing skills amongst dyslexic and non-dyslexic speakers of Arabic. Reading and Writing: An Interdisciplinary Journal, 20 (3), 273-294.

Elbro, C., \& Arnbak, E. (1996). The role of morpheme recognition and morphological awareness in dyslexia. Annals of Dyslexia, 46, 209-240.

Fowler, A., \& Liberman, I. (1995). The role of phonology and orthography in morphological awareness. In L. B. Feldman (Ed.) Morphological aspects of language processing. (pp. 157-188). Hillsdale, NJ: Erlbaum.

Francis, D. J., Rivera, M., Lesaux, N., Kieffer, M., \& Rivera, H. (2006). Practical guidelines for the education of English language learners: Research-based recommendations for instruction and academic interventions. Houston, TX: Center on Instruction.

Geva, E., \& Wang, M. (2001). The role of orthography in the literacy acquisition of young L2 learners. Annual Review of Applied Linguistics, 21, 182-204.

Gombert, J. E. (1992). Metalinguistic Development. Chicago, IL: University of Chicago Press.

Goswami, U., \& Bryant, P. (1990). Phonological skills and learning to read. Hillsdale, NJ : Erlbaum.

Hammer, C., Lawrence, F., \& Miccio, A. (2004). Bilingual children's language abilities and early reading outcomes in Head Start and kindergarten. Language, Speech, and Hearing Services in Schools, 38, 237-248.

Koda, K., \& Zehler, A. (eds.) (2008). Learning to read across languages: Crosslinguistic relationships in first- and second-language literacy development. New York, NY: Routledge.

Ku, Y., \& Anderson, R. (2003). Development of morphological awareness in Chinese 
and English. Reading and Writing: An International Journal, 16, 399-422.

Levin, I., Saiegh-Haddad, E., Hende, N., \& Ziv, M. (2008). Early literacy in Arabic: An intervention study among Israeli Palestinian kindergartners. Applied Psycholinguistics, 29, 413-436.

Liberman, I. (1973). Segmentation of the spoken word. Bulletin of the Orton Society, 23, 65-77.

MacGinitie, W., MacGinitie, R., Maria, K., \& Dryer, L. (2000). Gates-MacGinitie Reading Tests ( $4^{\text {th }}$ ed.). Itasca, IL: Riverside.

Mahoney, D., Singson, D., \& Mann, V. (2000). Reading ability and sensitivity to morphological relations. Reading and Writing: An Interdisciplinary Journal, 12, 191218.

McCarthy, J. (1985). Formal problems in Semitic phonology and morphology. New York, NY: Garland Publishing, Inc.

Nagy, W., Berninger, V., \& Abbott, R. (2006). Contributions of morphology beyond phonology to literacy outcomes of upper elementary and middle-school students. Journal of Educational Psychology, 98, 134-147.

Nagy, W., Herman, P. \& Anderson, R. (1985). Learning words from context. Reading Research Quarterly, 20, 233-253.

Nation, K, \& Snowling, M. (2004). Beyond phonological skills: Broader language skills contribute to the development of reading. Journal of Research in Reading, 27, 342-356.

Nation, K., Snowling, M., \& Clarke, P. (2007). Dissecting the relationship between language skills and learning to read: Semantic and phonological contributions to new vocabulary learning in children with poor reading comprehension. Advances in SpeechLanguage Pathology, 9 (2), 131-139. 
Perfetti, C. (1985). Reading ability. New York: Oxford University Press.

Perfetti, C. (2003). The universal grammar of reading. Scientific studies of reading, 7 (1), 3-24.

Perfetti, C., \& Dunlap, S. (2008). Learning to read: General principles and writing systems variations. In K. Koda and A. Zehler (Eds.), Learning to read across languages: Cross-linguistic relationships in first- and second-language literacy development. (pp 13-38). New York, NY: Lawrence Erlbaum.

Perfetti, C. \& Zhang, S. (1995). Very early phonological activation in Chinese reading. Journal of Experimental Psychology: Learning, Memory, \& Cognition, 21(1), 24-33.

Pinker, S. \& Prince, A. (1988). On language and connectionism. Cognition, 28, 73-193.

Roth, F., Speece, D., \& Cooper, D. (2002). A longitudinal analysis of the connection between oral language and early reading. Journal of Educational Research, 95 (5), 259272.

Saiegh-Haddad, E. (2003). Linguistic distance and initial reading acquisition: The case of Arabic diglossia. Applied Psycholinguistics, 24, 431-451.

Saiegh-Haddad, E. (2004). The impact of phonemic and lexical distance on the phonological analysis of words and pseudowords in a diglossic context. Applied Psycholinguistics, 25, 495-512.

Saiegh-Haddad, E. (2007). Linguistic constraints on children's ability to isolate phonemes Arabic. Applied Psycholinguistics, 28, 607-625.

Saiegh-Haddad, E., \& Geva, E. (2008). Morphological awareness, phonological awareness, and reading in English-Arabic bilingual children. Reading and Writing: An Interdisciplinary Journal, 21, 481-504.

Scarcella, R. C. (2003). Accelerating academic English: A focus on English Language 
Learners. Oakland, CA: Regents of the University of California.

Seidenberg, M. \& McClelland, J. (1989). A distributed developmental model of word recognition and naming. Psychological Review, 96, 523-568.

Seigneuric, A., \& Ehrlich, M. (2005). Contribution of working memory capacity to children's reading comprehension: A longitudinal investigation. Reading and Writing: An Interdisciplinary Journal, 18, 617-656.

Share, D. (2008). On the anglocentricities of current reading research and practice: the perils of overreliance on an outlier orthography. Psychological Bulletin, 134, 584-615.

Slavin, R., \& Cheung, A. (2005). A synthesis of research on language of reading instruction for English language learners. Review of Educational Research, 75, 247-284.

Snowling, M. (2000). Dyslexia. Blackwell: Oxford.

Stahl, S. (1999). Vocabulary development. Cambridge, MA: Brookline Books.

Stanovich, K. (2000). Progress in understanding reading: Scientific foundations and new frontiers. New York: Guilford Press.

Stevens, J. (1996). Applied multivariate statistics for the social sciences (3rd ed.). Hillsdale, NJ: Erlbaum.

Tabachnick, B., \& Fidell, L. (2007). Using multivariate statistics $\left(5^{\text {th }}\right.$ ed.). Boston, MA: Allyn \& Beacon.

Thorndike, R. (1973). Reading comprehension education in fifteen countries. New York: Wiley.

Torgesen, J., Wagner, R., Rashotte, C., Burgess, S., \& Hecht, S. (1997). The contributions of phonological awareness and rapid automatic naming ability to the growth of word reading skills in second to fifth grade children. Scientific Studies of Reading, 1, 161-185. 
Wagner, R., \& Torgesen, J. (1987). The nature of phonological processing and its causal role in the acquisition of reading skills. Psychological Bulletin, 101, 192-212.

Wagner, R., Torgesen, J., \& Rashotte, C. (1999). Comprehensive test of phonological processing. Austin, TX: PRO-ED.

Wechsler, D. (1992). Wechsler Individual Achievement Test. San Antonio, TX: Psychological Corporation.

Wiederholt, L., Bryant, B. (1992). Examiners' manual: Gray Oral Reading Test-3. Austin, TX: Pro-Ed.

Wilkinson, G., \& Robertson, G. (1984). Wide Range Achievement Test 4 professional manual. Lutz, FL: Psychological Assessment Resources.

Wimmer, H., \& Goswami, U. (1994). The influence of orthographic consistency on reading development-Word recognition in English and German children. Cognition, 51, 91-103.

Wolf, M. (2007). Proust and the Squid: The Story and Science of the Reading Brain. pp. 308. New York: HarperCollins Publishers.

Wolf, M., \& Bowers, P. (1999). The double-deficit hypothesis for the developmental dyslexias. Journal of Educational psychology, 91 (3), 415-438.

Wolf, M., \& Katzir-Cohen, T. (2001). Reading fluency and its intervention. Scientific Studies of Reading, 5, 211-239.

Woodcock (1987/1998). The Woodcock reading Mastery Tests-Revised-Normative Update. Circle Pines, MN: American Guidance Service.

Ziegler, J., \& Goswami, U. (2005). Reading acquisition, developmental dyslexia, and skilled reading across languages: A psycholinguistic grain size theory. Psychological Bulletin, 131(1), 3-29. 


\section{APPENDIXES}

APPENDIX A

English Morphological Awareness (Relatedness) Test: Duncan, Casalis, \& Cole (2009)

adapted from Mahoney et al. (2000).

Directions: "Now you will hear pairs of words. I want you to tell me if the two words are related. That is, if the second word comes from the first. For each pair of words, say YES if you think the two words are related to each other, and $\mathrm{NO}$ if you think the words are not related to each other."

Practice Items:

\begin{tabular}{|c|c|}
\hline ems & Correct Response \\
\hline Region-Regiona & (yes) \\
\hline Let-Letter & (No) \\
\hline ural & (yes) \\
\hline
\end{tabular}

If correct, say "That's right because Regional comes from the word Region; they are related. Now try the next pair of words."

If incorrect, say "That's not quite right because Letter has nothing to do with Let. It's just by accident that the words start with the same sounds. The correct answer is ---_--.. Let's try another pair."

Do you have any questions about what you are supposed to do?

\begin{tabular}{|c|c|c|c|}
\hline Test Items & $\begin{array}{c}\text { Score } \\
(1 / 0)\end{array}$ & Test Items & $\begin{array}{c}\text { Score } \\
(1 / 0)\end{array}$ \\
\hline $\begin{array}{l}\text { 1. Kit, kitten } \\
\text { Foil }\end{array}$ & & $\begin{array}{l}\text { 2. Mess, message } \\
\text { Foil }\end{array}$ & \\
\hline $\begin{array}{l}\text { 3. Tour, tourist } \\
\text { Target }\end{array}$ & & $\begin{array}{l}\text { 4. Pack, package } \\
\text { Target }\end{array}$ & \\
\hline $\begin{array}{l}\text { 5. Act, actor } \\
\text { Target }\end{array}$ & & $\begin{array}{l}\text { 6. Swim, swimmer } \\
\text { Target }\end{array}$ & \\
\hline $\begin{array}{l}\text { 7. Pet, petal } \\
\text { Foil }\end{array}$ & & $\begin{array}{l}\text { 8. Lad, ladder } \\
\text { Foil }\end{array}$ & \\
\hline $\begin{array}{l}\text { 9. Tail, tailor } \\
\text { Foil }\end{array}$ & & $\begin{array}{l}\text { 10. Rock, rocket } \\
\text { Foil }\end{array}$ & \\
\hline $\begin{array}{l}\text { 11.Cab, cabbage } \\
\text { Foil }\end{array}$ & & $\begin{array}{l}\text { 12. Ham, hammer } \\
\text { Foil }\end{array}$ & \\
\hline $\begin{array}{l}\text { 13.Van, vandal } \\
\text { Foil }\end{array}$ & & $\begin{array}{l}\text { 14. Beg, beggar } \\
\text { Target }\end{array}$ & \\
\hline $\begin{array}{l}\text { 15. Gold, golden } \\
\text { Target }\end{array}$ & & $\begin{array}{l}\text { 16. Pass, passage } \\
\text { Target }\end{array}$ & \\
\hline $\begin{array}{l}\text { 17. Art, artist } \\
\text { Target }\end{array}$ & & $\begin{array}{l}\text { 18. Sail, sailor } \\
\text { Target }\end{array}$ & \\
\hline $\begin{array}{l}\text { 19. Heat, heater } \\
\text { Target }\end{array}$ & & $\begin{array}{l}\text { 20. Sum, Summer } \\
\text { Foil }\end{array}$ & \\
\hline
\end{tabular}




\section{APPENDIX B}

English Morphological Awareness: Complex Word Reading Fluency: Items are adapted from Duncan, Casalis, \& Cole (2009) and Mahoney et al. (2000).

Directions: "Please read the following pairs of words as fast as you can." If the child stops or hesitates at any point, encourage her/him by saying "go to the next item."

No Feedback is provided throughout administration of this measure. Begin recording time when the child begins to read and stop when the child has read all items in the subtest.

\begin{tabular}{|c|c|c|c|}
\hline Test Items & $\begin{array}{c}\text { Score } \\
(\mathbf{1} / \mathbf{0})\end{array}$ & Test Items & $\begin{array}{c}\text { Score } \\
\mathbf{( 1 / 0 )}\end{array}$ \\
\hline 1. Kit, kitten & & 2. Mess, message & \\
\hline 3. Tour, tourist & & 4. Pack, package & \\
\hline 5. Act, actor & & 6. Swim, swimmer & \\
\hline 7. Pet, petal & & 8. Lad, ladder & \\
\hline 9. Tail, tailor & & 12. Ham, hammer & \\
\hline 11. Cab, cabbage & & 14. Beg, beggar & \\
\hline 13. Van, vandal & & 16. Pass, passage & \\
\hline 15. Gold, golden & & 18. Sail, sailor & \\
\hline 17. Art, artist & & 20. Sum, Summer & \\
\hline 19. Heat, heater & & & \\
\hline
\end{tabular}




\section{APPENDIX C}

Arabic Phonological Processing: Blending —Adapted from Taha \& Saiegh-Haddad (2008) كلمه درج

$\mathrm{T}+\mathrm{x}+\mathrm{\mu}+\mathrm{x}+\mathrm{u}$

كلمه عله

$J+x+w+x+\varepsilon$

\begin{tabular}{|c|c|c|}
\hline إجابة الطالب & الأجابة المتوقعة & الكلمة \\
\hline$-1+$ & 1. بَيْت & تب \\
\hline$-1+$ & 2. عَضل & J+x \\
\hline$-/+$ & 3.طالِب & ط \\
\hline$-/+$ & 4.كانون & كأك + \\
\hline$-/+$ & 5.دُرْج & ج \\
\hline$-/+$ & 6.شَنْع & $\varepsilon+\beta+x+$ ش \\
\hline$-/+$ & 7. قلم & ق \\
\hline$-/+$ & 8. ضنباب & ض +x + + + + + + \\
\hline$-/+$ & 9. ظالِم & ط \\
\hline$-/+$ & 10. عَصير & ع ع ص + ص + \\
\hline$-1+$ & 11. شَارع & $\varepsilon+x+\jmath+1+$ ش \\
\hline$-/+$ & 12. جارور & ج+ \\
\hline$-1+$ & 13.جسز & ج \\
\hline$-/+$ & 14.عُشْب & \\
\hline$-1+$ & 15. قُمَر & $2+x+5+x+3$ \\
\hline$-/+$ & 16. مرَض & م ض \\
\hline$-/+$ & 17. طارق & b+ \\
\hline$-1+$ & 18. صنباح & ص +x+c+ \\
\hline$-1+$ & 19. حَجر & $\jmath+x+z+x+z$ \\
\hline$-1+$ & 20. عَزيز & $j+ي+j+x+\varepsilon$ \\
\hline
\end{tabular}




\section{APPENDIX D}

Saiegh-Haddad (2008): Phonological Processing_Elision Test

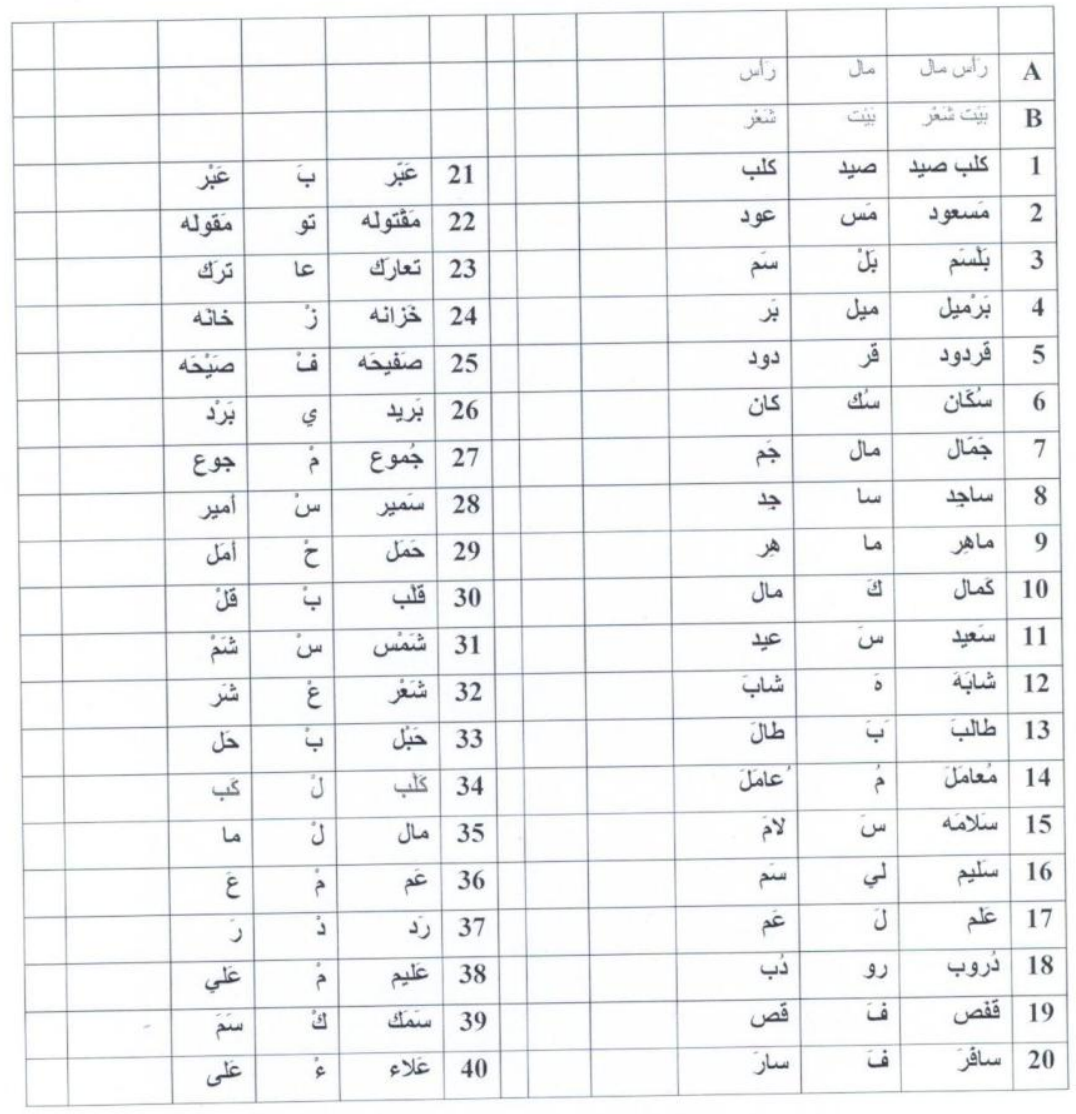




\section{APPENDIX E}

Taha \& Saiegh-Haddad (2008) Morphological Awareness: Relatedness Task

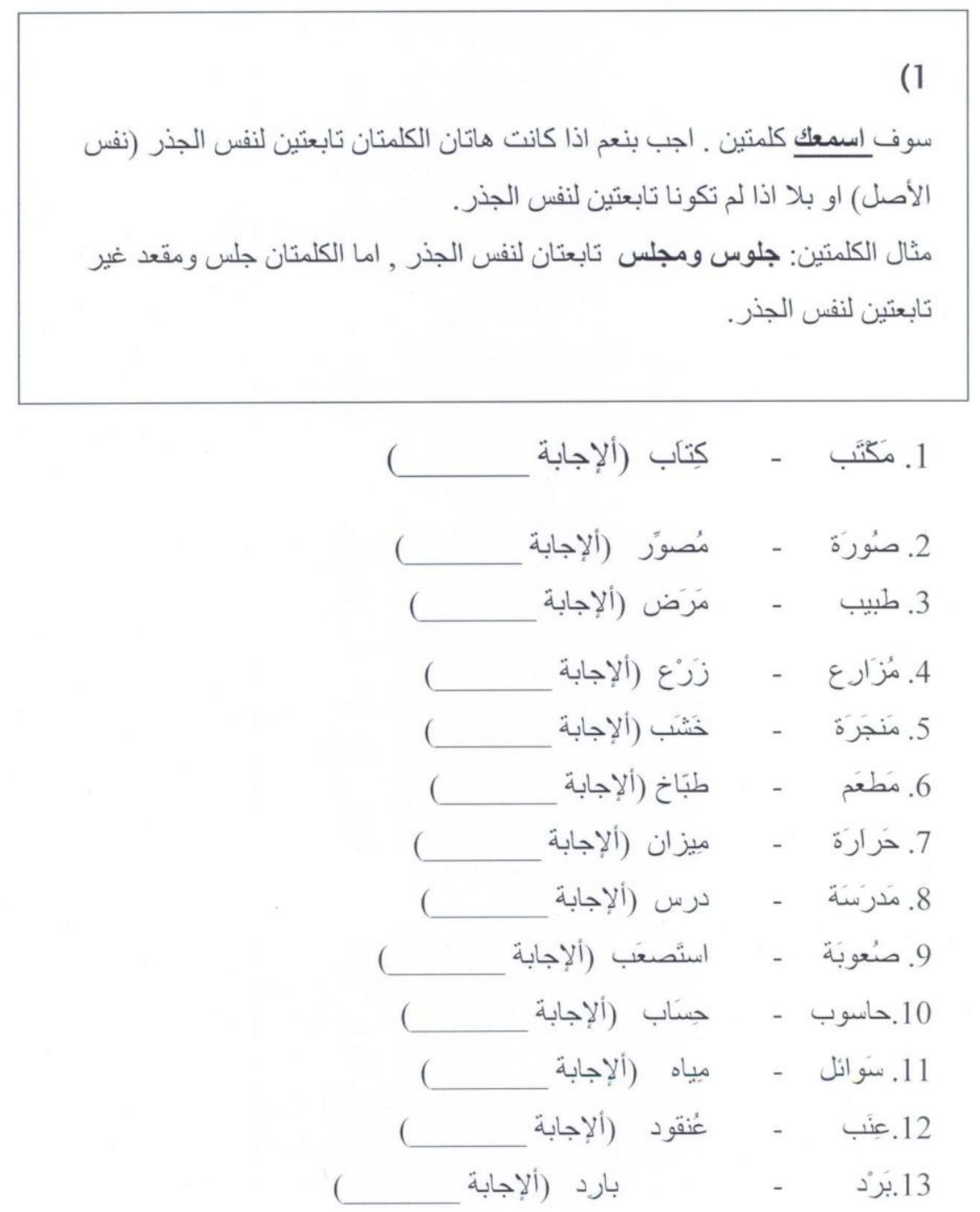




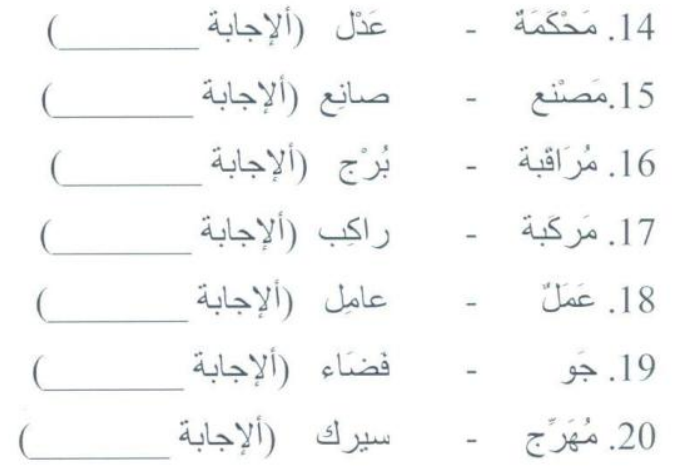




\section{APPENDIX F}

\section{Word Recognition (Vowelized)}

2) امامك قائمة كلمات، عليك قر اتها بصوت مسمو ع بشكل سريع ودقيق. إبدأ بالقر اءة عندما أطلب منك:((للفاحص: إبدأ بقياس الوقت عند البدء في القراءة. كل كلمة ثقر أخطأ ضع تحتها خطاً).

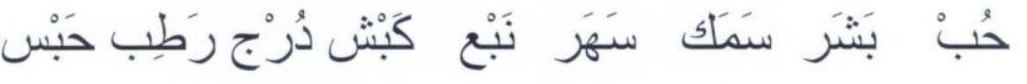

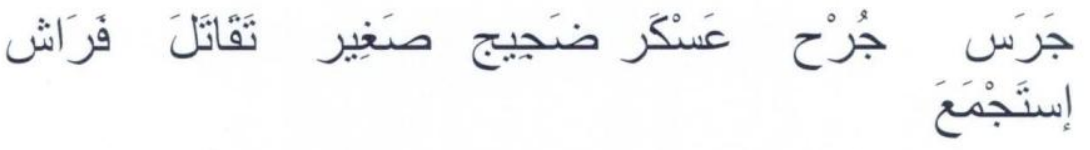

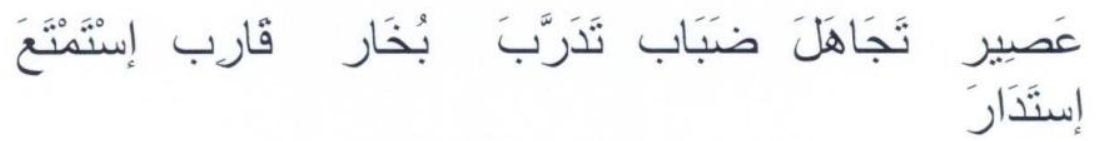

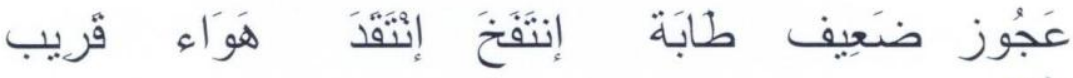

ظذان

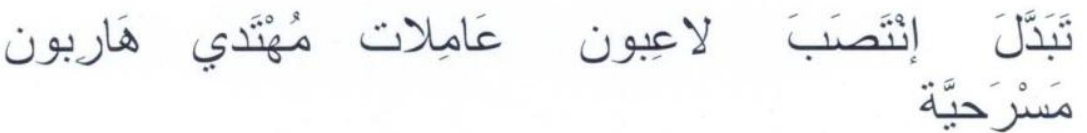




\section{Word Recognition (Unvowelized)}

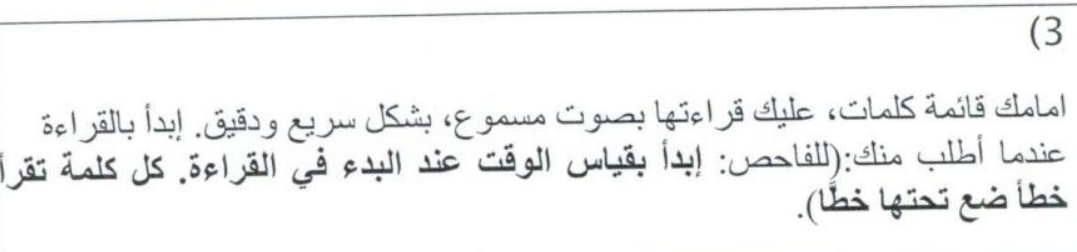

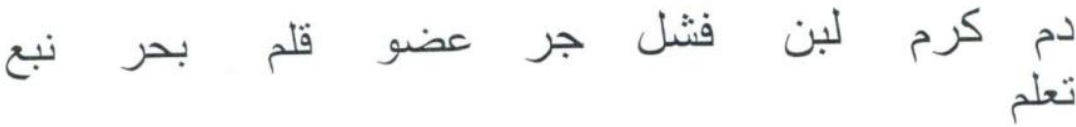

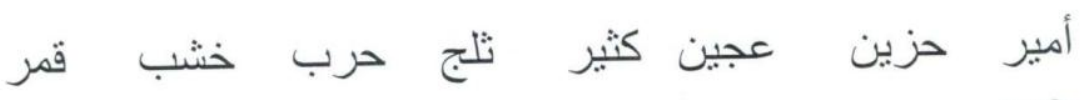

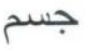

مطرب

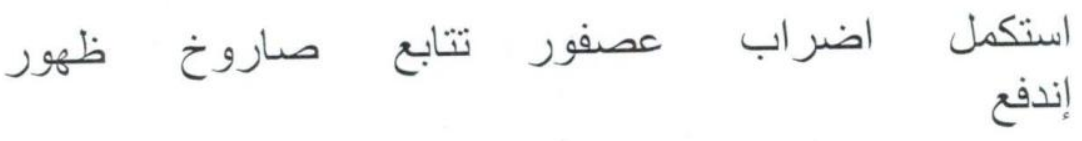

إنتصر خ إنتصر تمثيلية جماعة مؤتمر إختر إع 


\section{APPENDIX G}

Taha \& Saiegh-Haddad (2008)

Pseudoword Decoding

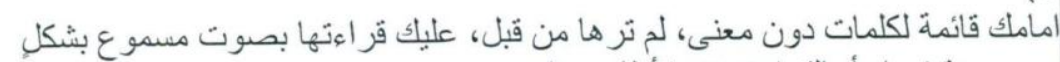

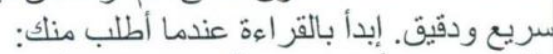

(للفاحص: إبدأ بقياس الوقتت عند البدء في القراءة. كل كلمة تقر أخطأ ضع تحتها خطا).

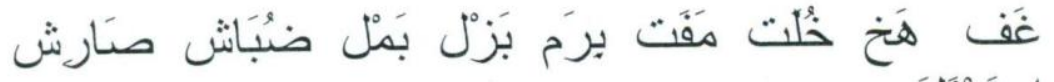
إسنَّعْفَلَ

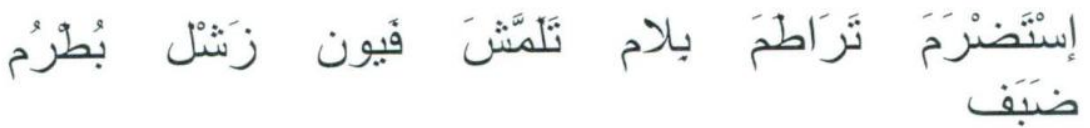

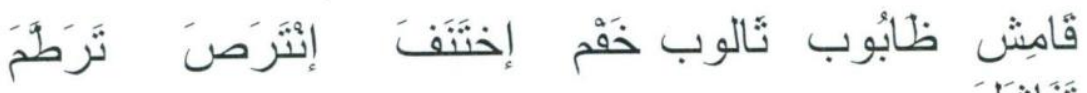

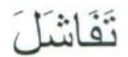

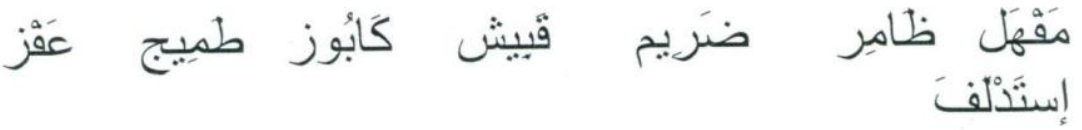

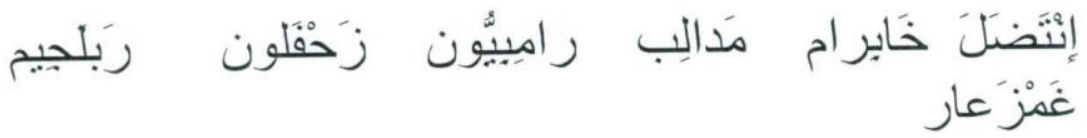




\section{APPENDIX H}
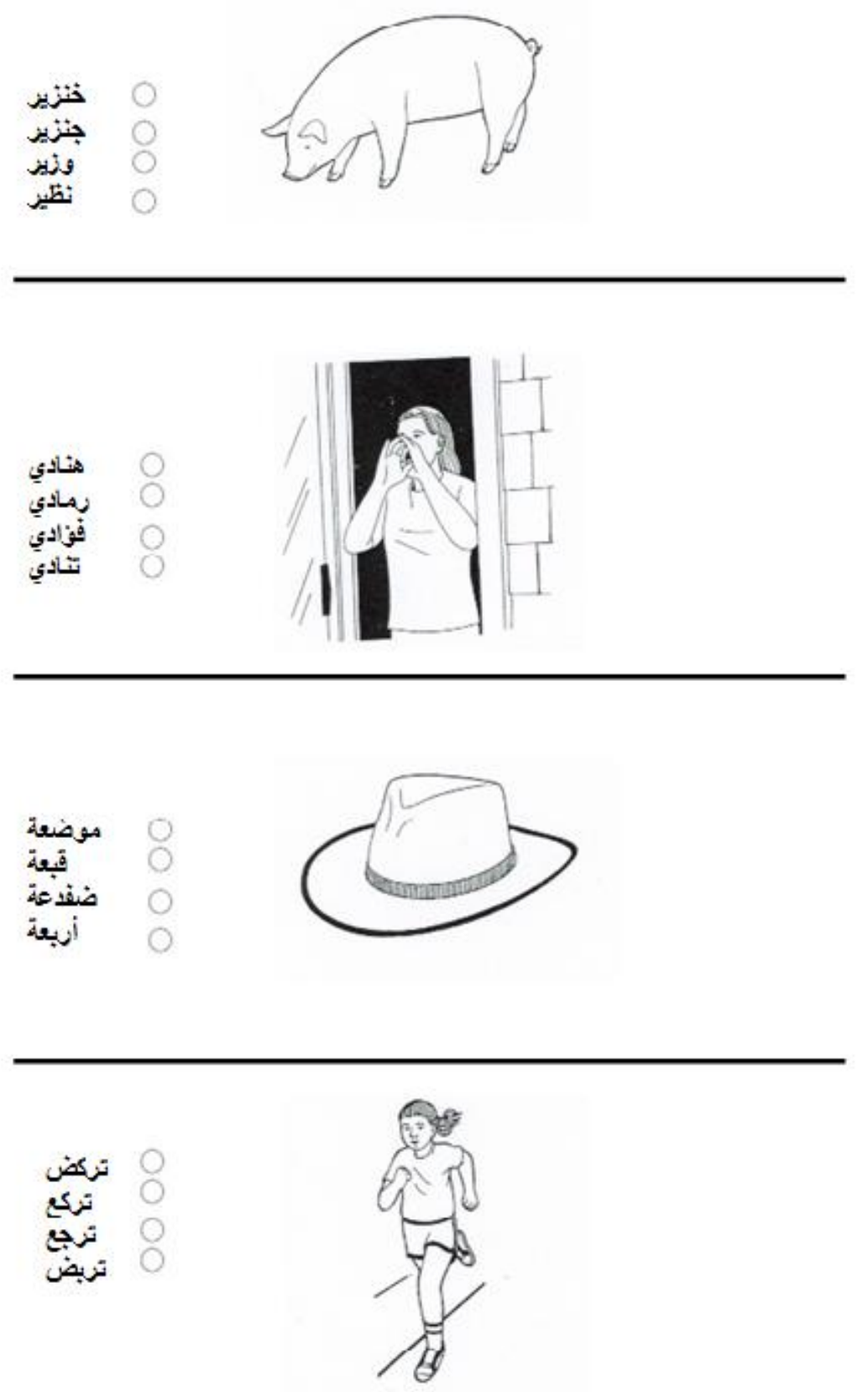


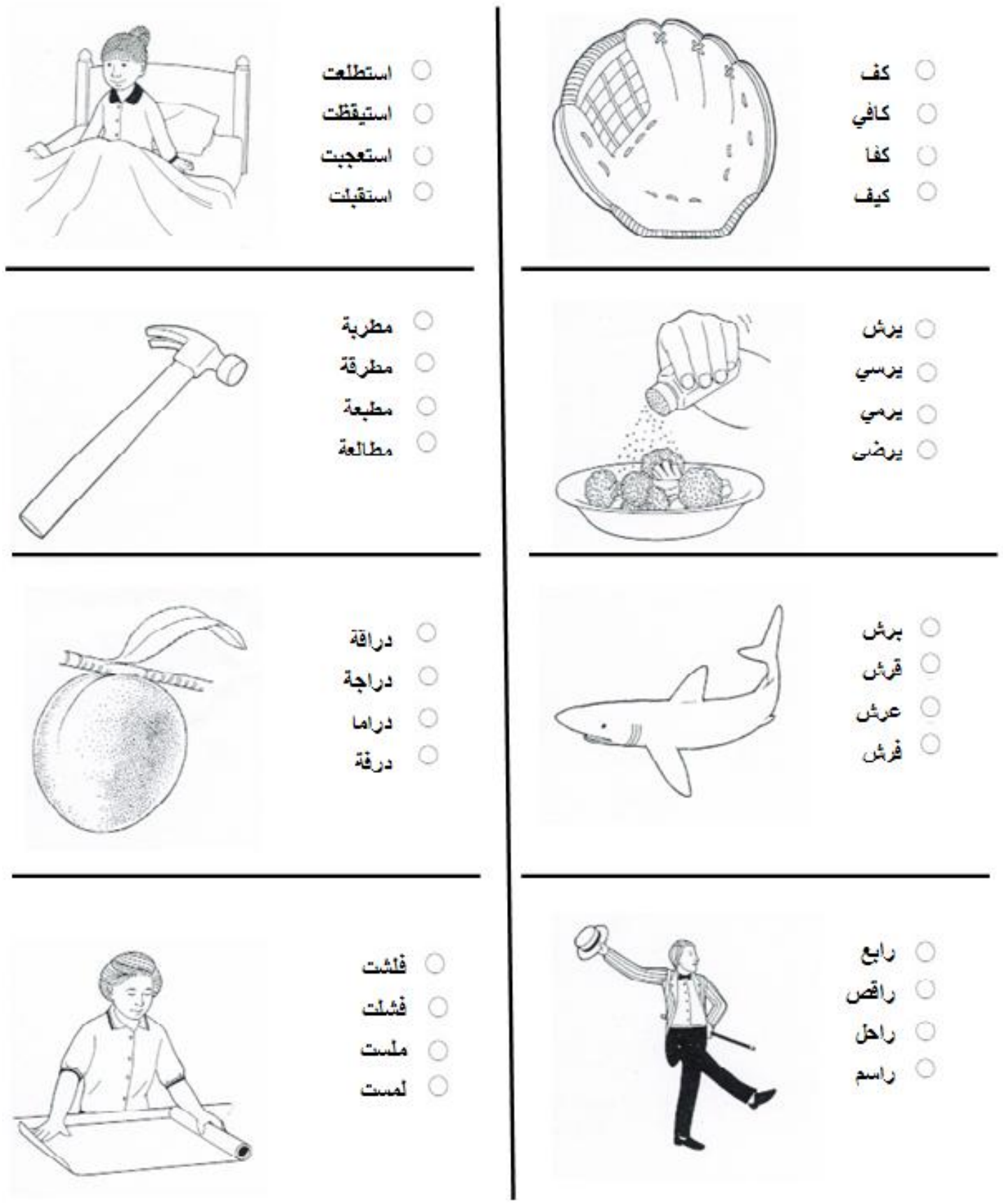




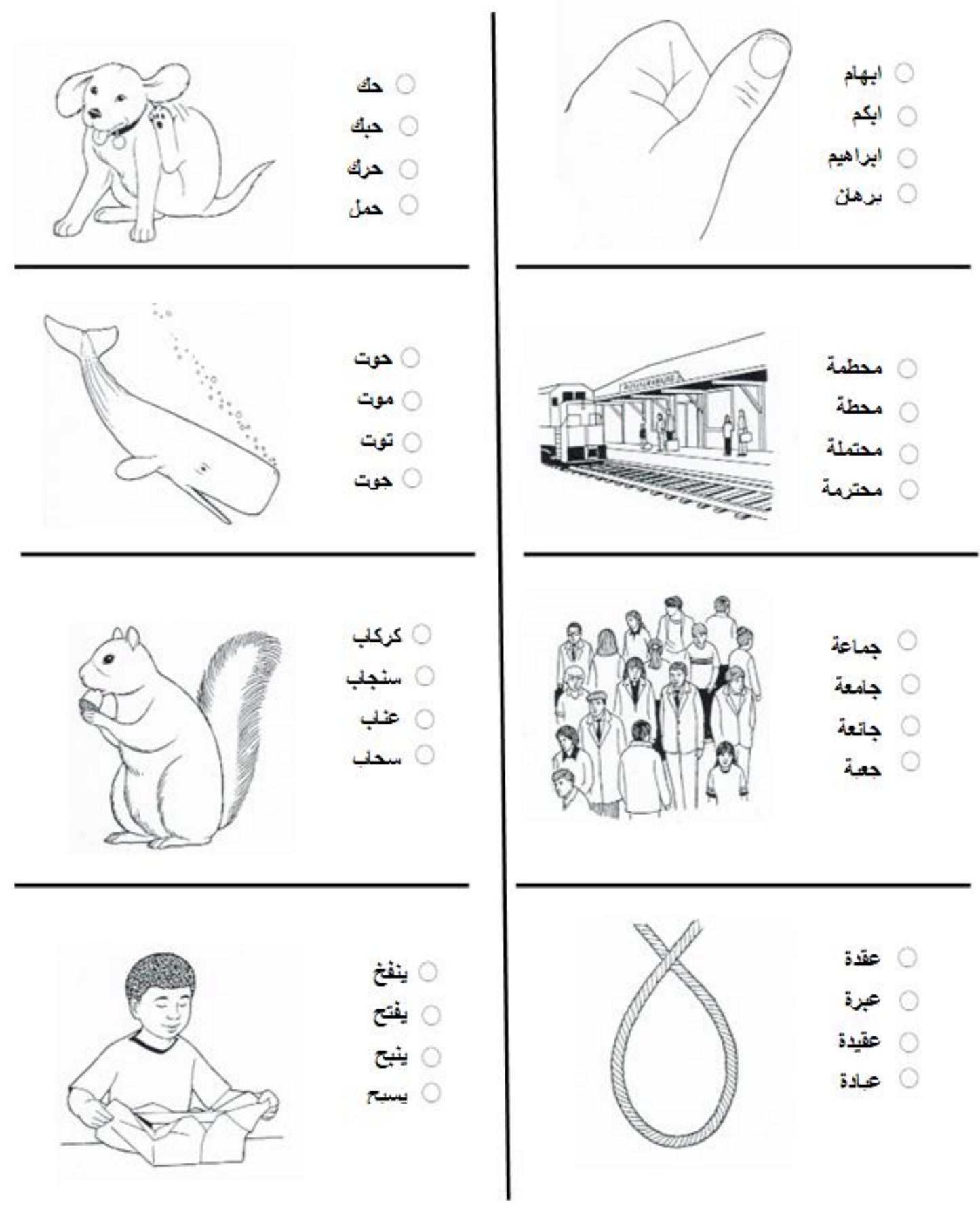



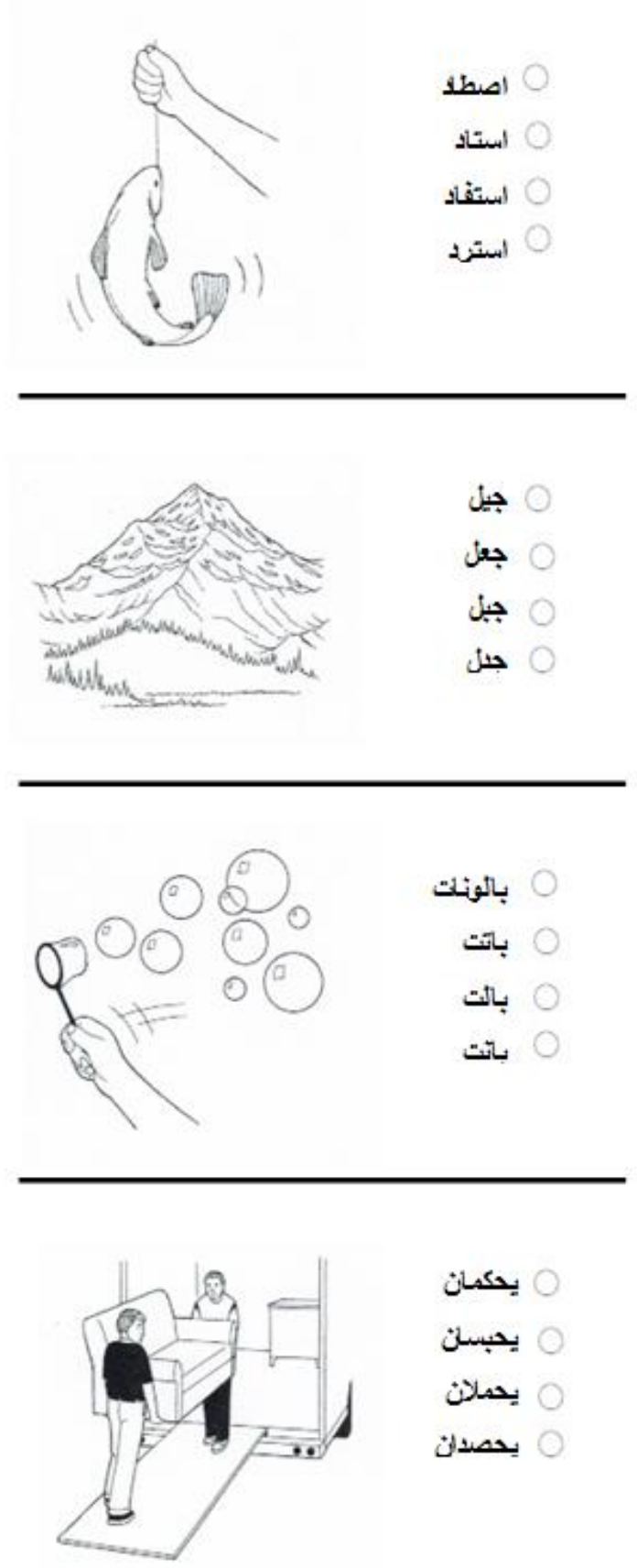
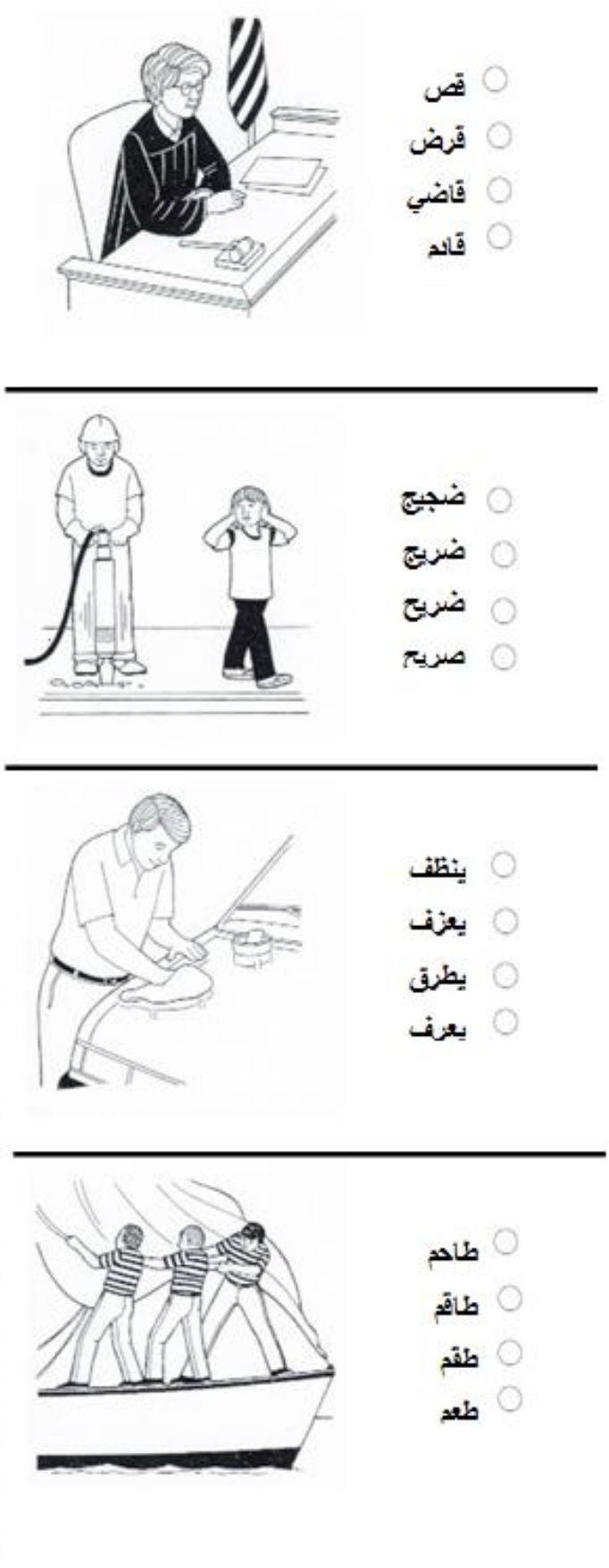


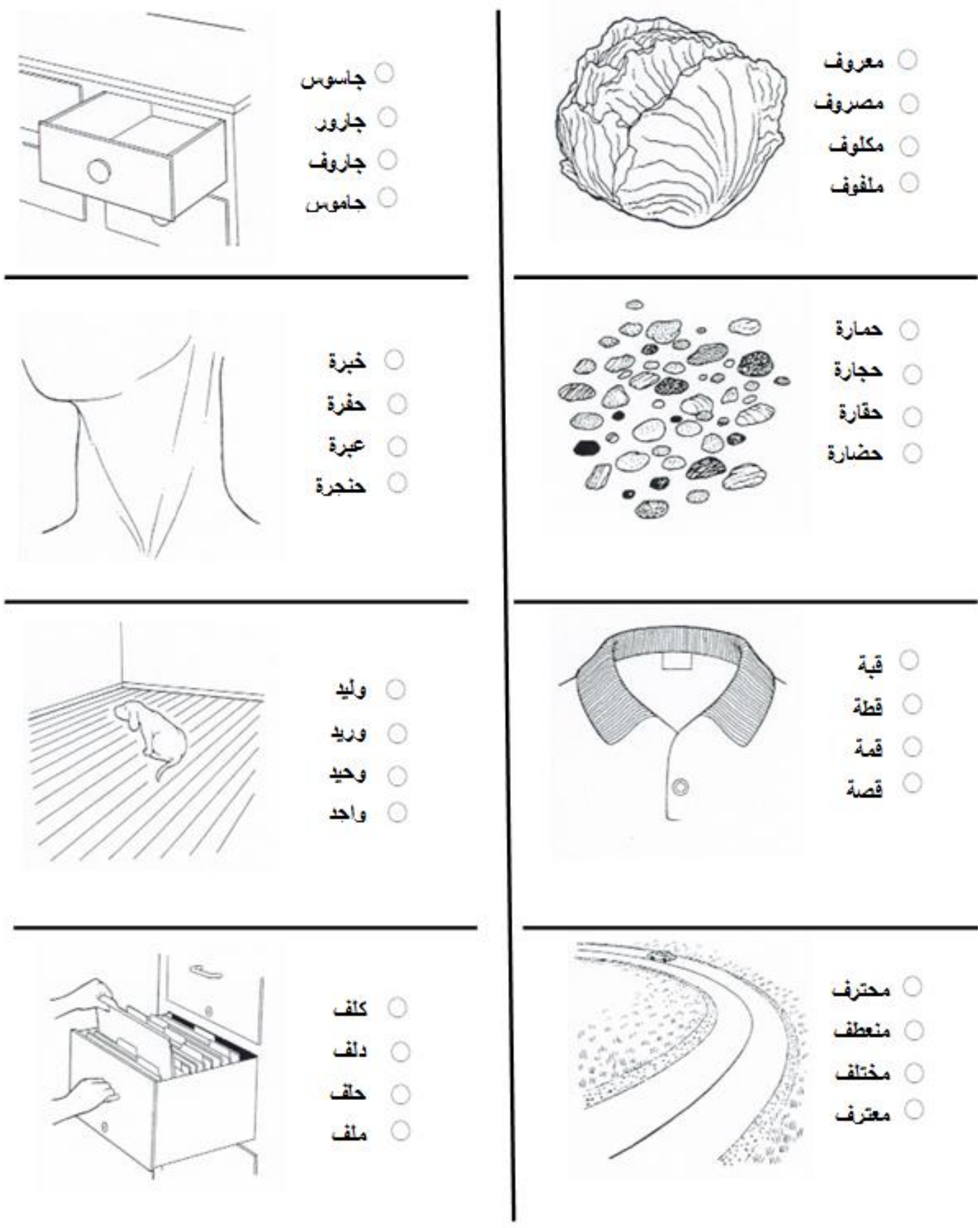




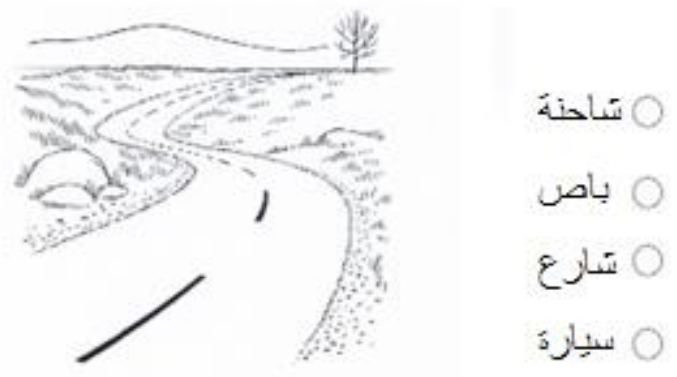

STOP 


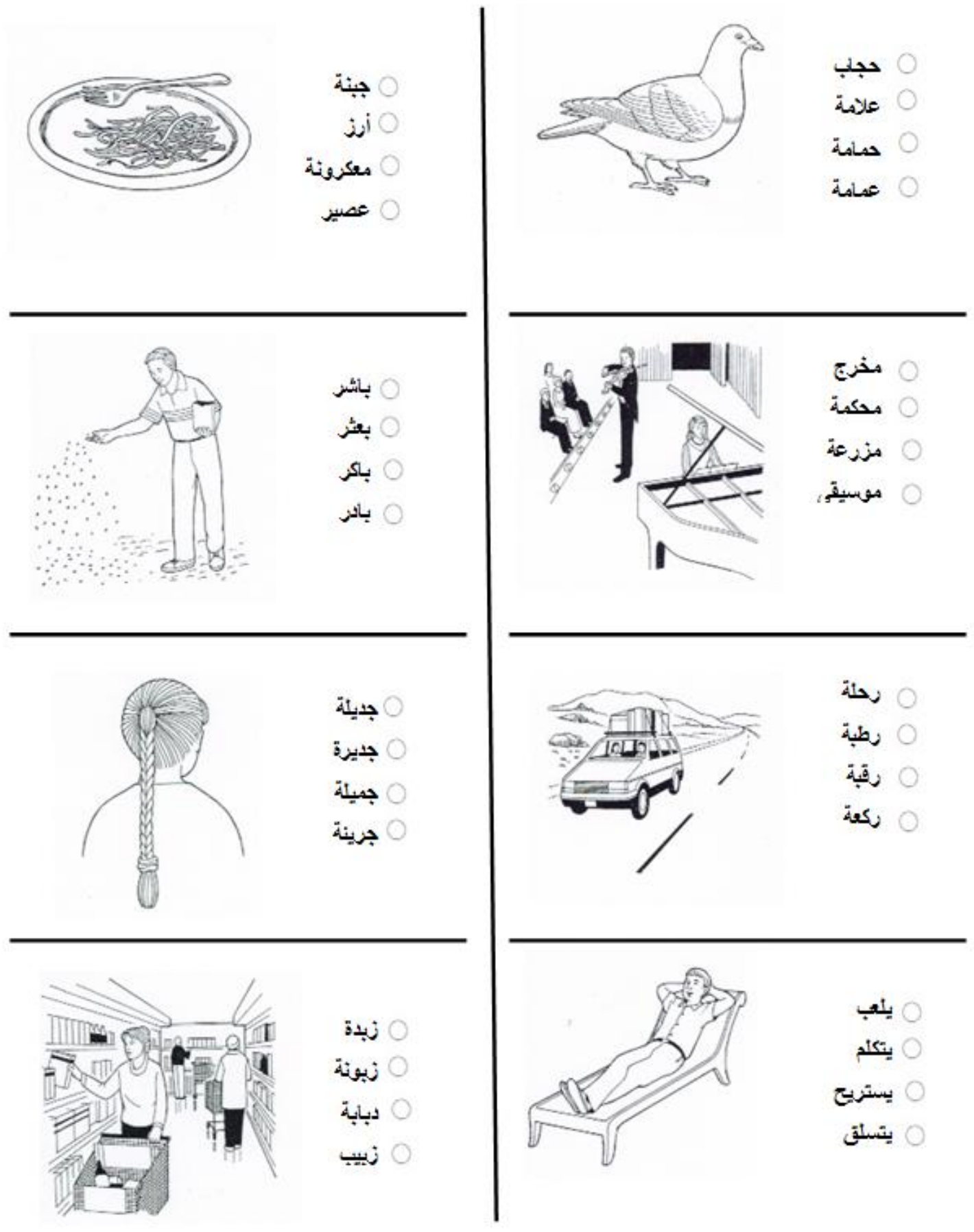



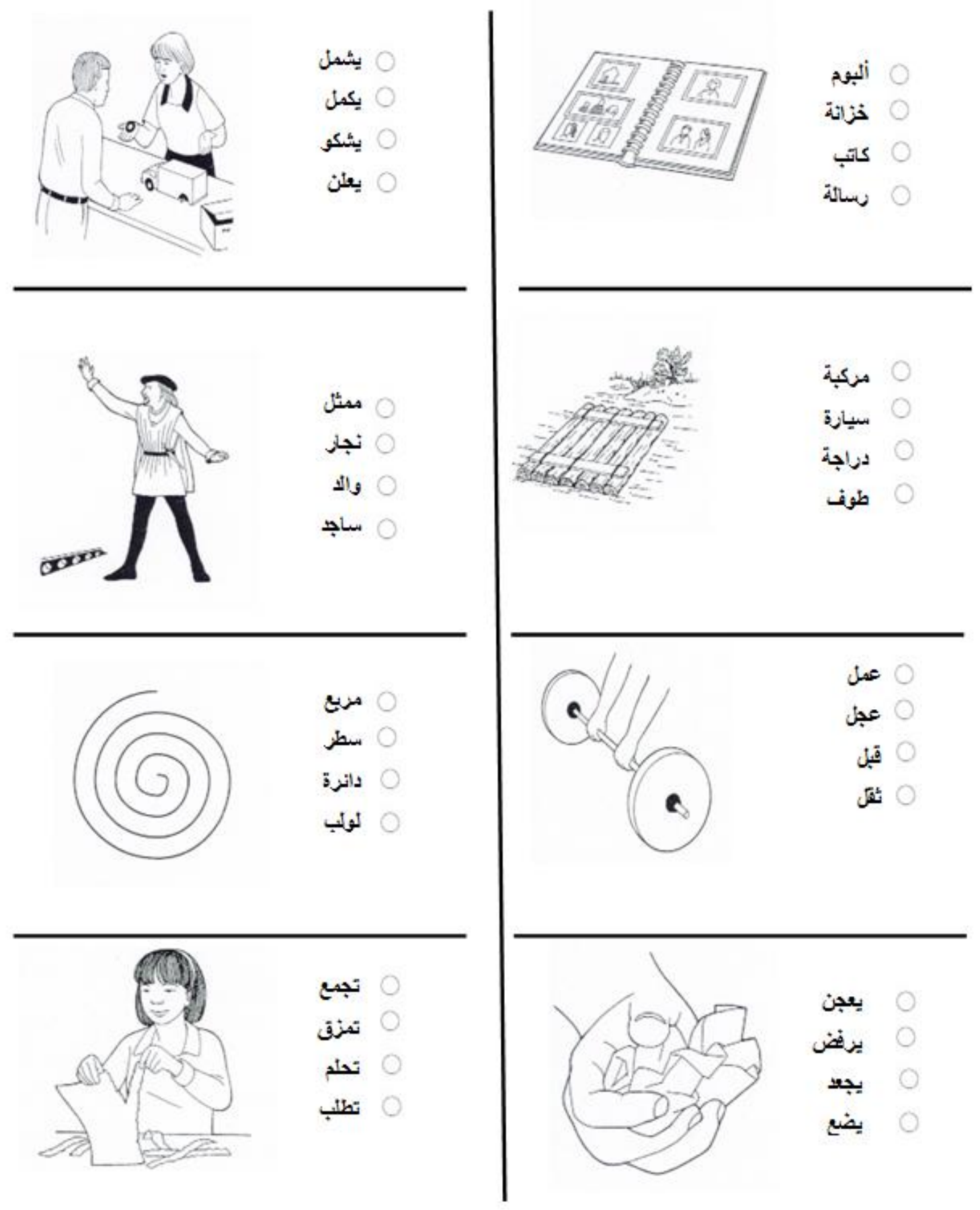

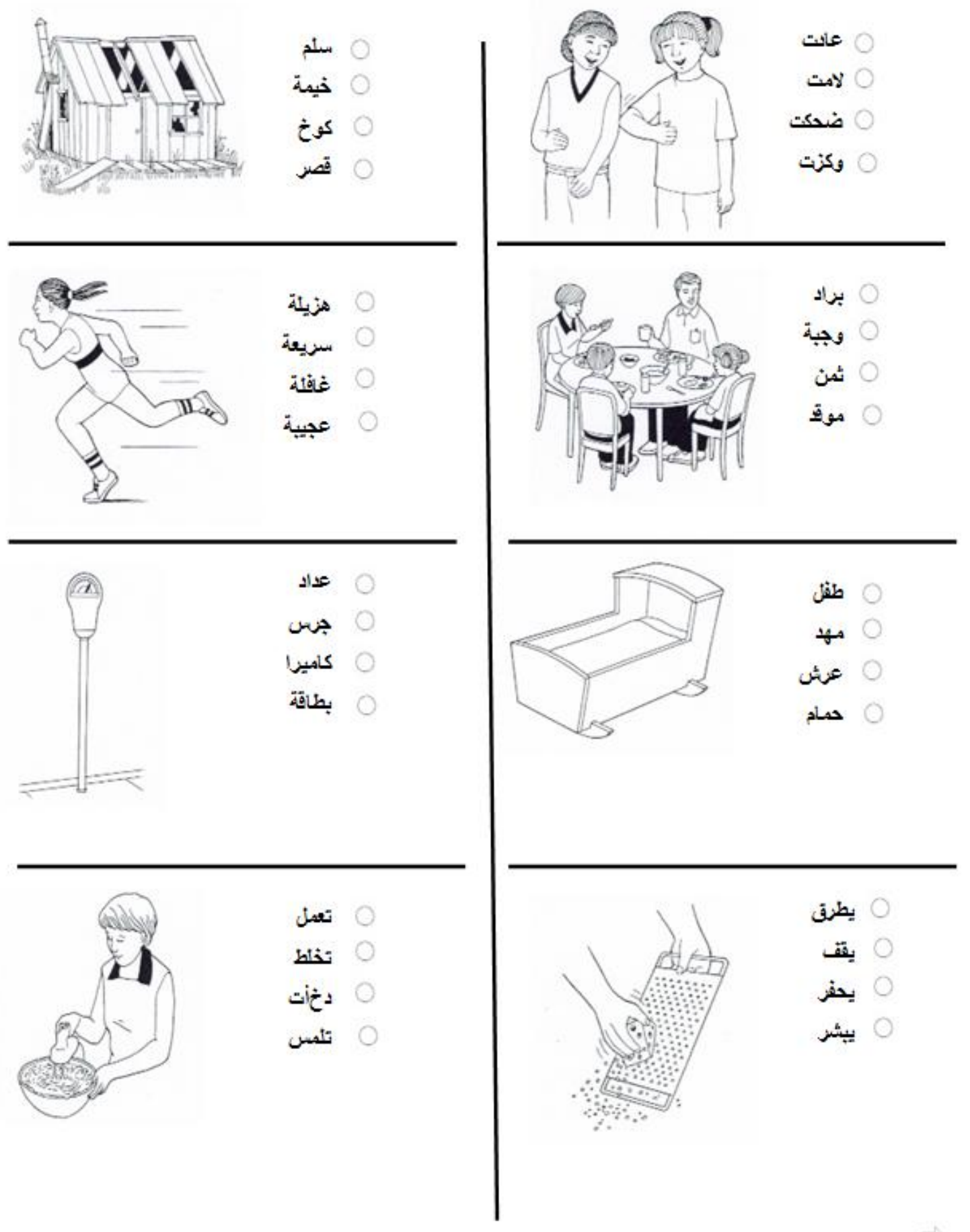

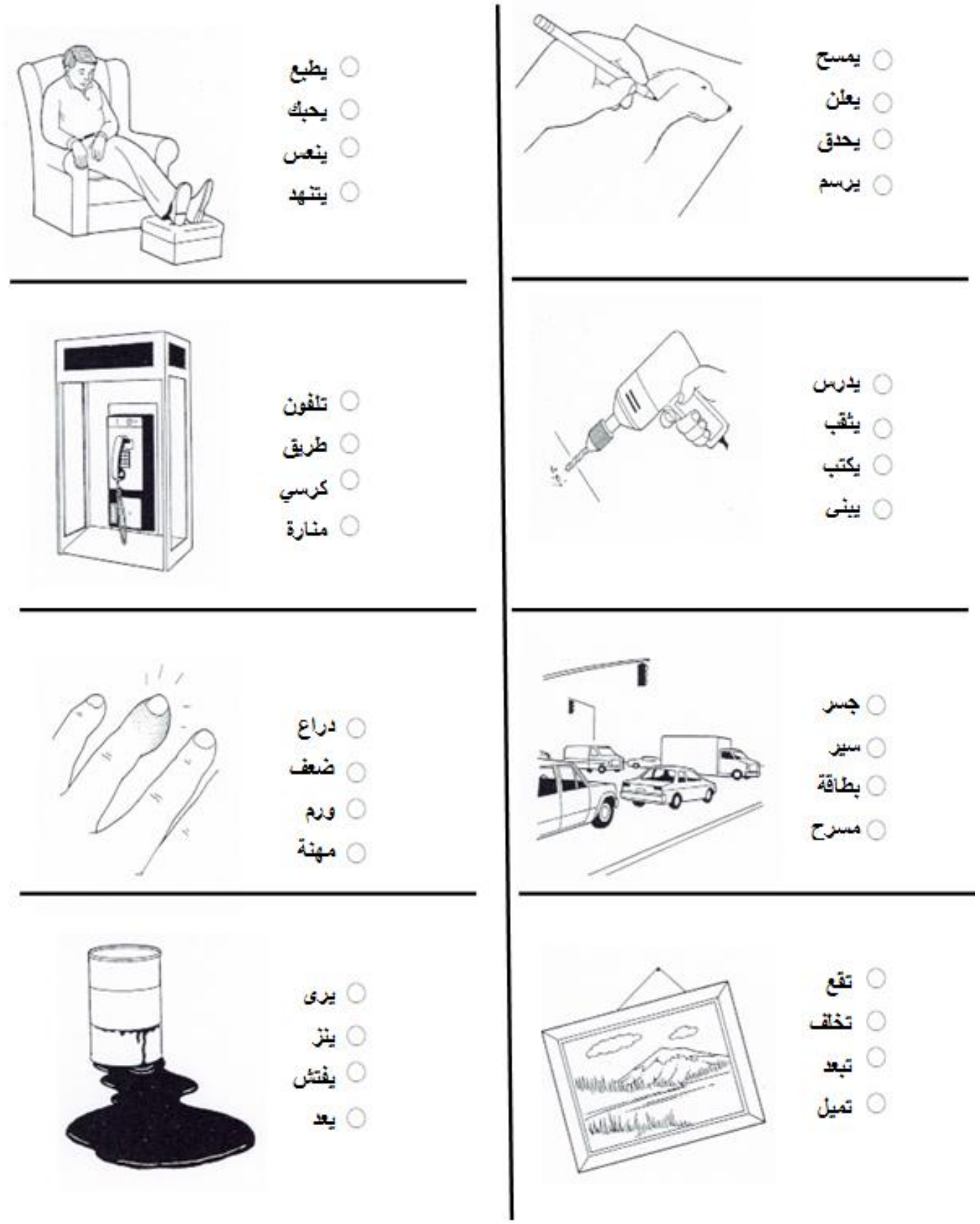


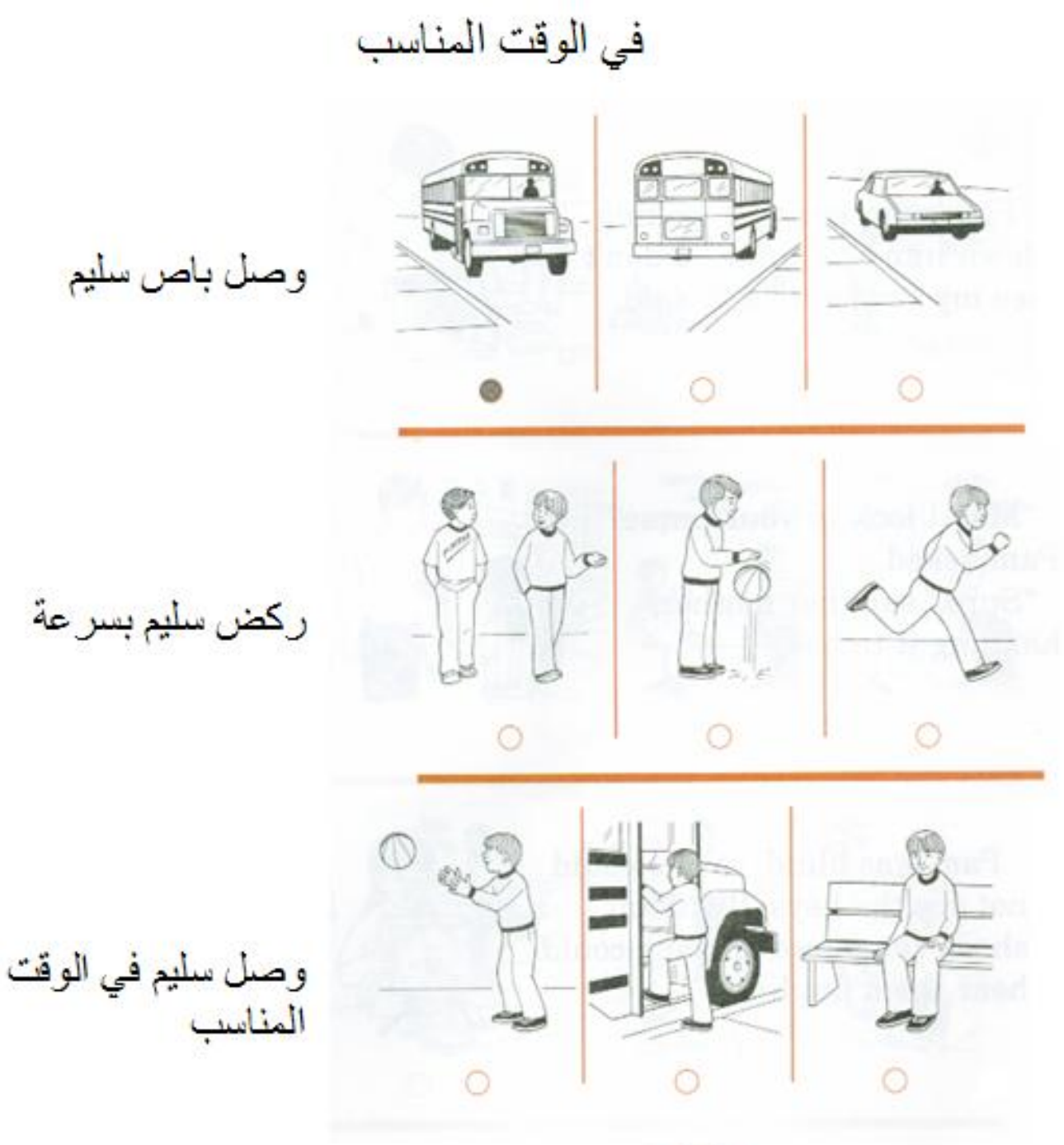




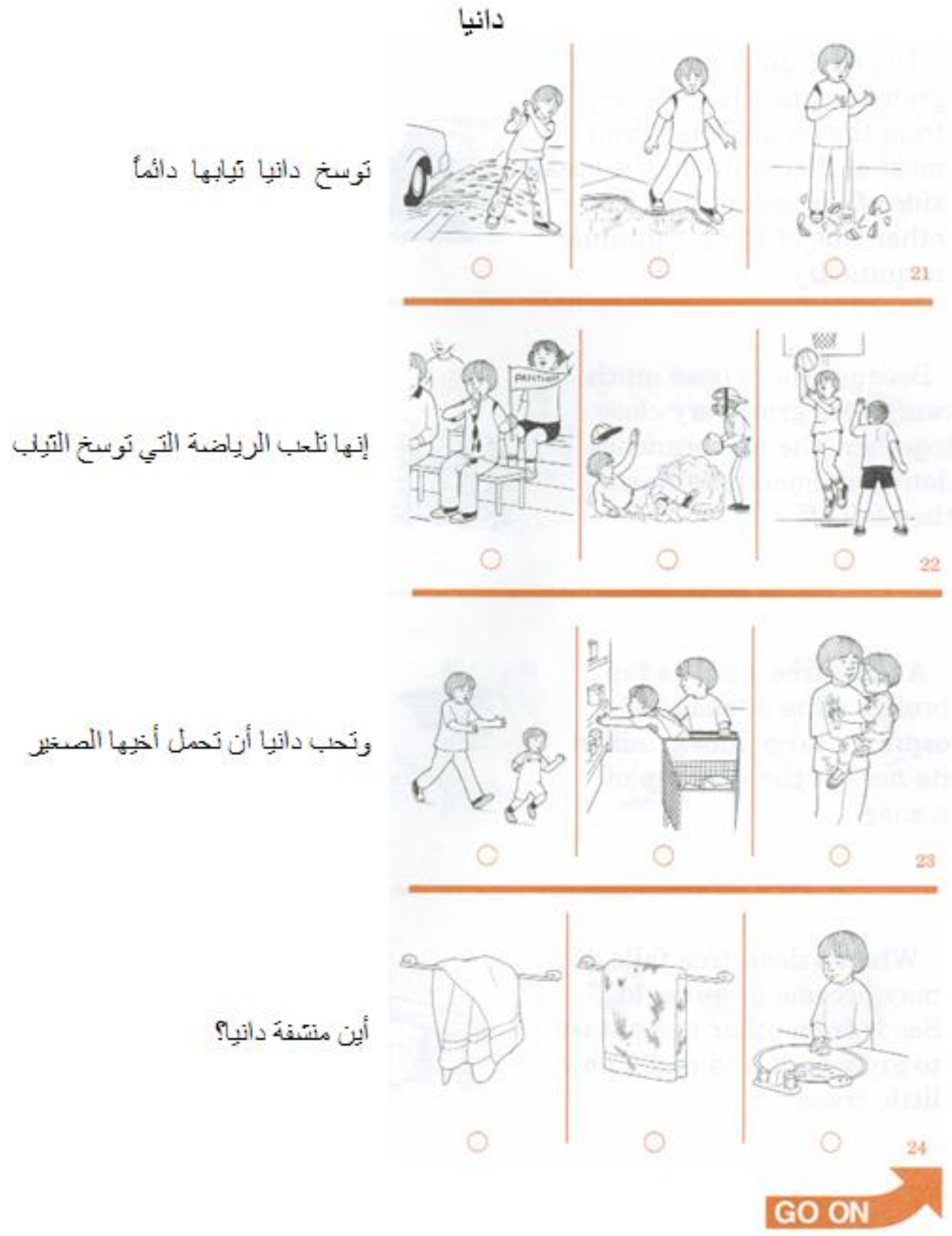




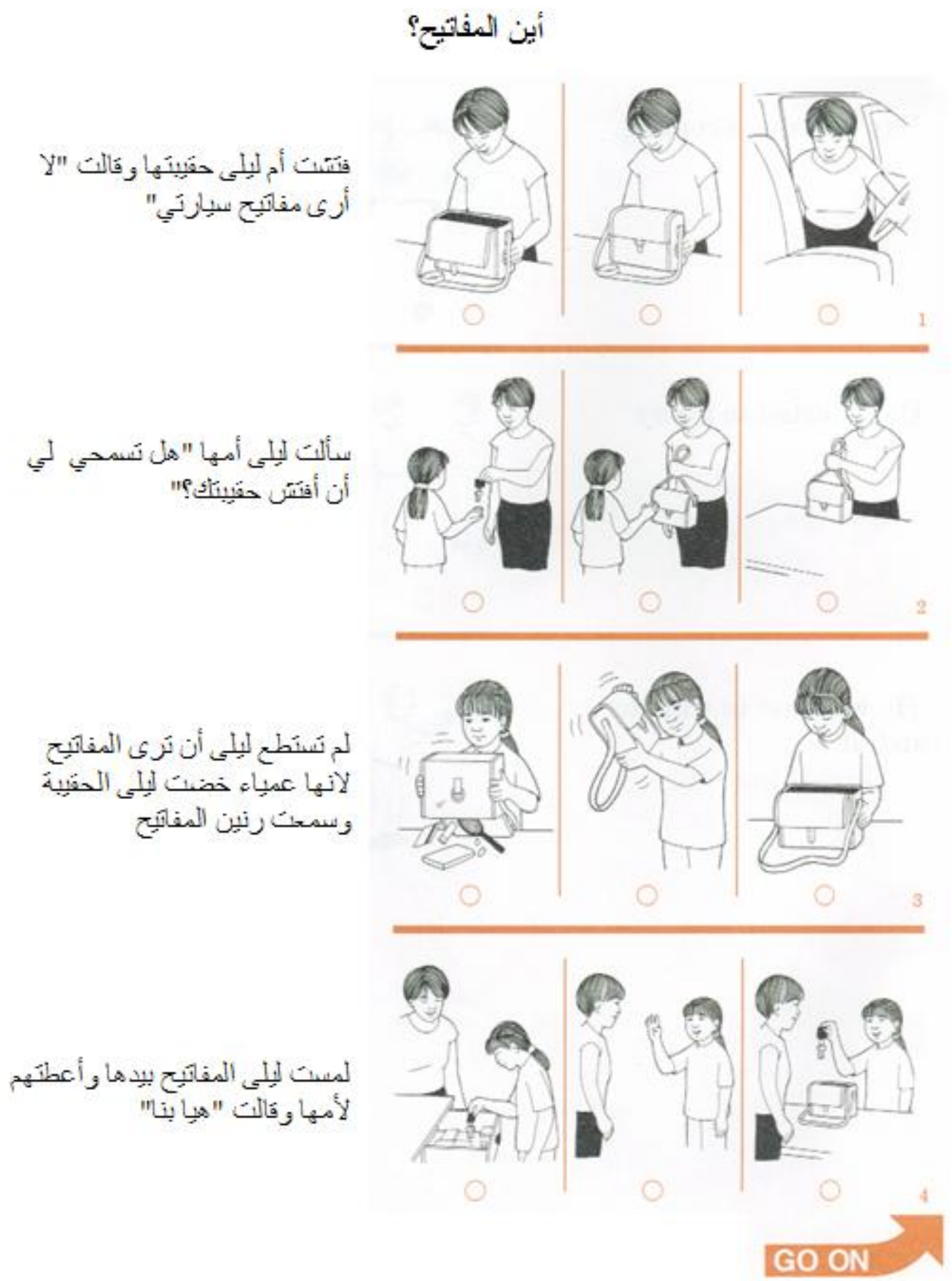




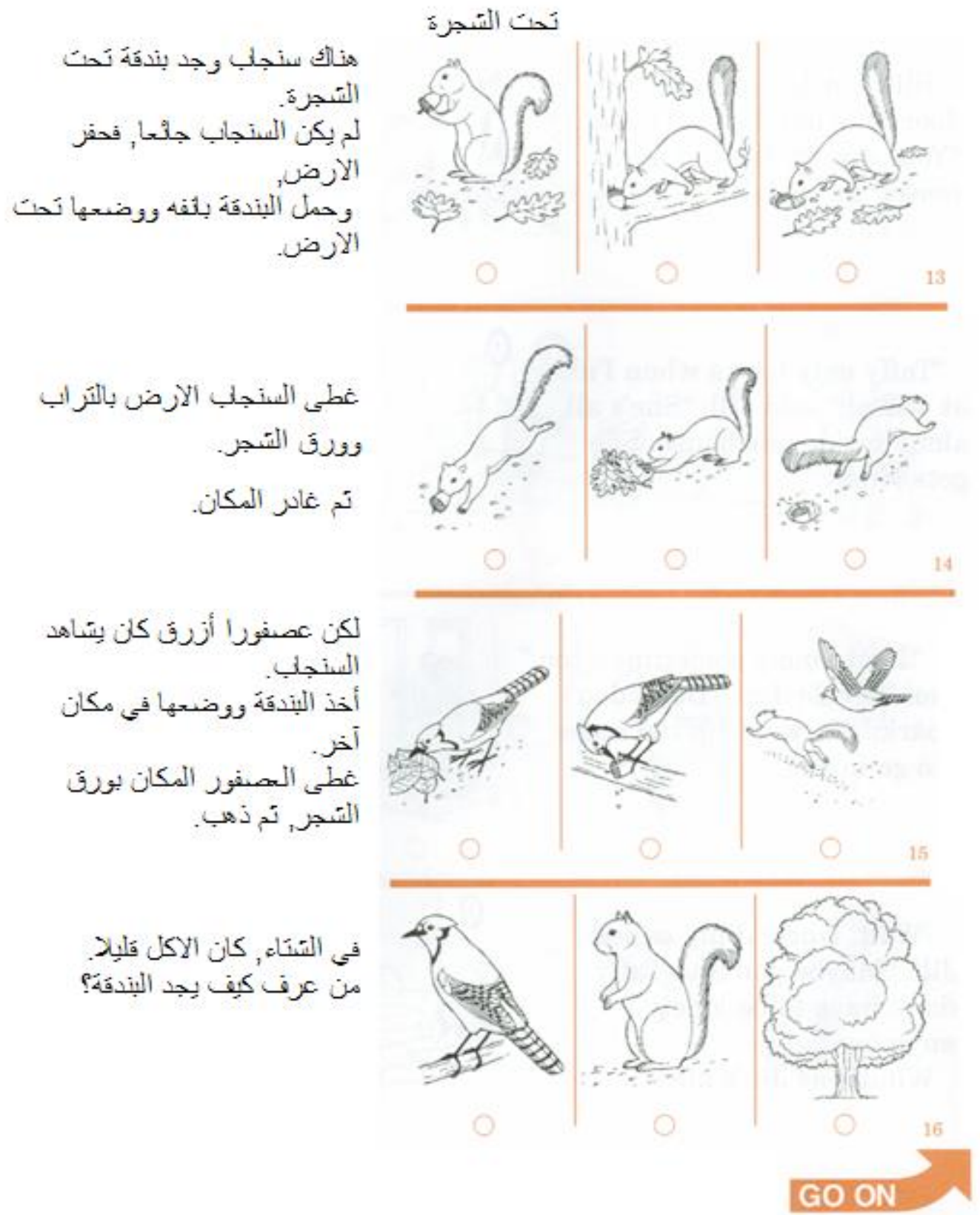




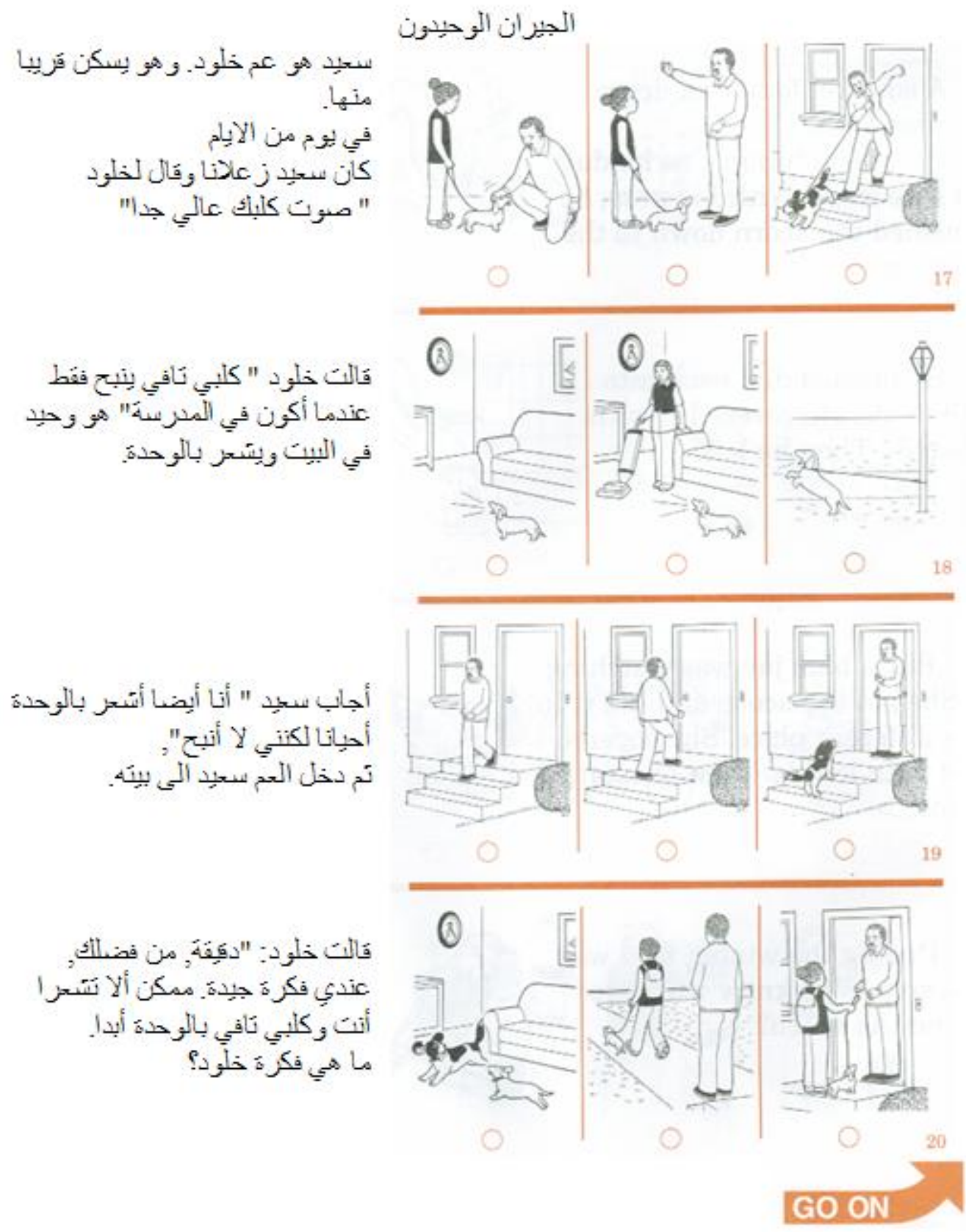



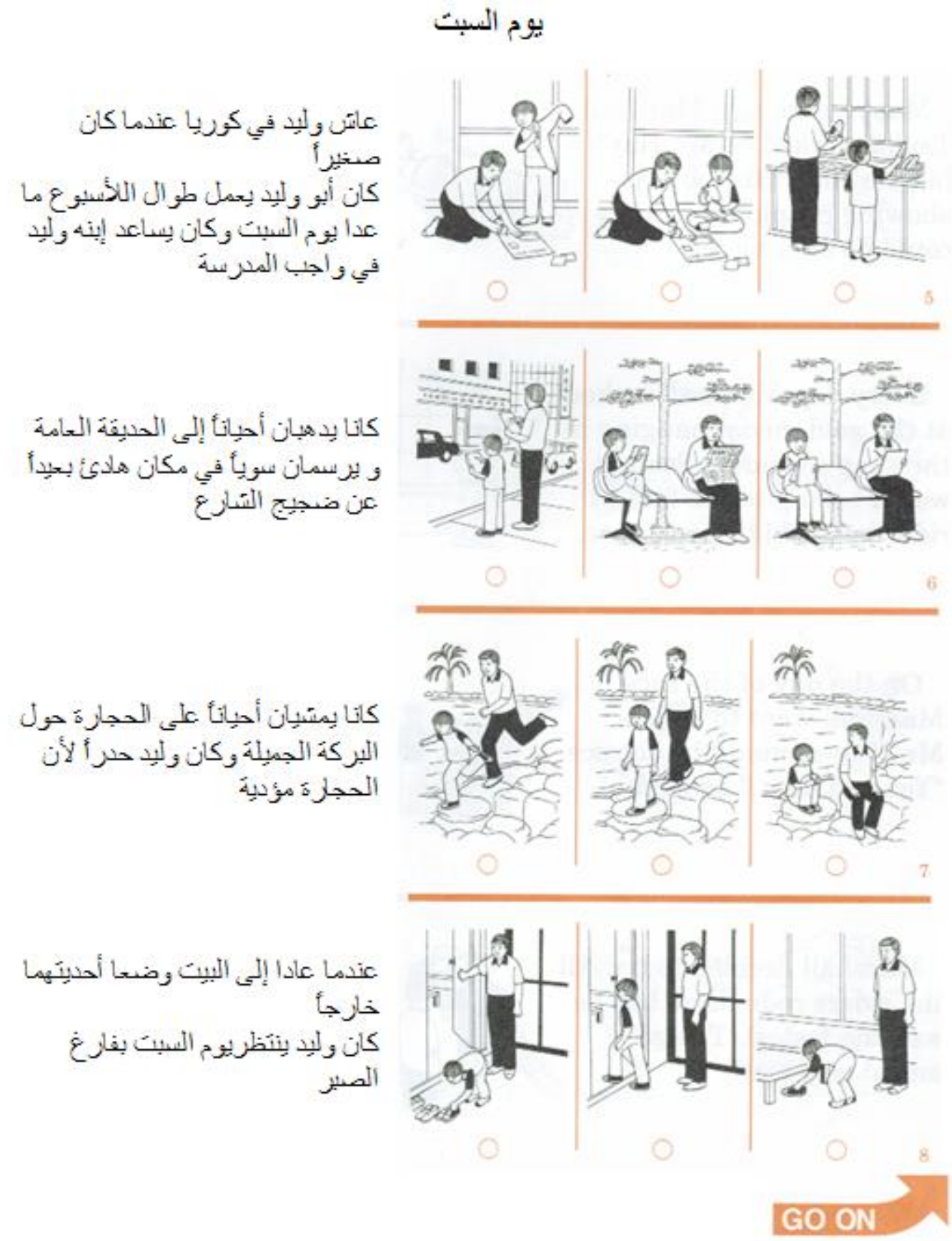


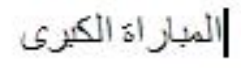

بعمل فادي في محل للنز اجات

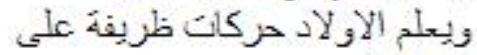
النراجة

كان فادي بنظز إلى المبد اللية

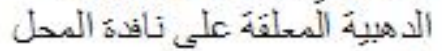

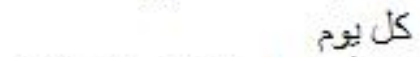

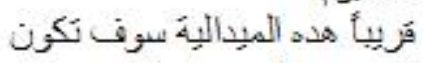

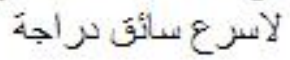
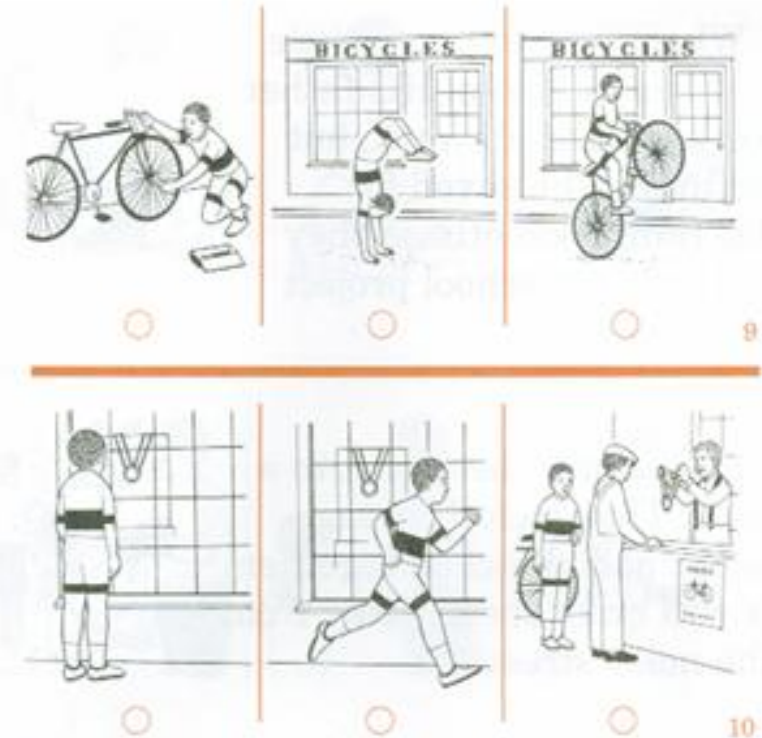

نَّزَج فادي على سباقَ النزباجات

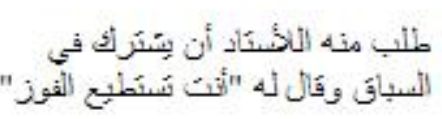

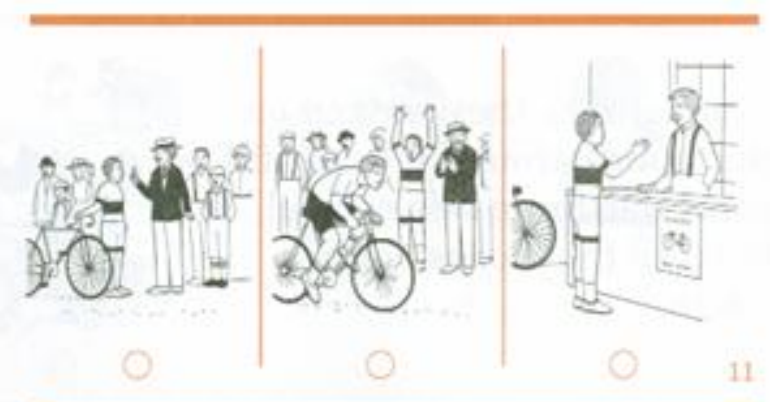

مَزْز فادي أن بِتَرك في النباق

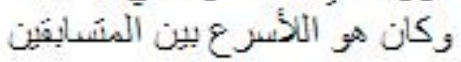
فاز فادي بالمبدالية الدهبية
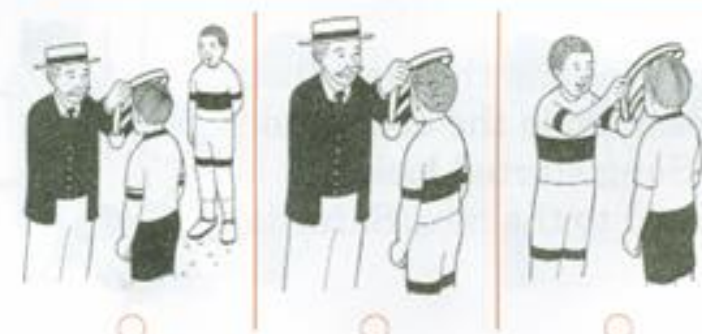

GO ON 
تلفن آدم عندما كنت أحضر الفحام

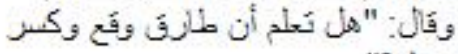

رجلَهب"

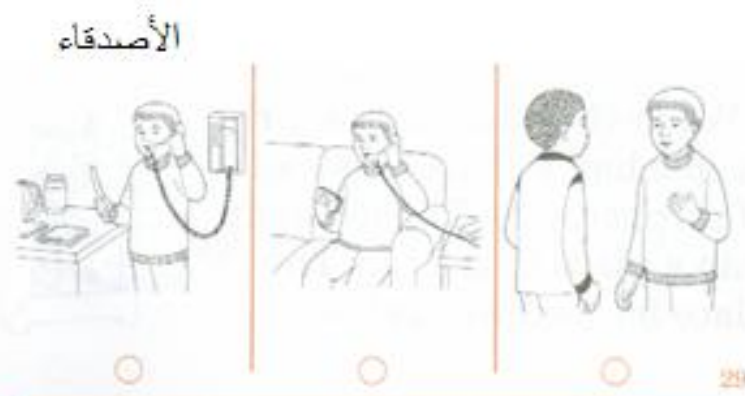

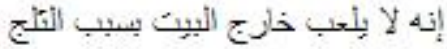

$$
\begin{aligned}
& \text { وهي بتشعز بالفنجز }
\end{aligned}
$$

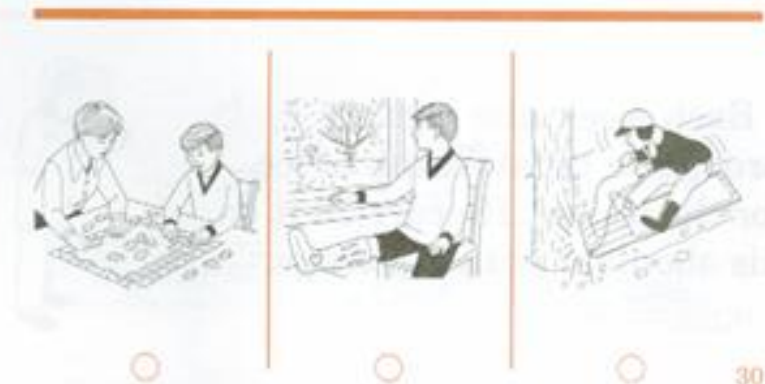

أناء: "هيا ينا نزوف طارق الآن بمكن

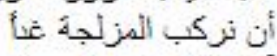

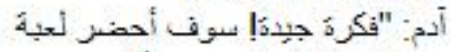

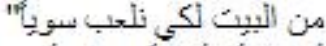

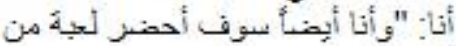

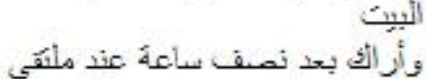
التشار عين لكي ندهب سويًا إلى يبيث مان

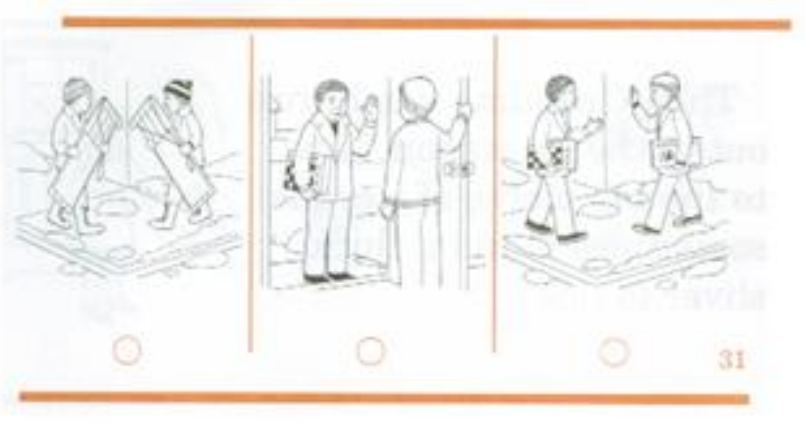

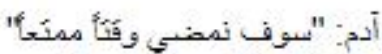

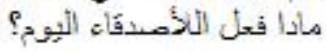

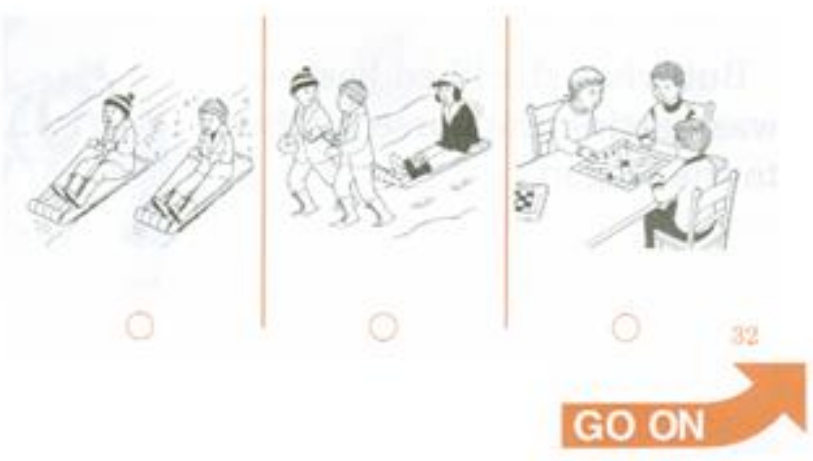

